\title{
Conformation of Glycopeptides and Glycoproteins
}

\author{
Bernd Meyer ${ }^{1} \cdot$ Heiko Möller ${ }^{2}(\varpi)$ \\ ${ }^{1}$ Institut für Organische Chemie, Universität Hamburg, Martin-Luther-King-Platz 6, \\ 20146 Hamburg, Germany \\ ${ }^{2}$ Fachbereich Chemie, Universität Konstanz, Universitätsstraße 10, 78457 Konstanz, \\ Germany \\ Heiko.Moeller@uni-konstanz.de
}

Introduction $\ldots \ldots \ldots \ldots \ldots \ldots \ldots \ldots \ldots$

2 Preparation of Glycopeptides and Glycoproteins

for Conformational Analysis . . . . . . . . . . . . . . . . . . 191

2.1 Natural Sources . . . . . . . . . . . . . . . . . . . . . . . . . 191

2.2 Expression Systems . . . . . . . . . . . . . . . . . . . . 193

2.3 Chemical Synthesis . . . . . . . . . . . . . . . . . . . . . 196

2.4 Semisynthesis: Native Chemical Ligation and Expressed Protein Ligation . 198

3 Determination of Composition and Primary Structure . . . . . . . . 199

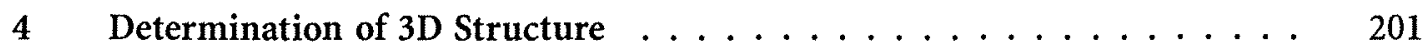

4.1 Conformational Analysis by NMR Spectroscopy . . . . . . . . . . . . 202

4.1 .1 Chemical Shift Assignment . . . . . . . . . . . . . . . . . 202

4.1.2 Nuclear Overhauser Enhancements . . . . . . . . . . . . . . . . 204

4.1 .3 Scalar Couplings . . . . . . . . . . . . . . . . . . . . . 207

4.1 .4 Residual Dipolar Couplings . . . . . . . . . . . . . . . . . . . 208

4.1 .5 Cross-Correlated Relaxation . . . . . . . . . . . . . 211

$4.2 \quad \mathrm{X}$-ray Crystallography . . . . . . . . . . . . . . . 211

4.3 Molecular Modeling . . . . . . . . . . . . . . . . 212

4.4 Statistical Analysis of Available 3D Structures . . . . . . . . . . 213

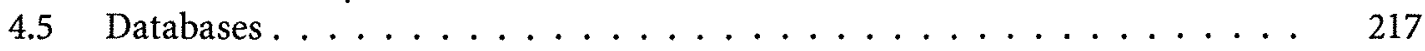

4.5.1 Glycoconjugate-Specific Databases . . . . . . . . . . . . . 219

5 3D Structures of Glycopeptides and Glycoproteins

and Implications for Biological Function . . . . . . . . . . . . . 220

5.1 Effect of $N$-Glycosylation on 3D Structure . . . . . . . . . . . . 221

5.1.1 HIV Envelope Glycoprotein GP120 . . . . . . . . . . . . . . . . . 221

5.1.2 Human T-Cell Specific Surface Glycoprotein CD2 . . . . . . . . . . . . 224

5.1.3 Human Chorionic Gonadotropin . . . . . . . . . . . . . . . . . . . 230

5.1.4 Effect of $N$-Glycosylation on the Structure of Peptides . . . . . . . . . . 234

5.2 Effect of $O$-Glycosylation on 3D Structure . . . . . . . . . . . 238

5.2 .1 Mucin-Type Glycoproteins . . . . . . . . . . . . . . . . 238

5.2 .2 Antifreeze Glycoproteins . . . . . . . . . . . . . . . . . 244

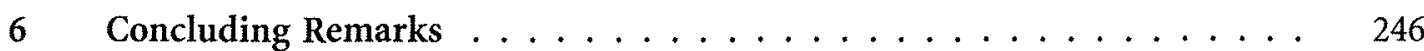

References . . . . . . . . . . . . . . . . . . . . 246 
Abstract Glycosylation is the most frequent post-translational modification found in proteins. Glycoproteins are involved in a highly diverse spectrum of biological functions, ranging from protein folding and molecular and cellular recognition to attack of pathogens and regulation of biological half-life. Consequently, understanding the structural role of glycosylation provides key insight into biological processes as well as ideas for medicinal applications. Here, we review the current methodology to arrive at highresolution structures of glycopeptides and glycoproteins. To achieve this, significant obstacles have to be overcome like preparation of sufficient amounts of sufficiently pure and homogeneous material, analyzing highly ambiguous spectroscopic data, and dealing with molecules that show local or global disorder. We will provide an overview of our knowledge of glycoprotein and glycopeptide structure, and illustrate with selected examples the performance and limitations of current methodology.

Keywords Glycopeptide - Glycoprotein - NMR spectroscopy · $\mathrm{X}$-ray crystallography $\cdot$ Molecular modeling

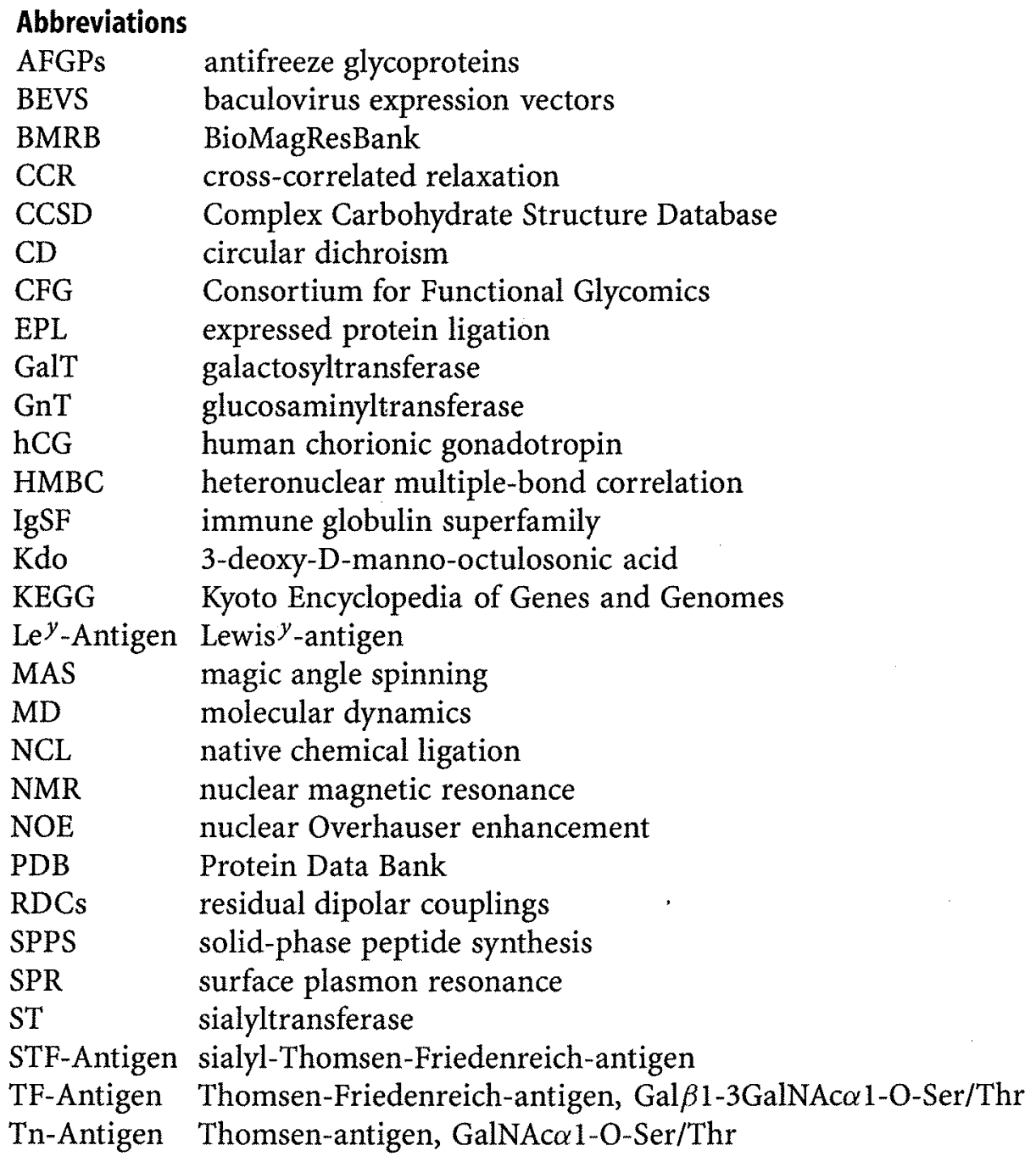




\section{Introduction}

In the era of post genomic and post proteomic research it has been widely accepted that post-translational modifications of proteins are key to understanding their function and regulation. Glycosylation is probably the most complex subset of post-translational modifications of proteins that is in fact very difficult to analyze. The challenges are illustrated by the fact that, as of October 2005, only about $3 \%$ of the 33500 structures deposited in the Protein Data Bank (PDB [1]) contain glycoprotein chains.

On the other hand, the relevance of research on glycoproteins becomes clear when regarding that an estimate of more than $50 \%$ of the eukaryotic proteins are glycosylated, which in turn demands considerable physiological effort and a whole range of enzymes to work together.

This estimate was derived from the SWISS-PROT database that, at that time, contained 75000 protein sequences two thirds of which have the Asn$\mathrm{X}$-Ser/Thr motif and are thus potentially $N$-glycosylated. From a subset of 749 well-characterized glycoproteins an occupancy of $2 / 3$ of these $N$-glycosylation sequons was determined. The majority of $N$-glycoproteins carry $O$-glycans, as well. The proportion of solely $O$-glycosylated proteins was determined at

Table 1 Potential and real glycosylation sites in the 749 well-characterized glycoproteins listed in the SWISS-PROT database by the end of 1998. (Reproduced with permission from [2])

\begin{tabular}{|c|c|c|c|c|c|c|c|c|}
\hline & \multicolumn{2}{|c|}{$\begin{array}{l}\text { Glycoproteins } \\
\text { with at least one } \\
\text { biochemically } \\
\text { characterized } \\
\text { ("real") glyco- } \\
\text { sylation site }\end{array}$} & \multicolumn{2}{|c|}{$\begin{array}{l}\text { Glycoproteins } \\
\text { with at least one } \\
\text { real } N \text {-glyco- } \\
\text { sylation site and } \\
\text { at least one real } \\
O \text {-glycosylation } \\
\text { site }\end{array}$} & \multicolumn{2}{|c|}{$\begin{array}{l}\text { Glycoproteins } \\
\text { with at least one } \\
\text { real } N \text {-glyco- } \\
\text { sylation site and } \\
\text { no real } O \text {-glyco- } \\
\text { sylation site }\end{array}$} & \multicolumn{2}{|c|}{$\begin{array}{l}\text { Glycoproteins } \\
\text { with at least one } \\
\text { real } O \text {-glyco- } \\
\text { sylation site and } \\
\text { no real } N \text {-glyco- } \\
\text { sylation site }\end{array}$} \\
\hline & Sites & Entries & Sites & Entries & Sites & Entries & Sites & Entries \\
\hline $\begin{array}{l}\text { Potential } \\
N \text {-glyco- } \\
\text { sylation sites } \\
\text { (sequons) }\end{array}$ & 2066 & 697 & 289 & 80 & 1679 & 582 & 98 & 35 \\
\hline $\begin{array}{l}\text { Real glyco- } \\
\text { sylation sites }\end{array}$ & 1965 & 749 & 556 & 80 & 1041 & 582 & 368 & 87 \\
\hline $\begin{array}{l}\text { Real } N \text {-glyco- } \\
\text { sylation sites }\end{array}$ & 1279 & 662 & 238 & 80 & 1041 & 582 & 0 & 0 \\
\hline $\begin{array}{l}\text { Real O-glyco- } \\
\text { sylation sites }\end{array}$ & 686 & 167 & 318 & 80 & 0 & 0 & 368 & 87 \\
\hline
\end{tabular}


10\% (Table 1) [2]. Together with less frequently observed post-translational modifications by carbohydrates like $C$-mannosylation or ribosylation, glycoproteins are found almost anywhere in the cell and are involved in a highly diverse spectrum of biological functions, ranging from protein folding, molecular and cellular recognition, and regulation of biological half-life [3].

Glycoproteins are, among others, preferred targets of pathogens, e.g. parasites or viruses. Furthermore, aberrantly glycosylated proteins play key roles in many degenerative diseases like cancer and autoimmune disease. Consequently, these properties make glycoproteins highly attractive targets for the development of new therapies and diagnostic methods. From the rapid increase of protein drug prescriptions in recent years we may expect a major industrial effort in glycoprotein production as well as to obtain a greater understanding of their functions [4].

This work reviews selected examples of our current knowledge of 3D structure and structural dynamics of selected glycopeptides and glycoproteins and gives an overview of the methodologies to arrive at high resolution structures. This review is not intended to be comprehensive and the reader is referred to other excellent reviews for further information [5-12]. A prerequisite of a structure elucidation is the availability of pure material. It is beyond the scope of this review to cover all synthetic and biochemical approaches towards glycopeptides and glycoproteins, which are described in other parts of this volume. Here, we will focus on high resolution 3D structures and their implications obtained from NMR or X-ray methods.

Aspects of glycopeptide and glycoprotein structure determination have very often been split into structure analysis of the glycan part on the one hand and of the peptide/protein part on the other, respectively. Excellent reviews cover these subjects including elucidation of primary structure, conformational analysis and molecular modeling [5,9-11,13-17]. We will focus on methods and developments that have been applied to intact glycoproteins or glycopeptides.

Even today, we should be cautious when trying to generalize what we know from glycoprotein structures solved so far. Our view is biased because the majority of 3D structures could be solved only after extensive manipulation of oligosaccharides before X-ray crystallography, expression in non-glycosylating organisms for NMR spectroscopy or from synthesis of truncated glycopeptide structures. Many proteins that essentially require glycosylation for structural stability or proper function have probably not been analyzed yet including the majority of membrane glycoproteins.

There are only a few very-well studied glycoproteins for which we have in-depth information on conformation of both the protein and the glycan fraction, on molecular flexibility and dynamics, and on the influence of glycosylation on biological function. One example is the human T-cell surface protein $\mathrm{CD} 2$ that crucially requires its $\mathrm{N}$-glycan for binding to its receptor CD58. Another example is the glycoprotein hormone human chorionic go- 
nadotropin (hCG) which is biologically inactive when deglycosylated. Both cases will be presented in greater detail.

\section{2 \\ Preparation of Glycopeptides and Glycoproteins for Conformational Analysis}

Conformational analysis of glycoproteins relies on the availability of sufficiently pure protein in sufficient amount. Depending on the type of analysis this ranges from microgram quantities of heterogeneous material, for example for $\mathrm{CD}$ experiments to multiple milligrams of very pure and homogeneous preparations for NMR studies or crystallography. Current methodology to obtain homogeneous glycopeptides and glycoproteins has been reviewed by Grogan et al. [18], and is covered in more detail in other parts of this volume.

\section{1}

\section{Natural Sources}

Apart from abundant glycoproteins like soy bean agglutinin, etc., usually only small quantities of glycoproteins can be extracted from natural sources, which can even make primary structure determination challenging. In addition, isotope labeling for NMR experiments is generally not easily possible at reasonable costs if proteins have to be extracted at basal expression levels.

An example for a glycoprotein that can be purified in sufficient amounts from natural sources is the complement regulatory protein CD59. It was extracted from human urine and its structure was determined already in 1994 by Neuhaus and coworkers by 2D NMR spectroscopy without ${ }^{15} \mathrm{~N}$ or ${ }^{13} \mathrm{C}$ labeling [19]. Complete resonance assignments were obtained for the polypeptide consisting of 77 residues and an extensive set of nuclear Overhauser effects (NOEs) allowed the protein structure to be determined at high resolution. Signal overlap prevented an unambiguous NMR assignment of the carbohydrate and GPI anchor part and of their NOEs except for the GlcNAc residue which is directly connected to Asn 18 . This glycan residue is the only one that shows NOEs to the polypeptide chain. The structure calculation led to two families of conformers consistent with these protein carbohydrate NOEs exhibiting disorder in the $\chi_{1}$ dihedral angle of Asn18 (for a definition of dihedral angles, see Fig. 1). In both conformers, the proximal GlcNAc residue has a similar orientation with respect to the protein covering hydrophobic side chains on the surface of the protein component. Sharp lines and the lack of protein carbohydrate NOEs for the remaining residues suggest that they are highly flexible and point into solution. Glycosylation of CD59 seems to be im- 
portant for organization of this protein in the membrane and for prevention of aggregation (Fig. 2).

Natural sources of glycoproteins have proven very useful for the isolation of oligosaccharides when only the glycan part is to be studied as there are

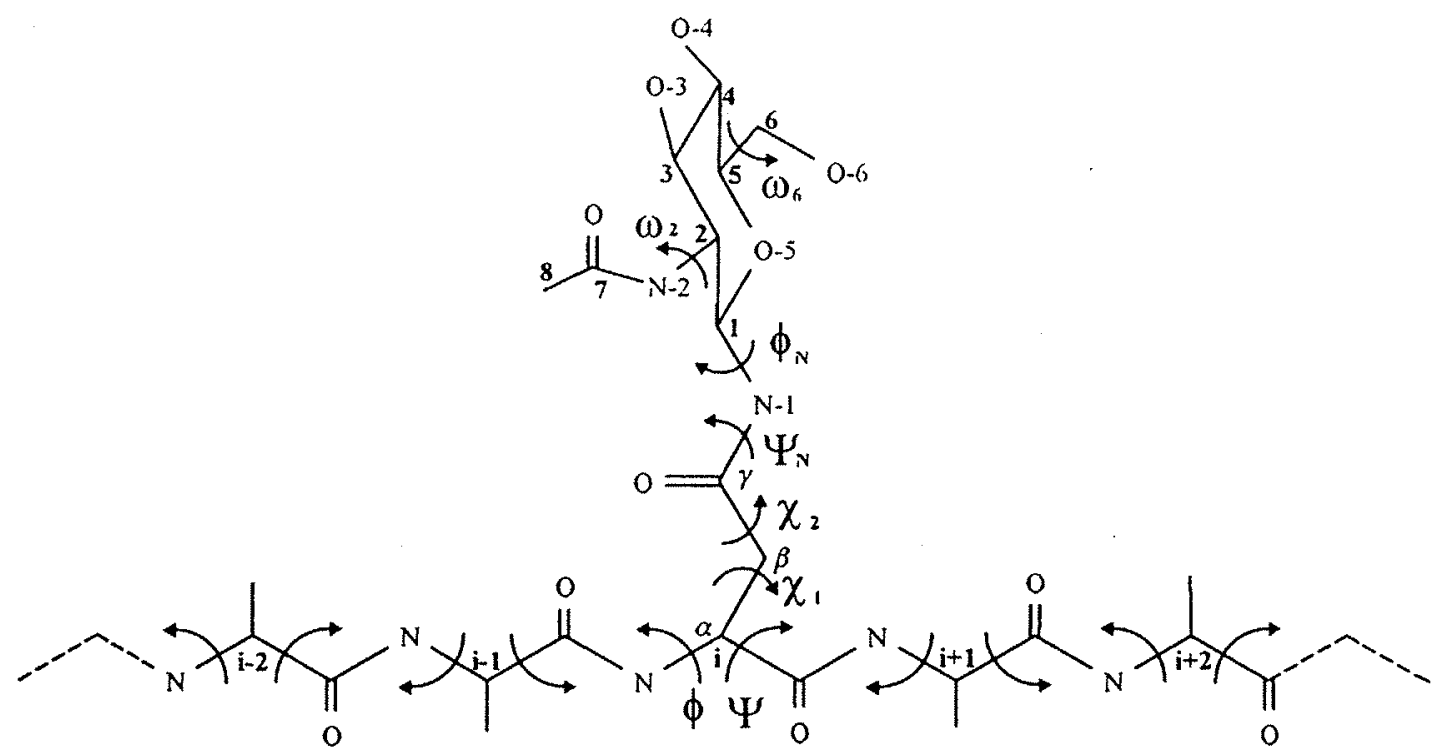

Fig. 1 Schematic representation of the $N$-linked GlcNAc together with the Asn-XxxSer/Thr-containing peptide fragment. The GlcNAc and Asn non-hydrogen atoms, together with torsion angles of interest, are labeled. (Adapted and reproduced with permission from [20])

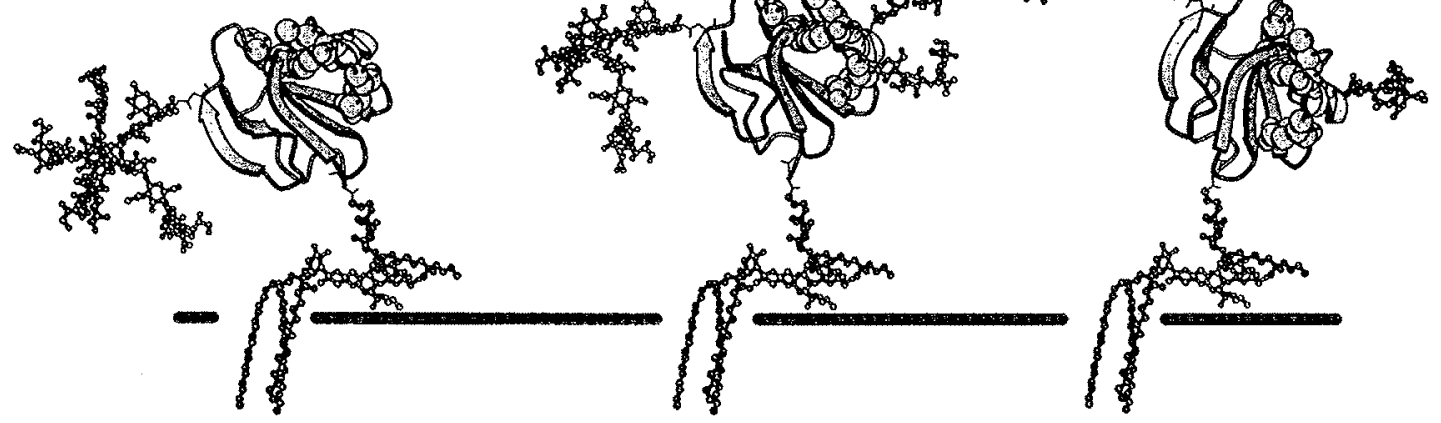

Fig. 2 A schematic figure showing the effect of CD59 glycosylation on the flexibility of the protein relative to the GPI anchor $[19,21]$. Three different glycoforms are shown. Both the $O$ - and $N$-linked oligosaccharides (size range 2-6 $\mathrm{nm}$ ) attached to CD59 (diameter of approximately $3 \mathrm{~nm}$ ) restrict the conformational space available to the protein and limit its interaction with the lipid bilayer. The sugars may therefore orient the active site of CD59 toward the C5b-9 complex, which is also inserted into the cell membrane. In addition, the heterogeneity of the sugars suggests that the glycans influence the geometry of the packing, and it is unlikely that CD59 molecules will form a regular array on the cell surface. The active site residues are highlighted in CPK. (Reproduced with permission from [21]) 
well-established sources for complex-type, high-mannose, and hybrid-type oligosaccharides, which can be released by trifluoromethanesulfonic acid, hydrazinolysis or enzymatic treatment and subsequent purification.

\section{2}

\section{Expression Systems}

Structural genomics initiatives have boosted the development of expression systems. After focusing initially on small bacterial and archeal genomes the field has subsequently moved to eukaryotic organisms which are more complex and more interesting due to the occurrence of a whole range of posttranslational modifications. Separate reviews cover the latest developments in this field and we will only highlight select aspects relevant to studying glycoproteins [22-24].

One common approach to simplify the issue is based on bacterial expression systems to produce a non-glycosylated variant of the protein of interest. This approach however often fails, as glycans are known to be often indispensable for proper folding or to avoid protein aggregation. Expression of glycoprotein sequences in yeast can give very good yields of protein. However, if one is interested in intact, natively glycosylated proteins, yeast expression results in a yeast-specific high mannose glycosylation that is very different from the glycosylation pattern in mammalian cells. Expression in the yeast $P$. pastoris is more suitable than in S. cerevisiae, because $P$. pastoris produces glycoproteins with shorter glycans attached to the same Asn-X-Ser/Thr site as in mammalian cells, and it also does not produce structures with terminal $\alpha 1,3$-linked mannose residues which are not found in mammalian cells. Table 2 gives an overview of the glycosylation properties of a variety of expression systems.

Baculovirus-infected insect cells are well-studied expression systems to yield glycoproteins with a simple oligosaccharide moiety called paucimannose (Fig. 3) [24]. Recently, modified baculoviral expression systems yielded glycoprotein structures carrying humanized oligosaccharides. This was achieved by transfecting the insect cell lines with Glucosaminyltransferase II (GnTII), Galactosyltransferase $(\beta 1,4-\mathrm{GalT})$ and Sialyltransferase $(\alpha 2,6-\mathrm{ST})$ to obtain biantennary complex-type structures terminated in 2,6-linked sialic acids. Chinese hamster ovary $(\mathrm{CHO})$ cells have been engineered to express humanlike glycoproteins by knocking out $\alpha 1,3-$ GalT and introducing $\alpha 2,6-\mathrm{ST}$.

As far as NMR experiments on isotopically labeled material are to be carried out, all of the above mentioned expression systems have to be adapted to minimal media. Homans and collaborators were the first to succeed in producing a ${ }^{13} \mathrm{C}-{ }^{15} \mathrm{~N}$-labeled glycoprotein, namely the $\alpha$-subunit of hCG, by growing $\mathrm{CHO}$ cells in a medium made from algal hydrolysates and supplemented with isotopically labeled amino acids (cf. Sect. 5.1.3) [26]. Even earlier Fesik et al. obtained isotopically labeled urokinase-type plasminogen acti- 
Table 2 The major glycosylation properties for different cell expression systems. (Reproduced with permission from [24])

\begin{tabular}{|c|c|c|c|c|c|}
\hline Organism & Cell type & $\begin{array}{l}\text { Type of } \\
\text { glyco- } \\
\text { sylation a }\end{array}$ & $\begin{array}{l}\text { Length } \\
\text { of oligo- } \\
\text { saccharide }\end{array}$ & $\begin{array}{l}\text { Composition } \\
\text { of oligo- } \\
\text { saccharide }\end{array}$ & $\begin{array}{l}\text { Glycosidic } \\
\text { linkage }\end{array}$ \\
\hline Bacterium & E. coli & - & - & - & - \\
\hline Yeast & S. cerevisiae & $O$-linked & $\mathrm{L}$ & $\begin{array}{l}\text { Man, Gal. } \\
\text { GlcNAc, GalNAc }\end{array}$ & $\beta 1,3$ \\
\hline \multirow[t]{2}{*}{ Yeast } & S. cerevisiae & $N$-linked & $\mathrm{L}$ & Man, GlcNAc & $\begin{array}{l}\alpha 1,6 ; \alpha 1,2 ; \\
\alpha 1,3\end{array}$ \\
\hline & Pichia pastoris & $N$-linked & $S$ & Man, GlcNAc & $\alpha 1,6 ; \alpha 1,2$ \\
\hline Plant & Tobacco BY2 & $N$-linked & $\mathrm{S}$ & Fuc, GlcNAc & $\alpha 1,3$ \\
\hline \multirow[t]{3}{*}{ Insect } & $\begin{array}{l}\text { Baculovirus- } \\
\text { infected insect } \\
\text { cells sf9 }\end{array}$ & $N$-linked & $\mathrm{S}$ & $\begin{array}{l}\text { Gal, Man, Fuc, } \\
\text { GlcNAc }\end{array}$ & $\alpha 1,6 ; \alpha 1,3$ \\
\hline & $\begin{array}{l}\text { Baculovirus- } \\
\text { infected insect } \\
\text { cells sf } 21\end{array}$ & $N$-linked & $\mathrm{S}$ & $\begin{array}{l}\text { Gal, Man, Fuc, } \\
\text { GlcNAc }\end{array}$ & $\alpha 1,6$ \\
\hline & E. acrea $\mathrm{Ea}-4$ & $N$-linked & $\mathrm{S}$ & Man, Fuc, GlcNAc & $\alpha 1,6$ \\
\hline Frog & Xenopus oocyte & $N$-linked & $\mathrm{S}$ & $\begin{array}{l}\text { Man, GlcNAc, } \\
\text { GalNAc, sialic acid }\end{array}$ & $\alpha 2,3$ \\
\hline \multirow[t]{2}{*}{ Hamster } & $\begin{array}{l}\text { CHO } \\
\text { O-linked }\end{array}$ & $N$-linked, & $\mathrm{S}$ & $\begin{array}{l}\text { Gal, Man, Fuc, } \\
\text { GlcNAc/GalNAc/NeuAc }\end{array}$ & $\alpha 1,6 ; \alpha 2,6$ \\
\hline & $\begin{array}{l}\text { BHK } \\
\text { O-linked }\end{array}$ & $N$-linked, & $\mathrm{S}$ & $\begin{array}{l}\text { Gal, Man, Fuc, } \\
\text { GlcNAc/GalNAc/NeuAc }\end{array}$ & $\begin{array}{l}\alpha 1,6 ; \alpha 1,3 ; \\
\alpha 2,3\end{array}$ \\
\hline \multirow[t]{5}{*}{ Mouse } & $\mathrm{C} 127$ & O-linked & $S$ & $\begin{array}{l}\text { Man, Fuc, Gal, } \\
\text { GalNAc, sialic acid, } \\
\text { NeuGc }\end{array}$ & $\begin{array}{l}\alpha 1,6 ; \alpha 1,3 ; \\
\alpha 2,3 ; \alpha 2,6\end{array}$ \\
\hline & Hybridoma & O-linked & $\mathrm{S}$ & $\begin{array}{l}\text { Man, Fuc, Gal, } \\
\text { sialic acid, NeuGc }\end{array}$ & $\begin{array}{l}\alpha 1,6 ; \alpha 1,3 \\
\alpha 2,6\end{array}$ \\
\hline & J558L & $O$-linked & $\mathrm{ND}$ & $\begin{array}{l}\text { Man, Fuc, Gal, } \\
\text { sialic acid, NeuGc }\end{array}$ & $\begin{array}{l}\alpha 1,6 ; \alpha 1,3 \\
\alpha 2,3 ; \alpha 2,6\end{array}$ \\
\hline & NSO myeloma & $\begin{array}{l}O \text {-linked, } \\
N \text {-linked }\end{array}$ & S & $\begin{array}{l}\text { Man, Fuc, Gal, } \\
\text { sialic acid, GlcNAc, } \\
\text { NeuGc }\end{array}$ & $\begin{array}{l}\alpha 1,6 ; \alpha 1,3 \\
\alpha 2,3 ; \alpha 2,6\end{array}$ \\
\hline & Transgenic & $N$-linked & $S$ & $\begin{array}{l}\text { Man, Fuc, Gal, } \\
\text { GlcNAc }\end{array}$ & $\alpha 1,6$ \\
\hline \multirow[t]{3}{*}{ Human } & Namalwa & $\begin{array}{l}N \text {-linked, } \\
O \text {-linked }\end{array}$ & $S$ & $\begin{array}{l}\text { Man, Fuc, sialic acid, } \\
\text { NeuGc, GlcNAc }\end{array}$ & $\begin{array}{l}\alpha 1,6 ; \alpha 2,3 \\
\alpha 2,6\end{array}$ \\
\hline & Pituitary & $\begin{array}{l}N \text {-linked, } \\
O \text {-linked }\end{array}$ & $S$ & $\begin{array}{l}\text { Man, Fuc, GalNAc, } \\
\text { sialic acid }\end{array}$ & $\begin{array}{l}\alpha 1,6 ; \alpha 2,3 \\
\alpha 2,6\end{array}$ \\
\hline & Heterohybridoma & $N$-linked & $S$ & $\begin{array}{l}\text { Man, Fuc, sialic } \\
\text { acid, GlcNAc, NeuGc }\end{array}$ & $\begin{array}{l}\alpha 1,6 ; \alpha 2,3 \\
\alpha 2,6\end{array}$ \\
\hline
\end{tabular}

${ }^{\text {a }}$ Although the characteristics of $O$-linked and $N$-linked glycosylations are not completely studied in some literature, it may possess both the profiles of glycosylation in the same expression system. 


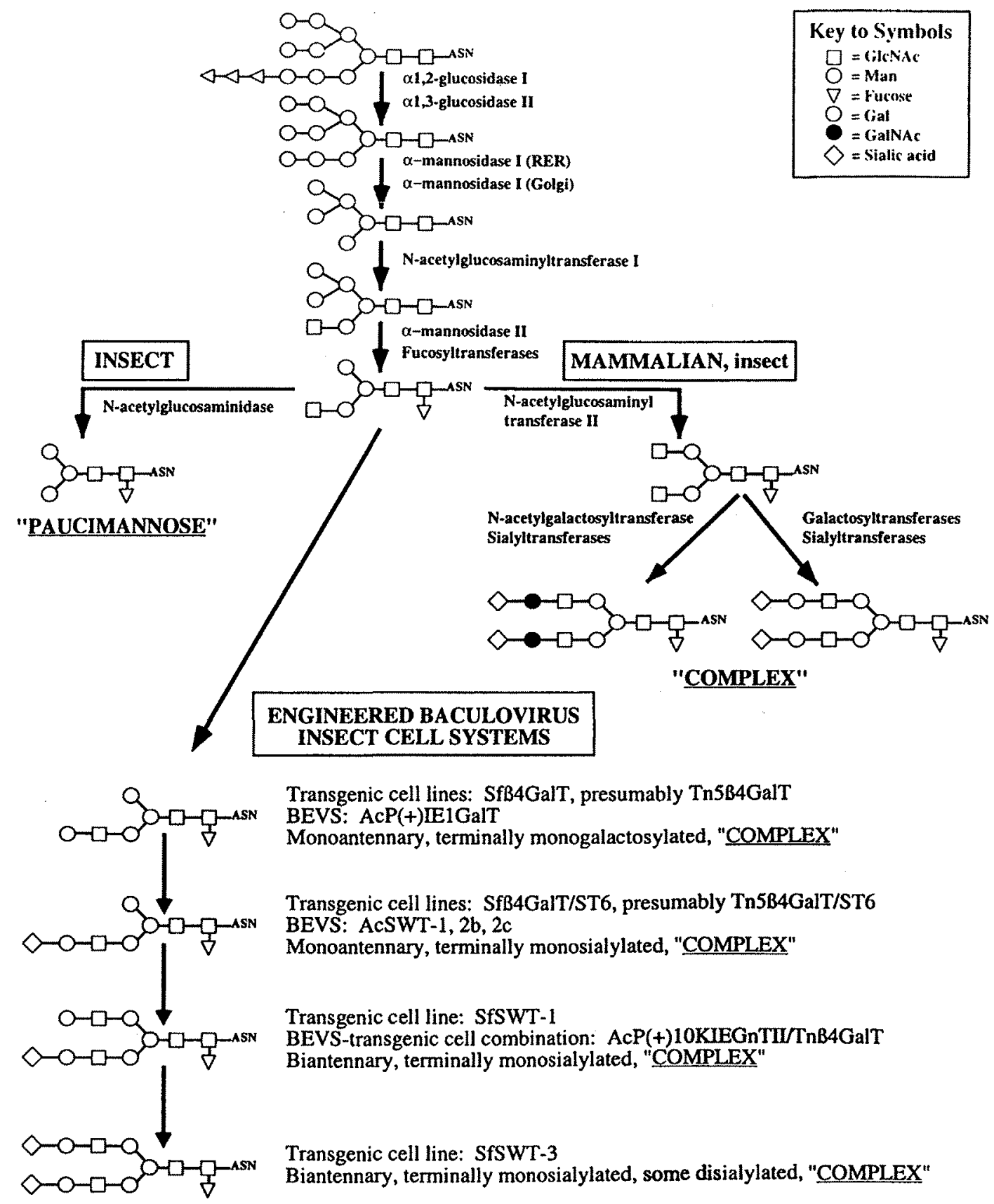

Fig. 3 Protein $\mathrm{N}$-glycosylation pathways in insect and mammalian cells. Monosaccharides are indicated by their standard symbolic representations, as defined in the key. The insect and mammalian $N$-glycan processing pathways share a common intermediate, as shown. The major products derived from this intermediate are paucimannose and complex $\mathrm{N}$-glycans in insect and mammalian cells, respectively. It is generally recognized that insect cells have only a limited capacity, at best, to produce complex $N$-glycans. However, this model accommodates the possibility that some insect cells can produce complex $\mathrm{N}$-glycans under certain circumstances. Complex $\mathrm{N}$-glycans are extremely diverse and only representative examples are shown in the figure. The structures of the $\mathrm{N}$-glycans produced by transgenic lepidopteran insect cell lines, modified baculovirus expression vectors (BEVS), and BEVS-transgenic insect cell combinations are shown as well. (Reproduced with permission from [25]) 
vator from mammalian cell lines, although they purified an unglycosylated portion of this glycoprotein [27]. The work on the adhesion domain of human CD2 in the laboratory of Wagner started out with unlabeled protein preparations. In later stages of the work, refined structures, especially concerning the glycosylation site, were obtained from amino acid-specifically or ubiquitously labeled CD2 expressed in CHO cells (cf. Sect. 5.1.2) [28].

Eukaryotic expression systems experience an increased application for isotopic labeling purposes $[22,29,30]$. One recent example is the work of Kessler et al. who succeeded in producing functionally folded, glycosylated GM2 activator protein suitable for NMR purposes in P. pastoris following a modified protocol reported by Laroche et al. [31,32]. Sometimes, extensive protein engineering is mandatory in order to improve the quality of NMR spectra [33].

The glycosyltransferases and the glycosylhydrolases of the cell lines chosen for expression of the glycoproteins normally produce a non homogeneous pattern of glycosylation at each glycosylation site (microheterogeneity). It has been shown that introduction and/or overexpression of additional enzymes of the glycosylation machinery can lead to glycoproteins with a more homogeneous structure [34]. Alternatively, oligosaccharides may have to be trimmed down to a common core by glycosidase treatment prior to structure determination [18]. A way of obtaining homogeneously glycosylated proteins was found by Schultz, Wong and coworkers who exploited an enhanced genetic code to incorporate glycosyl amino acids during protein translation in E. coli $[35,36]$.

Recently introduced cell-free expression systems are now well established in structural genomics efforts due to advantages in cloning, purification and because expression in these systems can be automatized. In addition, proteins specifically labeled at certain amino acids can be synthesized in a straightforward manner by providing suitably labeled monomers. As there is no amino acid metabolism present no scrambling of isotopic labels occurs. It will be very difficult, though, to transfer the eukaryotic glycosylation machinery into such a system.

\section{3 \\ Chemical Synthesis}

The chemical synthesis of glycopeptides and smaller glycoproteins can provide very pure molecules [8]. It is, however, very costly to produce isotopically labeled compounds. Also, there is a limitation in terms of size of these substances. Large proteins in their glycosylated form can still not be produced easily by chemical synthesis. Also, the introduction of arbitrary complex glycoside structures into these molecules is not easy. However, the glycosyl residue interacts mostly via the first and next few sugars with the protein. Therefore, truncated forms can be obtained by chemical synthesis as model compounds with maximum flexibility in choosing the site and type of glycosylation. Moreover, only by chemical means can we introduce a whole range 
of modifications that do not occur naturally which enables us to investigate the influence on glycopeptide conformation of specific structural elements. Both for $\mathrm{O}$ - and $\mathrm{N}$-glycosylated structures synthetic protocols have been established, by which it is possible to generate singly and multiply glycosylated glycopeptides. Both types of glycosylated peptides are usually being synthesized by introducing a glycosyl amino acid building block into the growing peptide chain in a conventional peptide synthesis. In the case of the $N$-type glycosides, either carbohydrates derived from natural sources are being used to obtain larger oligosaccharide structures or the carbohydrate portion is being chemically assembled, as well. Subsequently, the oligosaccharides are aminated at the reducing end to produce a glycosylamine structure. These are linked to the carboxyl group of the side chain of aspartic acid in an amidation reaction to produce a glycosyl amino acid building block (Fig. 4). The carbohydrate structure varies in size between just the $\mathrm{N}$-acetylglucosamine and a decasaccharide [37]. This glycosyl amino acid building block is then introduced into the growing peptide.

$O$-type glycosylation can be obtained in a similar way by chemical synthesis of the $O$-linked glycosyl linkage to serine or threonine where all types of $O$-linked core structures have been synthetically produced. Further modification of these structures can be obtained by chemo-enzymatic synthesis. These building blocks can then be introduced into the growing peptide chain to produce $O$-linked glycopeptides with one or several attachment sites of the carbohydrate to the peptide backbone. Chemo-enzymatic modifications can also occur after the complete synthesis of the glycopeptides [38]. For a detailed discussion of chemical and chemo-enzymatic synthesis of glycopeptides we refer to other overview articles that have recently been published, in part in this volume $[8,39-43]$.

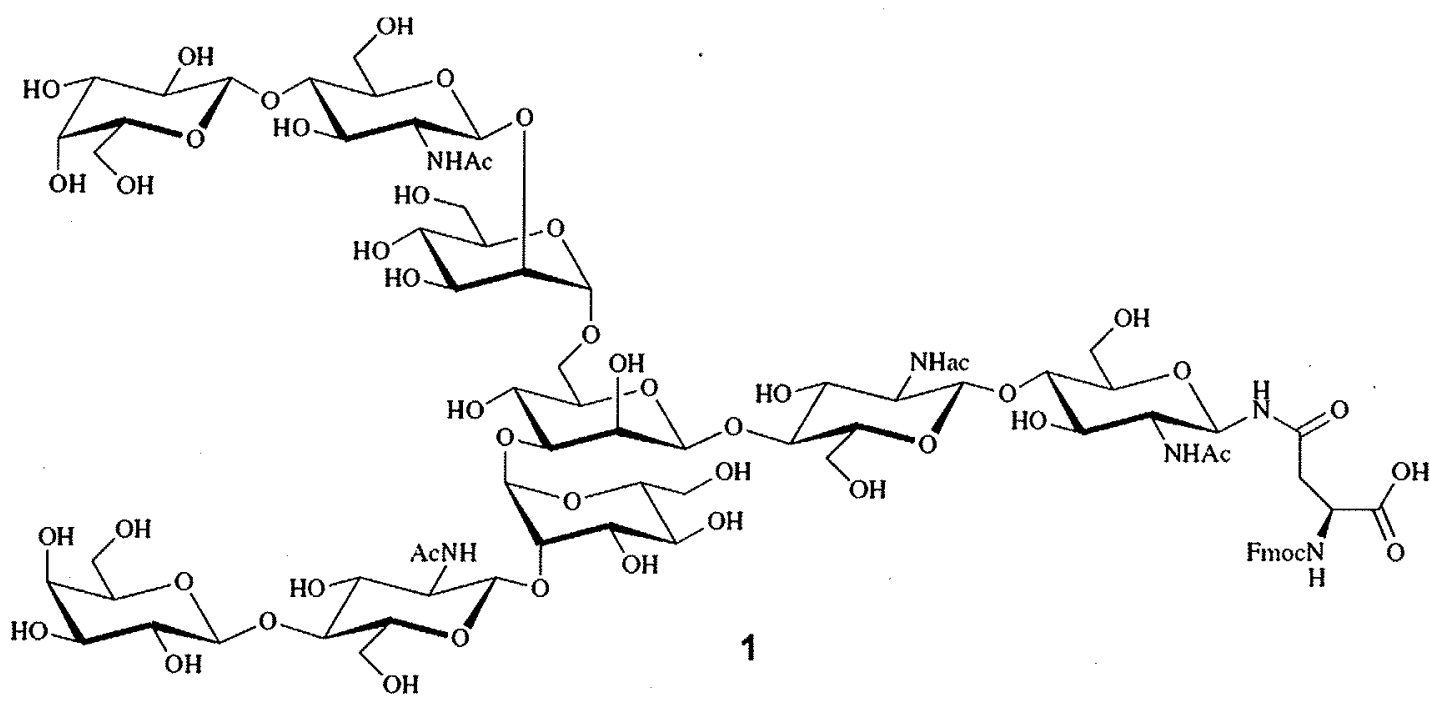

Fig. 4 Structure of a biantennary $N$-type building block 1 ready for use in solid-phase peptide synthesis (SPPS) 


\section{4}

\section{Semisynthesis: Native Chemical Ligation and Expressed Protein Ligation}

The synthesis of proteins has experienced a major advancement by the invention of two ligation methods, which allow for fusing one part of the target protein that has been obtained by expression techniques with another part that originates, for example, from solid-phase peptide synthesis. Both methods rely on transesterification of thioester groups followed by a sulfurto-nitrogen rearrangement that finally yields native backbone polypeptides. In native chemical ligation (NCL) a chemically synthesized peptide with a C-terminal thioester group is coupled to a second peptide or protein which has an N-terminal cysteine residue [44]. The other method, expressed protein ligation (EPL), utilizes the peculiar behavior of protein domains called inteins which catalyze a protein splicing reaction leading to excision of the intein part and joining the polypeptides (exteins) that surround the intein at its $\mathrm{N}$ - and $\mathrm{C}$-terminus. With this reaction one can introduce a $\mathrm{C}$-terminal thioester functionality into an expressed protein which can then be linked via NCL to a peptide containing an N-terminal cysteine [45].

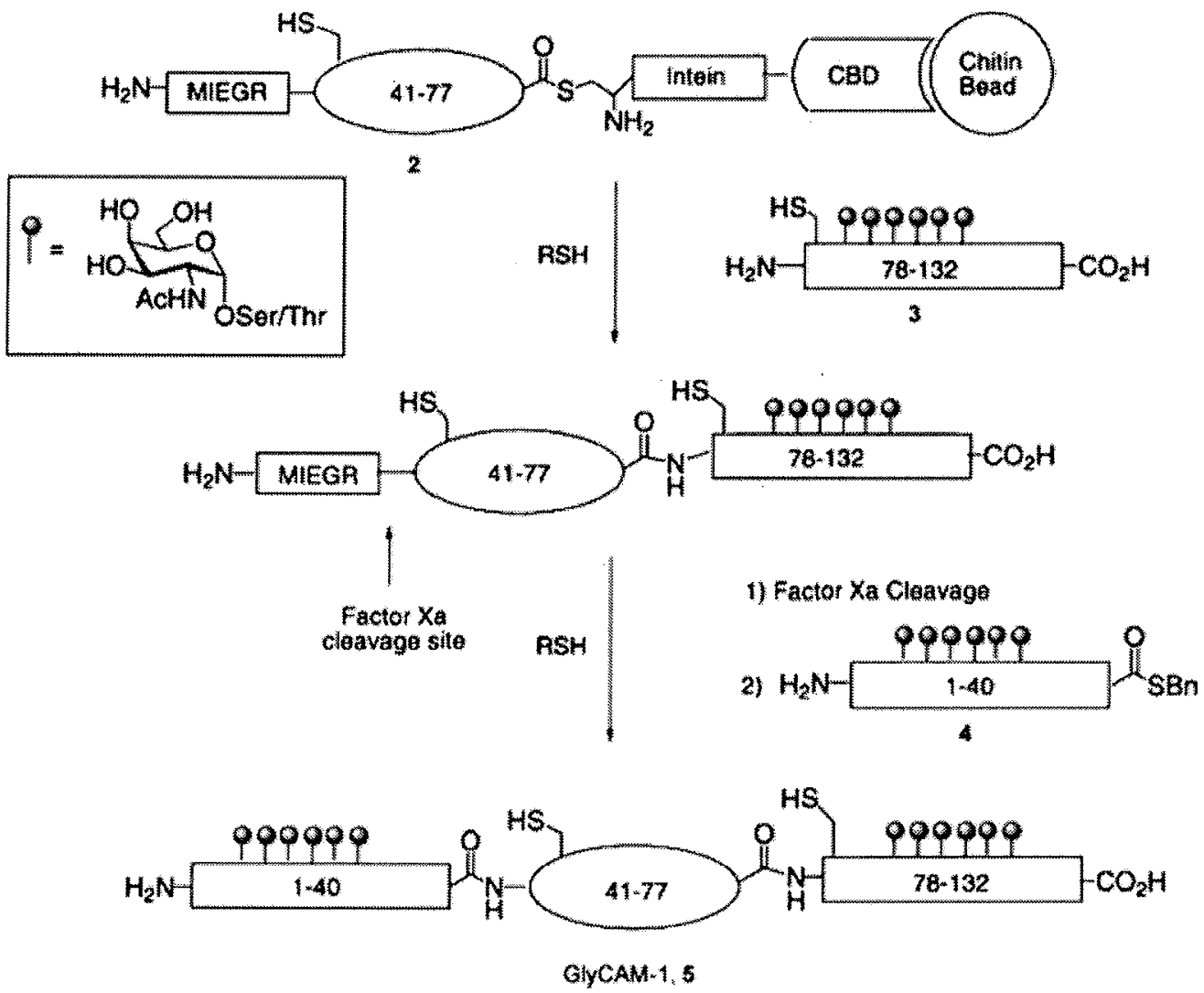

Fig. 5 Synthesis of glycosylated GlyCAM-1 (5) by expressed protein ligation (EPL) to synthetic mucin domains 4 and 5. Factor Xa proteolysis allows late-stage exposure of an $N$-terminal cysteine for the timed NCL to 4 (CBD, chitin-binding domain) [46]. (Reproduced with permission from [18]) 

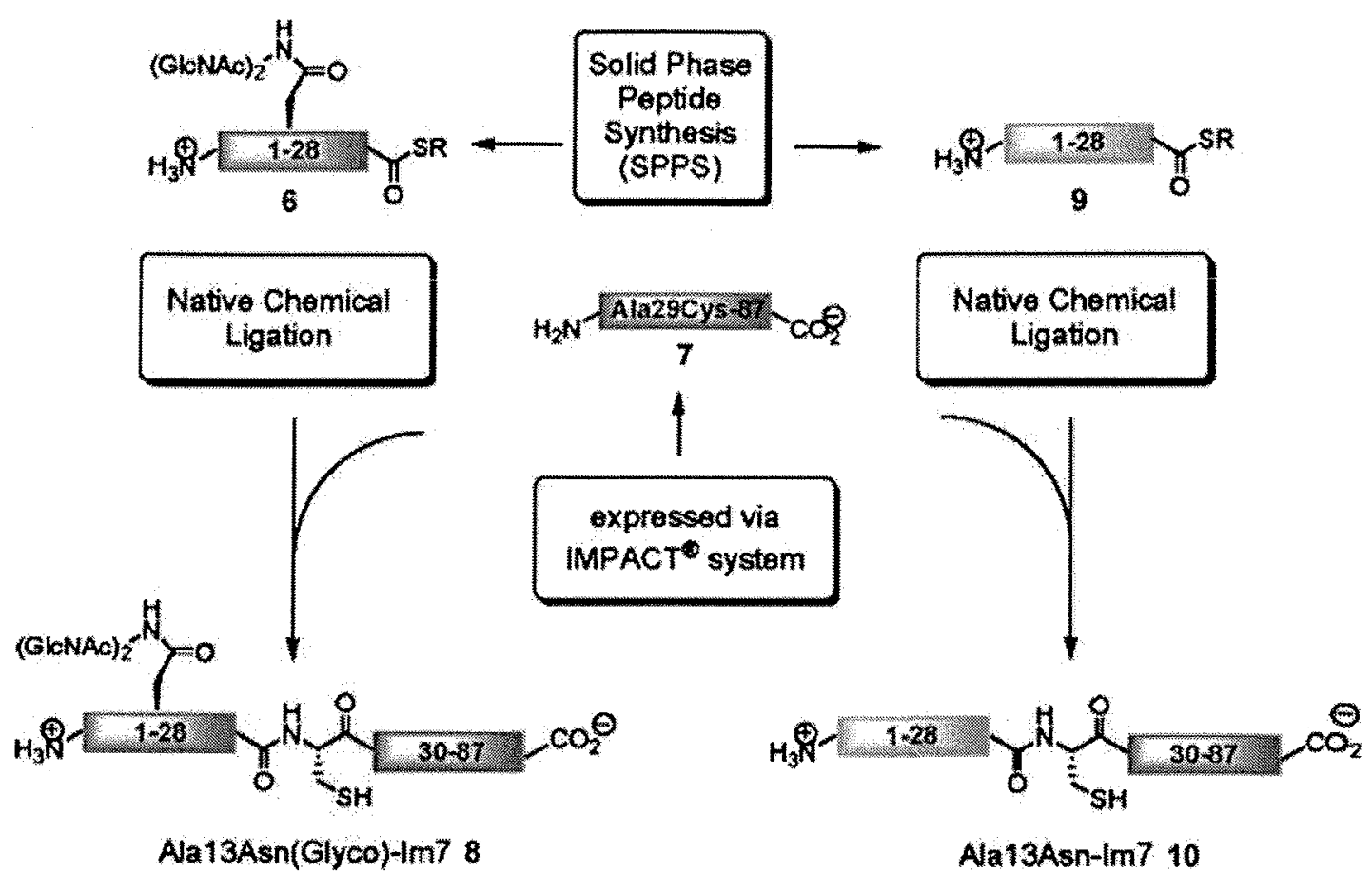

Fig. 6 Semisynthetic strategy for glycosylated and unglycosylated $\operatorname{Im} 7$ analogues 8 and 10. (Reproduced with permission from [48])

These thioester ligation reactions are compatible with peptide or protein fragments carrying unprotected carbohydrates and are thus an attractive route to glycoproteins that are too large for SPPS or that cannot be expressed in sufficient amount or homogeneity. The potential of the EPL method for glycoprotein synthesis has been demonstrated by Bertozzi and coworkers who synthesized different glycoforms of the murine L-selectin ligand GlyCAM-1 (Fig. 5) [46]. Native chemical ligation of SPPS-derived peptides has been employed in Bertozzi's group to yield the O-glycosylated T-cell chemokine lymphotactin and by Hojo et al. for synthesizing the $N$-chitobiosylated Ig-1 domain of Emmprin, a cell surface protein of tumor cells [47].

Hackenberger et al. constructed, following the NCL strategy, $N$-glycosylated and unglycosylated variants of the four helix immunity protein Im7 in order to investigate the influence of the $N$-chitobiosyl residue upon folding of this well characterized model system (Fig. 6) [48].

\section{3}

\section{Determination of Composition and Primary Structure}

A prerequisite of 3D structure determination to high resolution is the precise knowledge of the primary structure and composition of the glycoprotein of interest. Apart from classical biochemical approaches like gene sequencing 
and Edman degradation that yield the primary structure of the polypeptide and potential glycosylation sites, special techniques have to be employed in order to accurately define (i) the presence of carbohydrate modifications at specific positions in the amino acid sequence, (ii) the type and the size of glycan, (iii) the carbohydrate branching pattern, i.e., the positions of glycosidic linkages, (iv) the anomeric configuration of glycosidic linkages, and (v) covalent modifications like sulfation or acetylation. In this regard, adept application of specific enzymatic cleavage reactions followed by chromatographic separation and identification of the purified carbohydrate substructures by lectins can yield the desired information [49].

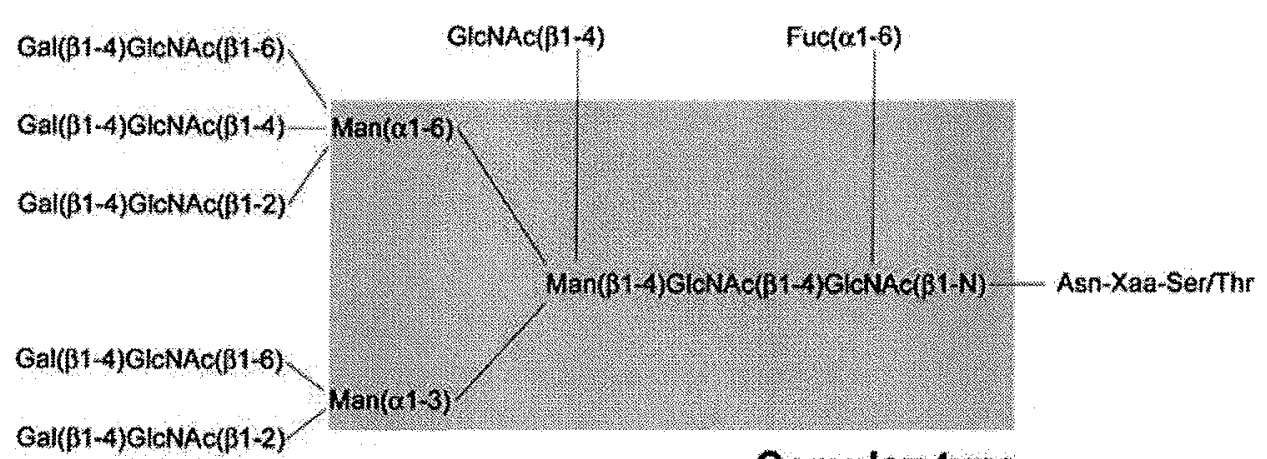

Complex-type

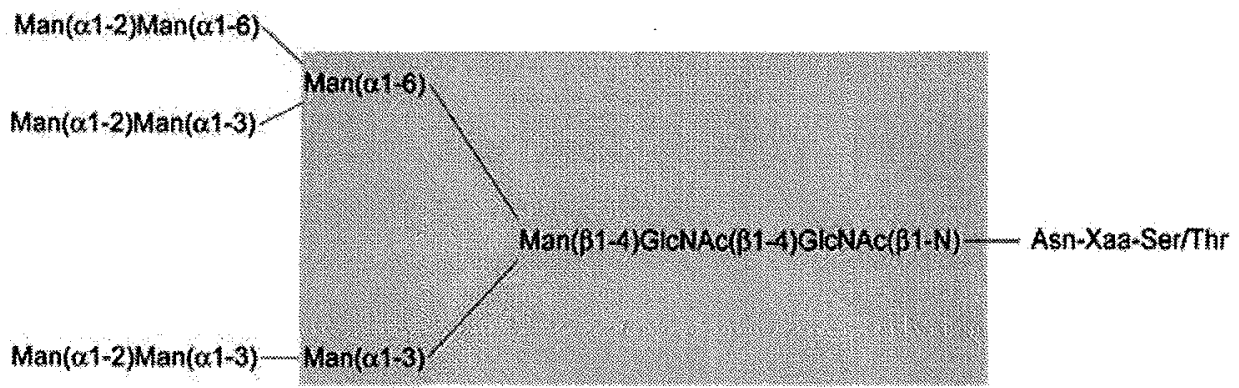

High-mannose-type

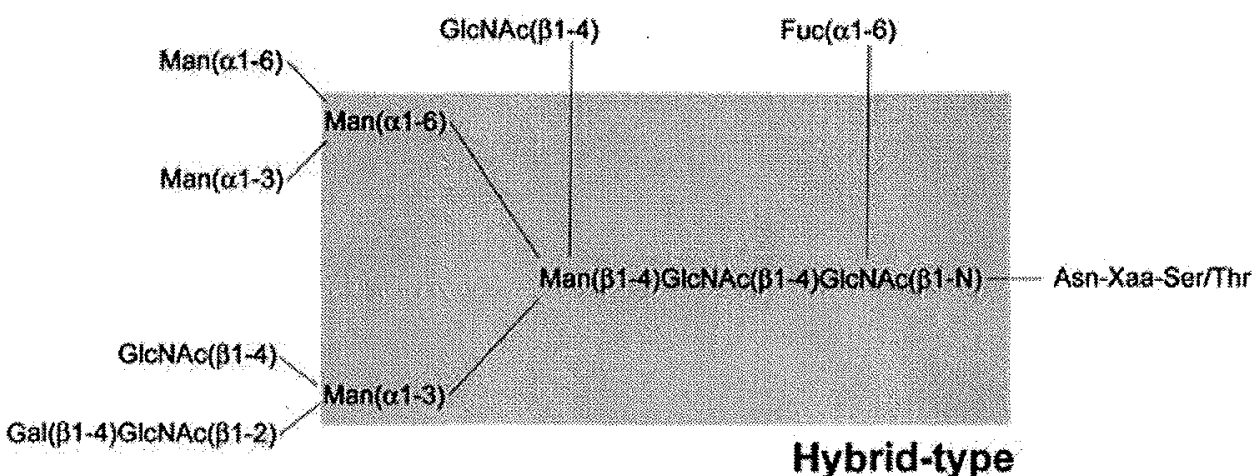

Fig.7 Structures of the complex-, high-mannose- and hybrid-type sugar chains which constitute the three most common subgroups of $N$-linked glycans. The structure within the gray box represents the pentasaccharide core common to all $\mathrm{N}$-glycans. All sugars except Fuc are D-sugars 

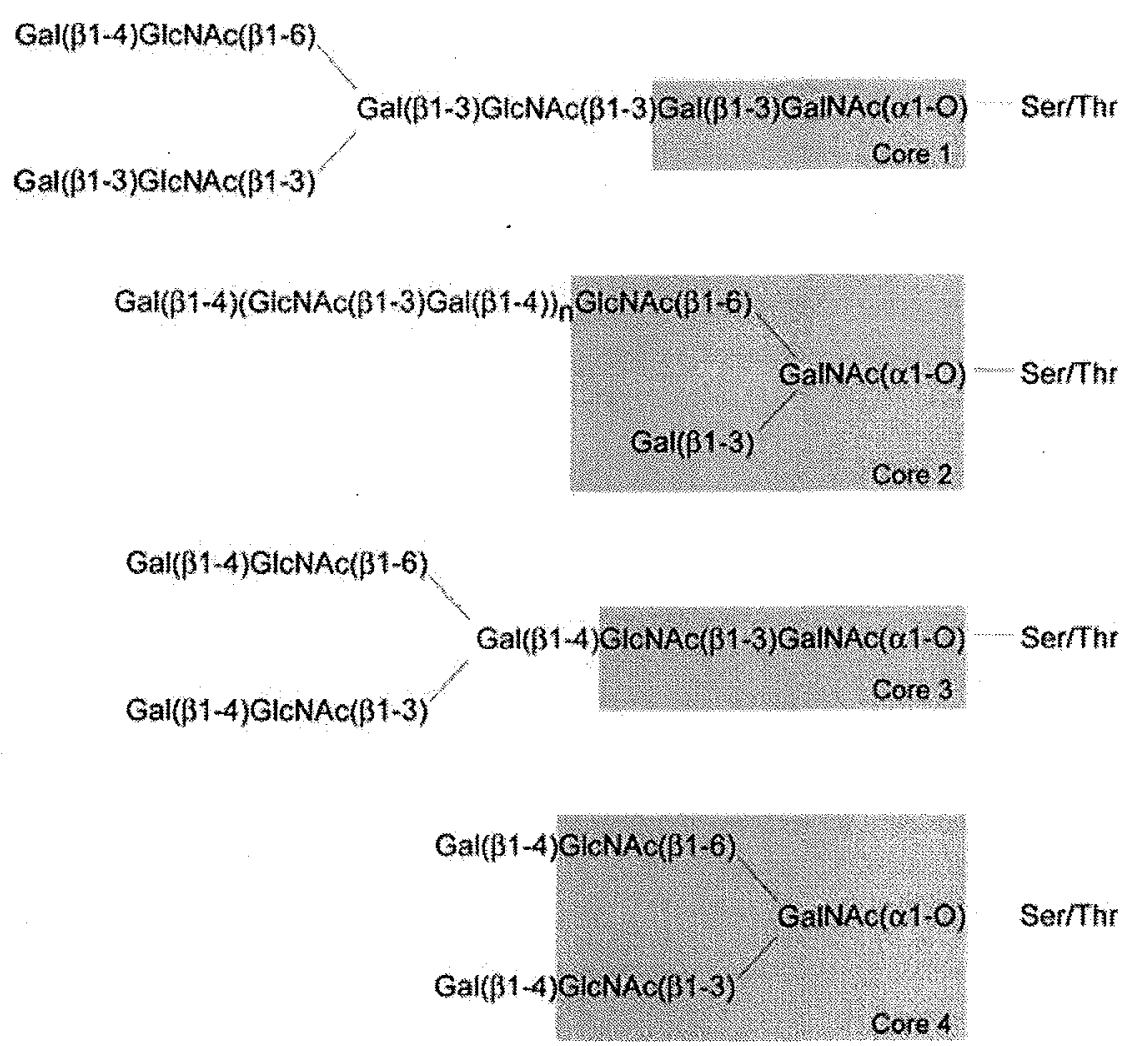

Fig. 8 Examples for O-glycans found in mucin-type glycoproteins. The oligosaccharides shown here are based on four O-glycan core structures which are indicated by gray boxes

In recent years, ultrahigh-sensitivity techniques like combinations of HPLC or capillary electrophoresis with tandem mass spectrometry have become increasingly important, especially for analyzing sub-picomol amounts of mixtures of glycoforms [50-52]. Because of the advent of high-sensitivity NMR probes with cryo-technology and extremely small sample volumes for HPLC-NMR as well as for MAS applications, NMR spectroscopy is of major importance not only for 3D structure determination but for elucidating glycoconjugate primary structures as well $[9,53,54]$. Examples of glycan structures found in $\mathrm{N}$ - and $O$-glycoproteins are given in Figs. 7 and 8.

\section{4}

\section{Determination of 3D Structure}

The structure determination of proteins by X-ray crystallography or NMR spectroscopy is well established. However, extension of this methodology to glycopeptides and glycoproteins bears major challenges due to several reasons $[5,10-12]$. In addition to problems in obtaining pure homogeneous glycopeptides or glycoproteins from chemical or biochemical synthesis, these compounds are inherently difficult to crystallize. There are probably sev- 
eral reasons for this behavior. (a) No larger oligosaccharide structure has been crystallized even as pure isolated carbohydrate only, which is probably due to an unfavorable packing in the crystal due to structural irregularities; (b) the large hydration shell of the oligosaccharides make direct contacts of the molecules in a crystal less favorable; and (c) the flexibility and dynamics of the oligosaccharides attached to proteins often produce no defined $3 \mathrm{D}$ arrangements of the individual residues, which results in a crystal disorder effect from the carbohydrates. Therefore, even when crystals are obtained, very often part or all of the glycan is invisible in the electron density map due to local disorder. NMR on the other hand does not require single crystals. However, the population of multiple conformational states leads to time-averaged NMR parameters that cannot directly be converted into a 3D structure. Rather, NMR experiments have to be combined with extensive computational studies to predict possible conformations and to extract their relative populations.

The conformational analysis of glycopeptides and glycoproteins has very often been separated into the peptide and the glycan part ignoring the potential interdependence of both. Only recently have experimental tools become available that allow structure determinations of natively glycosylated proteins and there are a couple of new techniques that still await being employed for conformational analysis of glycoproteins. Structure determinations and analyses of molecular flexibility and dynamics of entire glycoproteins are still rare. Methodical advances in this regard shall be the focus of this review.

\section{1}

\section{Conformational Analysis by NMR Spectroscopy}

Being a technique for structure determination in solution capable of handling molecular disorder and dynamic equilibria, NMR spectroscopy should be the method of choice for the investigation of glycoproteins. Whereas for carbohydrates a wealth of knowledge has been achieved on conformational analysis, and excellent reviews cover this subject [5,10-12], reports on glycopeptide and glycoprotein structure determination by NMR are still of limited number.

\subsection{1}

\section{Chemical Shift Assignment}

Conformational analysis by NMR requires chemical shift assignments for as many resonances of the glycoconjugate of interest as possible. In this regard, the polypeptide part poses fewer challenges than the carbohydrate moiety due to generally better dispersion of its resonances, much lower variation of the connectivity between monomers-there are only peptide bonds between 
Table 3 Selected sugars and their characteristic NMR features. All the sugars listed are D unless otherwise noted. (Adapted and reproduced with permission from [9])

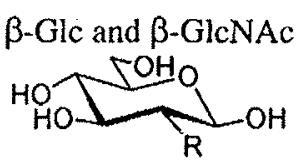

$\mathrm{R}=\mathrm{OH}, \mathrm{NHAC}$

$\beta$-Gal and $\beta$-GalNAc

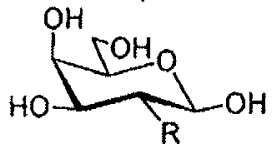

$\mathrm{R}=\mathrm{OH}, \mathrm{NHAC}$
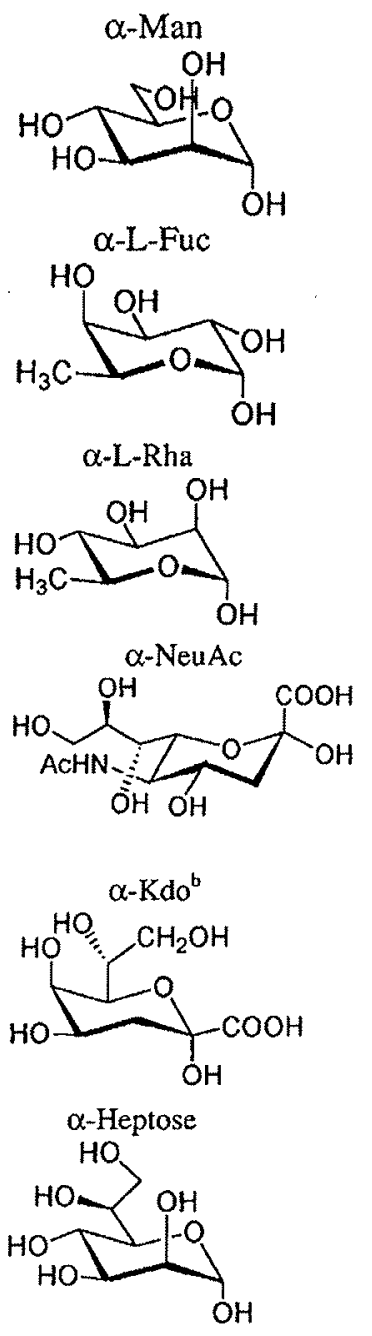

${ }^{3} \mathrm{~J}_{\mathrm{HH}}\left(\mathrm{H}^{1}-\mathrm{H}^{2}, \mathrm{H}^{2}-\mathrm{H}^{3}, \mathrm{H}^{3}-\mathrm{H}^{4}, \mathrm{H}^{4}-\mathrm{H}^{5},[\mathrm{~Hz}]\right)$

$\alpha$ Glc: $3.6,9.5,9.5,9.5[60]$

$\beta$ Glc: $7.8,9.5,9.5,9.5[60]$

The coupling pattern is similar for GlcNAc.

GlcNAc, $\delta\left(\mathrm{CH}_{3}\right) \sim 2 \mathrm{ppm}$

Upfield shift of $\delta(\mathrm{C} 2)$ :

$\alpha \mathrm{GlcNAc}: \delta(\mathrm{C} 2) \sim 55.4 \mathrm{ppm}$

$\beta$ GlcNAc: $\delta(\mathrm{C} 2) \sim 58 \mathrm{ppm}[60,61]$

${ }^{3} \mathrm{~J}_{\mathrm{HH}}\left(\mathrm{H}^{1}-\mathrm{H}^{2}, \mathrm{H}^{2}-\mathrm{H}^{3}, \mathrm{H}^{3}-\mathrm{H}^{4}, \mathrm{H}^{4}-\mathrm{H}^{5},[\mathrm{~Hz}]\right)$

$\alpha$ Gal: $3.8,10,3.8,1[60]$

$\beta$ Gal: $8,10,3.8,1[60]$

The coupling pattern is similar for GalNAc.

GalNAc, $\delta\left(\mathrm{CH}_{3}\right) \sim 2 \mathrm{ppm}$

Upfield shift of $\delta(\mathrm{C} 2)$ :

$\alpha$ GalNAc: $\delta(\mathrm{C} 2) \sim 51.4 \mathrm{ppm}$

$\beta$ GalNAc: $\delta(\mathrm{C} 2) \sim 54.9 \mathrm{ppm}[60,61]$

${ }^{3} \mathrm{~J}_{\mathrm{HH}}\left(\mathrm{H}^{1}-\mathrm{H}^{2}, \mathrm{H}^{2}-\mathrm{H}^{3}, \mathrm{H}^{3}-\mathrm{H}^{4}, \mathrm{H}^{4}-\mathrm{H}^{5},[\mathrm{~Hz}]\right)$

$\alpha$ Gal: 1.8, 3.6, 10.0, 9.8 [60]

$\beta$ Gal: $1.5,3.8,10.0,9.8[60]$

$\delta(\mathrm{C} 6) \sim 16.3 \mathrm{ppm}[61]$

$\delta(\mathrm{H} 6) \sim 1.1 \mathrm{ppm}[60]$

The coupling pattern is similar to Gal.

${ }^{3} \mathrm{~J}_{\mathrm{H} 5 \mathrm{H} 6}=6.3 \mathrm{~Hz}[60]$

$\delta(\mathrm{C} 6) \sim 18.0 \mathrm{ppm}[61]$

$\delta(\mathrm{H} 6) \sim 1.2 \mathrm{ppm}[60]$

The coupling pattern is similar to Man.

${ }^{3} \mathrm{~J}_{\mathrm{H} 5 \mathrm{H} 6}=6.2 \mathrm{~Hz}[60]$

$\delta(\mathrm{H} 3 \mathrm{ax}) \sim 1.9 \mathrm{ppm}, \delta$ (H3eq) $\sim 2.3 \mathrm{ppm}[62]$

Upfield shift of $\delta(\mathrm{C} 3)$

$\alpha$ NeuAc: ${ }^{3} \mathrm{~J}_{\mathrm{C} 1 \mathrm{H} 3 \mathrm{ax}} \sim 6 \mathrm{~Hz}$

$\beta$ NeuAc: ${ }^{3} \mathrm{~J}_{\mathrm{C} 1 \mathrm{H} 3 \mathrm{ax}}<1 \mathrm{~Hz}[63,64]$

Upfield shift of $\delta(\mathrm{C} 3) \sim 34.8 \mathrm{ppm}$ [61]

Coupling pattern similar to NeuAc acid for anomeric configuration

The coupling pattern is similar to Man.

For identification assignment of $\mathrm{C} 7$ is required, where both a $\mathrm{L}$ and $\mathrm{D}$ form can be found. 
Table 3 (continued)

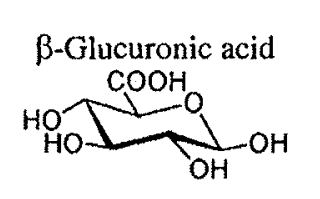

$\beta$-Galacturonic acid

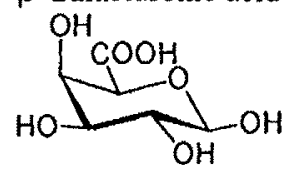

The coupling pattern is similar to Glc.

$\delta(\mathrm{C} 6)$ is $\mathrm{pH}$ dependent [61]:

$\alpha \mathrm{GlcA}$ :

$\mathrm{pH}=7.8: \delta(\mathrm{C} 6) \sim 176.9 \mathrm{ppm}$

$\beta$ GlcA: $\mathrm{pH}=1.8: \delta(\mathrm{C} 6) \sim 172.9 \mathrm{ppm}$

$\mathrm{pH}=7.8: \delta(\mathrm{C} 6) \sim 177.6 \mathrm{ppm}$

$\mathrm{pH}=1.8: \delta(\mathrm{C} 6) \sim 173.8 \mathrm{ppm}$

The coupling pattern is similar to $\mathrm{Gal}$

$\delta(\mathrm{C} 6)$ is $\mathrm{pH}$ dependent [61]:

$\alpha$ GalA:

$\beta$ GalA: $\mathrm{pH}=6: \delta(\mathrm{C} 6) \sim 172.6 \mathrm{ppm}$

$\mathrm{pH}=6: \delta(\mathrm{C} 6) \sim 173.5 \mathrm{ppm}$

$\alpha$-amino and $\alpha$-carboxyl groups and most of them are trans-and, in most cases, due to a lower degree of flexibility. Classical strategies of peptide and protein NMR spectroscopy usually lead to sufficiently complete resonance assignment $[15,55,56]$.

Chemical shift assignment of the glycan part turns out to be much more difficult due to severe overlap of resonances in the region between 3 and $4 \mathrm{ppm}$. Provided that glycoconjugates isolated from natural sources or expressed in cellular systems are being investigated, the glycan part raises additional questions in that the composition, sequence and connectivity have to be characterized prior to conformational analysis. Strategies in this area have been summarized in detail by the groups of Bock and Vliegenthart $[9,57]$. Table 3 gives an overview on characteristic NMR parameters of monosaccharide building blocks found in glycoproteins. Databases that compile and provide statistical analysis of chemical shifts greatly facilitate the assignment task. The corresponding database to the BioMagResBank (BMRB [58]) of the protein field is Sugabase for the carbohydrate part. After termination of funding its content is now accessible, for example via the Glycosciences.de internet portal (cf. Sect. 4.5). Recently, a new method for metabolic incorporation of ${ }^{13} \mathrm{C}$ - and ${ }^{2} \mathrm{H}$-isotopic labels into glycoproteins has been described that on the one hand facilitates heteronuclear NMR experiments and, in addition, provides clues for the assignment of specific building blocks from the ratio of H/D incorporation [59].

\subsection{2}

\section{Nuclear Overhauser Enhancements}

Despite the advent of NMR methods that extend the repertoire of structural restraints, like residual dipolar couplings (RDCs), cross-correlated relaxation 
(CCR), and paramagnetic pseudocontact shifts, most 3D structure determinations published to date are still based on the analysis of nuclear Overhauser enhancements (NOEs) providing short-range distance information between pairs of nuclei, and on the measurement of scalar couplings that can be translated into dihedral angles by application of a Karplus relationship.

NOE-based structure determination is most successful in closely packed regions of a protein where many redundant distance restraints can be extracted. However, structures calculated from NOEs alone suffer from two major complications. Extended structures or protruding protein loops give rise to a relatively sparse number of NOEs that lead to low structural definition in this area. In addition, peptide chains with little contact to the protein core tend to adopt multiple conformations. The NOEs originating from these conformers are being time-averaged with the inverse sixth power of the internuclear distance as a weighting factor, i.e. short distances contribute much more strongly to the intensity of an NOE cross peak than long distances of the same pair of nuclei present in other conformers.

Both of these complications have a large impact on structure calculations of the oligosaccharide part of glycopeptides and glycoproteins. If the glycan protrudes into solution, there are usually very few long-range NOEs to the peptide part or between monosaccharide units. The conformation would have to be calculated mainly from NOEs bridging glycosidic linkages. This approach inherently suffers from the effect that small inaccuracies during distance determination accumulate to large structural uncertainties when looking from the core to the periphery of the glycan. The flexible nature of oligosaccharides gives rise to non-linear averaging of NOEs that complicate distance calculations even more.

Apart from evaluating other structural parameters with different averaging behavior or distance dependence, one way to address these problems is employing more sophisticated molecular modeling that involves backcalculation of NOE and ROE intensities from molecular dynamics (MD) trajectories as has been recently demonstrated by Lommerse et al. for two core $N$-glycans of snail $\alpha_{D}$-hemocyanin (Fig. 9 and Table 4) [65].

A variety of NMR methods has been developed in order to provide an optimum of conformational information when oligosaccharides are involved. Spectral overlap is addressed by heteronuclear experiments that have recently become more feasible due to the development of cryogenic NMR probes with drastically improved sensitivity. Homonuclear 3D spectra have been shown to provide additional information not accessible by $2 \mathrm{D}$ spectra $[66,67]$. The number of NOEs originating from the carbohydrate part of a glycoconjugate can be significantly increased, if the exchange rates of hydroxyl protons are being decreased by application of solvent mixtures and/or low temperature measurements [68]. 

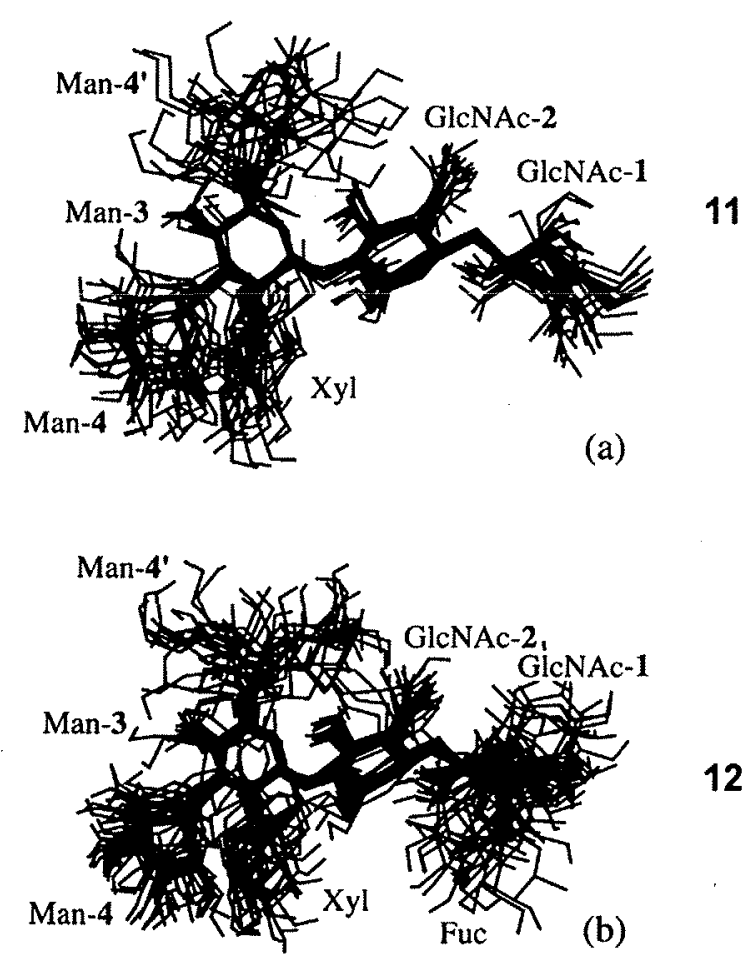

Fig. 9 Conformations appearing during the $\mathrm{MD}$ simulations of two $\mathrm{N}$-glycan core structures in $\alpha_{\mathrm{D}}$-hemocyanin of the snail Helix pomatia superimposed on the Man-3-( $\beta 1$ 4)GlcNAc-2- $(\beta 1-4)$ GlcNAc-1 element. a Xylosylated oligosaccharide $\operatorname{Man}(\alpha 1-6)$ [Man(1 $\alpha$ 3)] $[\mathrm{Xyl}(\beta 1-2)] \operatorname{Man}(\beta 1-4) \operatorname{GlcNAc}(\beta 1-4) \operatorname{GlcNAc}(\beta 1-\mathrm{OMe})$ (11) and b xylosylated ( $\alpha 1-$ 6)-fucosylated oligosaccharide $\operatorname{Man}(\alpha 1-6)[\operatorname{Man}(\alpha 1-3)][\operatorname{Xyl}(\beta 1-2)] \operatorname{Man}(\beta 1-4) \operatorname{GlcNAc}(\beta 1$ 4) [Fuc $(\alpha 1-6)]$ GlcNAc $(\beta 1-\mathrm{OMe})$ (12). (Reproduced with permission from [65])

Table 4 Stability of local minima at the glycosidic linkages, probed by short MD simulations for 11 and 12 from Fig. 9. Criterion for a stable local minimum is a difference between starting and final conformation (after 50 ps simulation for 11 and 40 ps simulation for 12) of less than $30^{\circ}$ for both $\phi$ and $\psi$. Given are the starting $\phi, \psi$ values. $s=$ stable, ns $=$ not stable. (Reproduced with permission from [65])

\begin{tabular}{|c|c|c|c|c|c|c|}
\hline Glycosidic linkage & $\begin{array}{l}\text { Compound } \\
11 \\
\phi\end{array}$ & $\psi$ & & $\begin{array}{l}\text { Compound } \\
12 \\
\phi\end{array}$ & $\psi$ & \\
\hline \multirow{3}{*}{$\operatorname{Xyl}(\beta 1-2)-\operatorname{Man}-3$} & -150 & -150 & $\mathrm{~s}$ & -150 & -150 & ns \\
\hline & 40 & -105 & s & 40 & -105 & ns \\
\hline & -30 & -70 & ns & -80 & -140 & ns \\
\hline \multirow[t]{4}{*}{ Man-4- $(\alpha 1-3) \operatorname{Man}-3$} & 170 & -70 & ns & 170 & -70 & $s$ \\
\hline & 60 & 70 & ns & 60 & 170 & s \\
\hline & 90 & 90 & s & 90 & 90 & $s$ \\
\hline & & & & 140 & 180 & ns \\
\hline \multirow{4}{*}{$\begin{array}{l}\text { Man- }-4^{\prime}-(\alpha 1-6) \text { Man-3 } \\
\left(\omega=-60^{\circ}\right)\end{array}$} & 120 & 90 & ns & 120 & 90 & $s$ \\
\hline & 120 & 90 & ns & 120 & 90 & $s$ \\
\hline & 150 & -110 & $\mathrm{~ns}$ & 150 & -110 & ns \\
\hline & 140 & 165 & $s$ & 140 & -165 & ns \\
\hline
\end{tabular}


Table 4 (continued)

\begin{tabular}{|c|c|c|c|c|c|c|}
\hline Glycosidic linkage & $\begin{array}{l}\text { Compound } \\
11 \\
\phi\end{array}$ & $\psi$ & & $\begin{array}{l}\text { Compound } \\
12 \\
\phi\end{array}$ & $\psi$ & \\
\hline & 40 & 100 & ns & 160 & 100 & $\mathrm{~ns}$ \\
\hline & & & & 100 & 150 & ns \\
\hline & & & & 40 & 180 & ns \\
\hline Man- $4^{\prime}-(\alpha 1-6)$ Man-3 & 140 & 100 & $s$ & 140 & 100 & $\mathrm{~ns}$ \\
\hline \multirow[t]{6}{*}{$\left(\omega=60^{\circ}\right)$} & 160 & -140 & ns & 160 & -140 & ns \\
\hline & 70 & 90 & ns & 100 & 140 & $s$ \\
\hline & 150 & 170 & ns & 180 & 120 & ns \\
\hline & & & & 60 & 40 & ns \\
\hline & & & & 180 & 40 & ns \\
\hline & & & & 80 & -100 & $s$ \\
\hline \multirow[t]{4}{*}{ Man-3-( $\beta 1-4)$ GlcNAc-2 } & -90 & -70 & $s$ & -120 & 70 & $s$ \\
\hline & -130 & 70 & ns & -130 & -50 & $s$ \\
\hline & -60 & -30 & s & & & \\
\hline & -90 & 60 & ns & & & \\
\hline \multirow[t]{5}{*}{ GlcNAc-2-( $(\beta 1-4)$ GlcNAc-1 } & -60 & -30 & ns & -60 & -30 & $s$ \\
\hline & -90 & 80 & ns & -90 & 80 & $s$ \\
\hline & 20 & 120 & s & 20 & 120 & ns \\
\hline & & & & -90 & -70 & s \\
\hline & & & & 80 & 60 & s \\
\hline $\operatorname{Fuc}(\alpha 1-6)$ GlcNAc-1 & & & & -100 & 60 & $s$ \\
\hline \multirow{3}{*}{$\left(\omega=-60^{\circ}\right)$} & & & & -160 & 120 & ns \\
\hline & & & & -20 & -120 & ns \\
\hline & & & & -60 & 120 & $s$ \\
\hline $\operatorname{Fuc}(\alpha 1-6)$ GlcNAc-1 & & & & -100 & 80 & s \\
\hline \multirow{6}{*}{$\left(\omega=60^{\circ}\right)$} & & & & -140 & -140 & $s$ \\
\hline & & & & -160 & 140 & ns \\
\hline & & & & -160 & 40 & ns \\
\hline & & & & -50 & -70 & $s$ \\
\hline & & & & -60 & -160 & ns \\
\hline & & & & -80 & 100 & ns \\
\hline
\end{tabular}

\subsection{3}

\section{Scalar Couplings}

NOE-based structure calculations are generally supported by dihedral angle constraints that can be derived from ${ }^{3} \mathrm{~J}$ scalar coupling constants. This is well established in protein structure determination. Whereas ${ }^{3} \mathrm{JHH}_{\mathrm{HH}}$-couplings have been used already for a long time to determine the ring stereochemistry of monosaccharide building blocks and to derive the $\omega$ torsion angle of the hydroxymethyl group of pyranoses, gaining information on the $\phi$ and $\psi$ angle of the glycosidic linkage requires more experimental effort as 
heteronuclear couplings have to be measured. This is traditionally done by HMBC-type experiments at natural abundance that exploit the sensitivity increase of inverse detection $[69,70] .{ }^{13} \mathrm{C}$-labeled compounds open the route to a variety of experiments that yield long-range $\mathrm{H}-\mathrm{C}$ and even $\mathrm{C}-\mathrm{C}$ couplings as proposed by Homans, Bush and Serianni $[67,71,72]$. Xu et al. demonstrate that ${ }^{3} \mathrm{~J}_{\mathrm{CH}}$-couplings can be reliably measured by quantitative J-correlation methods [73]. Deriving a Karplus relationship for transglycosidic angles is complicated by the high diversity of possible linkages and stereochemistries of the building blocks depending on the relative position of oxygens attached to the four atom fragment that defines the torsion angle [72]. Karplus parameters for interglycosidic J-couplings have been reported for $\mathrm{H}-\mathrm{C}$ and $\mathrm{C}-\mathrm{C}$ scalar couplings $[67,72,74,75]$.

In the case of molecules with flexible portions, like protein loops or oligosaccharides, structure determination based on scalar couplings has the major advantage of a much simpler averaging behavior compared to the NOE. The J-coupling values are simple linear averages over the ensemble of conformers. Martin-Pastor and Bush have shown that, for flexible oligosaccharides that populate distinct minima separated by substantial energy barriers, modeling based on scalar coupling data is superior to NOE-based modeling [71]. For a heptasaccharide of Streptococcus mitis it was possible to narrow the search space for allowed torsion angles for each individual glycosidic linkage. It turned out that the flexibility of this heptasaccharide is mainly localized to certain linkages and that only very few conformers are required to reproduce experimental coupling and NOE data. Although these methods have proved to be very powerful for determination of carbohydrate structure and dynamics, an application to intact glycopeptides or glycoproteins is still lacking.

\subsection{4 \\ Residual Dipolar Couplings}

Whereas dipolar couplings are completely canceled out under conditions of isotropic tumbling, partial alignment of molecules with respect to the magnetic field of the NMR spectrometer gives rise to observable line splittings. The magnitude and sign of these residual dipolar couplings (RDCs) depend on the extent of molecular alignment and on the angle between the magnetic field and the vector connecting the coupled nuclei (Fig. 10) [76-78]. In the protein field, residual dipolar couplings are today widely used as additional restraints during structure calculation, for structure validation and refinement, and recently, as probes of dynamic processes [79, 80].

The major advantage of RDC-derived restraints compared to NOEs and scalar couplings is that RDCs provide long-range information from which the relative orientation of remote substructures can be concluded. The problem of small errors in short-range distances or torsion angles that accumulate to 


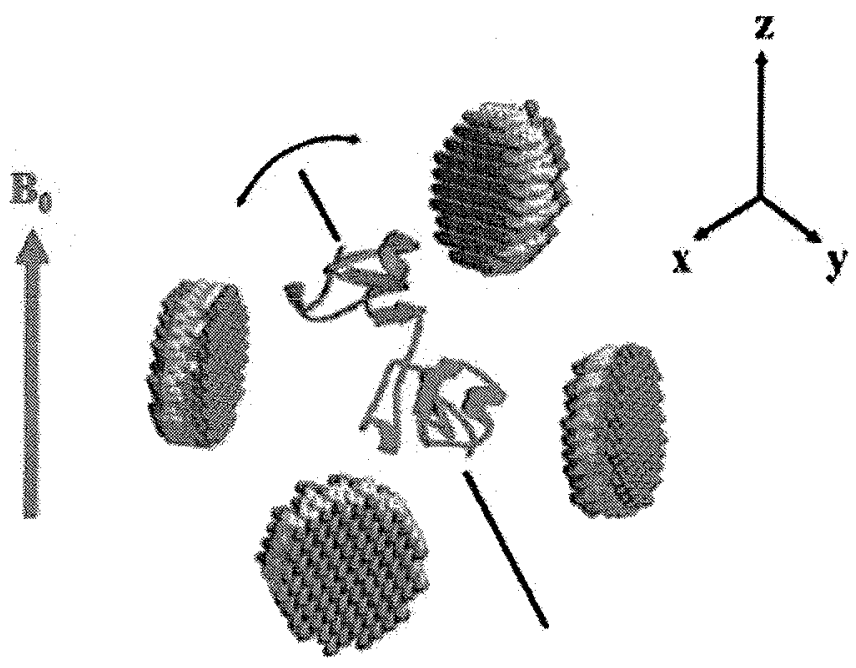

Fig. 10 Partial alignment of biomolecules: A two-domain construct from barley lectin oriented by collisions with bicelles. The protein's long axis tends to align parallel to the bicelle surfaces. (Adapted and reproduced with permission from [78])

large deviations in the entire structure is absent when looking at RDCs. This predestines RDCs as parameters for structure calculations of glycan chains of glycopeptides and glycoproteins that are otherwise poorly defined due to lack of long-range NOE contacts.

Applications to glycosylated peptides or proteins have not been reported, yet. The major reason for this might be the lack of reliable methods for introducing isotopic labels into glycoconjugates and complications due to motional averaging. The former limitation can be circumvented in part by using highest sensitivity NMR spectrometers equipped with cryogenic probes and/or operating at high field. In addition, significant advances have been made regarding expression systems for glycoproteins (cf. Sect. 2.2).

Motional averaging makes the analysis of RDC data more challenging compared to the situation encountered with more or less rigid, globular protein domains. On the other hand, RDCs are sensitive probes of dynamic processes and, complementary to relaxation rate and NOE techniques, cover a timescale that is not accessible by other NMR parameters (Fig. 11) [80-83].

Recently, characterization of conformation and dynamics of oligosaccharides by RDCs has been reported [84-86]. Azurmendi et al. could show from measurements of one-bond $\mathrm{C}-\mathrm{H}$ dipolar couplings combined with Monte-Carlo simulations that two blood group epitopes, namely $\operatorname{Fuc}(\alpha 1$ $2)[\operatorname{GalNAc}(\alpha 1-3)] \mathrm{Gal}(\alpha 1-\mathrm{OH})$ and $\mathrm{Fuc}(\alpha 1-2)[\mathrm{Gal}(\alpha 1-3)] \mathrm{Gal}(\alpha 1-\mathrm{OH})$, adopt essentially one single conformation in solution in contrast to theoretical models that suggest the existence of two conformers [84].

Duus and coworkers analyzed the dynamic conformational equilibrium of the trisaccharide $\operatorname{Man}(\alpha 1-3)[\operatorname{Man}(\alpha 1-6)] \operatorname{Man}(\alpha 1-\mathrm{OMe})$ (13) which represents the core region of $\mathrm{N}$-glycans. Hetero- and homonuclear RDCs served as restraints for long (50 ns) molecular dynamics simulations in explicit water. 


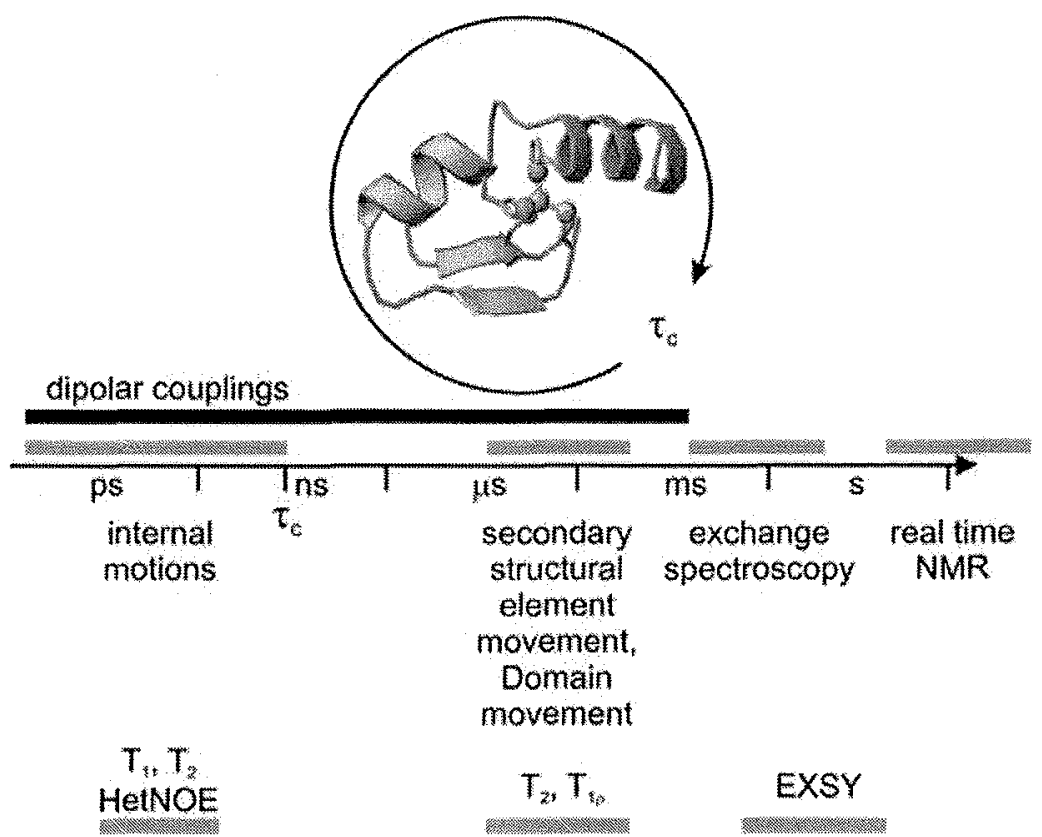

Fig. 11 Time scales that can be detected by various methods in NMR: The fast motions ps to ns are measurable by relaxation of, e.g., ${ }^{15} \mathrm{~N}$, the motion between approximately $50 \mu \mathrm{s}$ and $10 \mathrm{~ms}$ by $\mathrm{T} 1 \rho$ measurements, the slower time scales by exchange spectroscopy and even slower ones by real time NMR. Dipolar couplings cover all time scales from ps to $\mathrm{ms}$ and therefore can report also about the "dark" region of time scales. (Adapted and reproduced with permission from [80])

The results indicate almost equal populations of the $g g$ and $g t$ rotamers of the $\alpha$ 1-6-linkage, whereas the $t g$ rotamer was predicted to be unpopulated in aqueous solution (Fig. 12) [85].

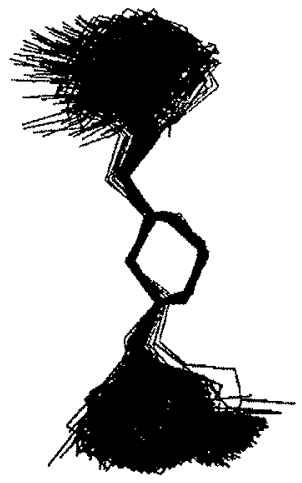

13

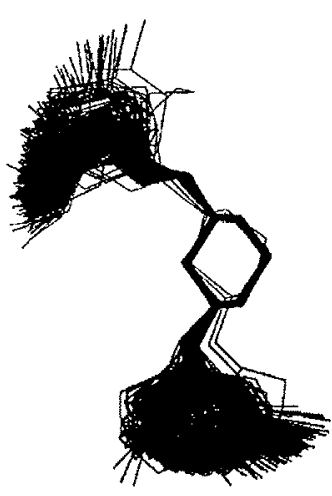

13

Fig. 12 The two dynamic conformations of the trisaccharide $\operatorname{Man}(\alpha 1-3)[\operatorname{Man}(\alpha 1-6)]$ $\operatorname{Man}(\alpha 1-\mathrm{OMe})(13)$. On the left is the $g g$ conformation of the ( $\alpha 1-6)$ linkage and on the right the gt. In this diagram only the ring carbons, oxygens and the glycosidic oxygens have been drawn. They have been overlayed by best-fitting to the central sugar ring. (Reproduced with permission from [85]) 


\subsection{5}

\section{Cross-Correlated Relaxation}

Another NMR parameter that allows for measuring angles between bond vectors is the relaxation rate that originates from cross-correlation between relaxation mechanisms like dipole-dipole interaction or chemical shift anisotropy. This cross-correlated relaxation (CCR) rate provides direct information on the projection angle between bond vectors, provided that double or zero quantum coherence can be exited between the nuclei of interest as shown in Fig. 13 for two amide bond vectors of the protein rhodniin $[87,88]$. In addition CCR rates contain information on local anisotropic dynamics $[89,90]$.

CCR methodology is still in rapid development for proteins and nucleic acids and has only recently been applied to the carbohydrate field for studying internal dynamics of monosaccharides [91], and to support primary structure elucidation of bacterial polysaccharides [92]. It remains to be seen whether CCR measurements will extend the repertoire for 3D structure determination of glycoconjugates, as well.

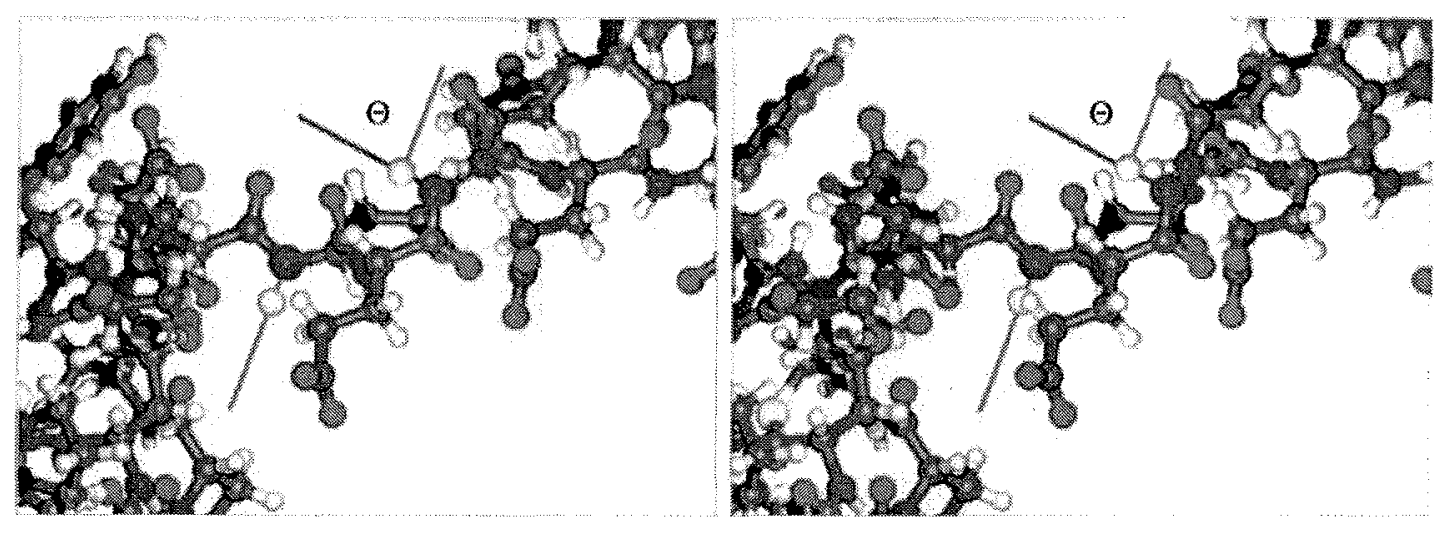

Fig. 13 Stereoview showing a close-up of the structure of the protein rhodniin. The two gray lines indicate the bond vectors of two spin pairs. The angle between the two interatomic vectors is indicated by $\theta$. Atoms are depicted by the following colors: hydrogen, white; carbon, black; sulfur, yellow; oxygen, red; and nitrogen, blue. (Reproduced with permission from [87])

\section{2}

\section{X-ray Crystallography}

As of October 2005, the Protein Data Bank (PDB [1]) listed 1094 3D structures containing glycoprotein chains, 1073 of which were solved by X-ray crystallography. Many of the molecules studied had to have their glycans truncated or removed in order to be crystallized. This might bias us to see mainly glycoprotein structures with glycan residues that are, at least in the mature form of the protein, not of crucial importance for structure or function. 
The disorder problem associated with flexible glycan chains of glycoproteins can at least in part be overcome when the oligosaccharide conformation and/or orientation is being stabilized by intra- or intermolecular contacts. This leads to another family of X-ray structures that display oligosaccharides at a comparatively high degree of resolution caused by lectin-like protein carbohydrate interactions that stabilize the glycan in the crystal. One should on the other hand be cautious when interpreting this kind of study as the carbohydrate binding auxiliary might force the glycoprotein or its oligosaccharides to be trapped in one favorable conformation or even adopt non-native conformations. The dynamic behavior of the glycoprotein is most certainly altered compared to the free molecule. Structure determination of highly flexible carbohydrates by X-ray crystallography is facing inherent problems such that dynamic features of these molecules are much better addressed by solution techniques.

Nevertheless, methodological advances have been reported that allow for determining medium-resolution structures from partly disordered glycoprotein crystals as exemplified by the work of Chen et al. who were able to obtain the structure of a fully glycosylated SIV gp120 envelope glycoprotein in an unliganded conformation by X-ray crystallography at $4.0 \AA$ resolution $[93,94]$. By optimizing beam geometry and the strategy for phase improvement including multi-crystal averaging, a 3D structure was obtained that showed at least four ordered sugars on many of the 13 oligosaccharides (Sect. 5.1.1).

\section{3 \\ Molecular Modeling}

Both experimental methods for structure determination at atomic resolution, X-ray crystallography and NMR spectroscopy, face significant complications when applied to highly flexible molecules coexisting in numerous conformations as is mostly the case for the oligosaccharide portion of glycoproteins and is of importance for the peptide part of glycopeptides, as well.

This makes molecular modeling an invaluable tool for searching conformational space and for calculating structures which are consistent with experimental data. Apart from very small glycopeptides, most molecules of biological interest still exceed the capabilities of quantum mechanical approaches in terms of the number of atoms and degrees of freedom. Therefore, force field calculations dominate the field. A whole variety of potential energy functions has been developed and extended in order to accommodate the polypeptide as well as the glycan part, including AMBER [95-99], CHARMM [100-102], GROMOS [103, 104], OPLS [105, 106], and TRIPOS $[107,108]$.

All implementations have to face as a major challenge the high degree of hydrophilicity and thus extensive solvation of the carbohydrate part, elec- 
tronic arrangements that largely vary with conformation, leading to the anomeric, exo-anomeric and gauche effects, and a correct representation of the forces that act between the glycan and the protein part, including electrostatic and van der Waals interactions as well as entropic effect due to solvation/desolvation processes. A comparison of the performance of $20 \mathrm{dif}-$ ferent force fields including their carbohydrate-specific parameters has been carried out by Pérez et al. [109]. Even though computational methods for structure calculation are highly sophisticated, today, many features of physical reality are still being neglected, ranging from induced polarization effects via protonation equilibria to a thorough treatment of solvation $[10,11]$.

Apart from considerations relating to the force field, an important aspect is the software implementation that has to be capable of handling all available experimental restraints in a flexible way. Regarding NMR spectroscopic data of glycopeptides and glycoproteins, special emphasis pertains to treating highly ambiguous distance restraints due to overlap of carbohydrate resonances, and to incorporating the growing number of restraints derived from tensorial interactions. In addition, the high degree of conformational flexibility of these molecules demands incorporating restraints in an ensemble and/or time-averaged form [110]. Flexible options for this have been implemented, for example into AMBER [95], X-PLOR/CNS [111,112], and GROMOS [103].

\section{4 \\ Statistical Analysis of Available 3D Structures}

The entirety of available crystallographic data on oligosaccharides, glycoproteins, and glycan-binding proteins was analyzed by Petrescu et al. in 1999 [113]. From 639 glycosidic linkage structures distinct conformers could be identified. The O5-C1-O-C $(\mathrm{x})^{\prime}$ torsion angles for all these distinct conformers appears to be determined chiefly by the exo-anomeric effect. The favored conformations identified in this study should prove useful when modeling "average" glycan structures and should, in analogy to the Ramachandran plot for proteins, also allow the easy identification of distorted glycosidic linkages.

More recently, Petrescu et al. focused on the peptide glycosidic linkage, and the peptide primary, secondary, and tertiary structures around $N$-glycosylation sites [114]. At that time, less than $3 \%$ of the proteins in the PDB were glycosylated. Regarding that over $50 \%$ of eukaryotic genes code for glycoproteins this again illustrates the immense technical difficulties associated with crystallization of glycoproteins [2]. Out of 2592 glycosylation sequons 1683 (65\%) were occupied by $N$-glycans. An increased occurrence of aromatic residues and a deficit of acidic residues upstream from occupied glycosylation sites was found. Glycosylated sequons showed strong preference of threonine with respect to serine at position +2 whereas proline at position 
+1 seems to completely prevent glycosylation. Other than that, no pattern of remote amino acid distribution was found.

Glycosylation can occur on all types of secondary structure, with a bias towards turns and bends. It is noteworthy that glycosylation sites occur at or very close to protein regions where there is a change in secondary structure. The authors hypothesize that this reflects a specific role of glycans in organizing the folding process. As might be expected, many of the occupied $N$-glycosylation sites are found at convex surfaces (33\%). On the other hand, a surprisingly large number of glycosylated asparagine residues have a low accessibility with $10 \%$ being in deep recesses and $20 \%$ with the attached glycan filling a cleft both primarily formed by hydrophobic, especially aromatic, amino acid side chains (Table 5). These findings provide evidence for the im-

Table 5 Analysis of surface geometry and relative accessibility of the Asn residue for all occupied glycosylation sites in a non-redundant data set of $386 \mathrm{~N}$-glycosylation sites. The surface geometry was qualitatively classified in two orthogonal directions by inspection and the following attributes were assigned for each direction: convex $(x)$, concave $(v)$, inflection ( $i)$, and flat $(f)$. Very frequently, $N$-glycosylation was found at the edge of a groove. These sites were separately labeled as $e$ (edge). The relative accessibility of the Asn residue to a probe of radius $3 \AA$ was defined as the ratio between the side chain accessibility of the Asn residue and that of an Asn residue located in a fully extended GlyAsn-Gly tripeptide. Asn SC (-G), Asn side chain relative accessibility in the absence of the glycan; Asn SC $(+G)$, Asn side chain relative accessibility in the presence of the glycan; Asn $\mathrm{Bkb}(+\mathrm{G})$, Asn backbone relative accessibility in the presence of the glycan. (Adapted and reproduced with permission from [114])

\begin{tabular}{llllll}
\hline $\begin{array}{l}\text { Sites } \\
(\%)\end{array}$ & $\begin{array}{l}\text { Asn SC } \\
(-\mathrm{G})\end{array}$ & $\begin{array}{l}\text { Asn SC } \\
(+\mathrm{G})\end{array}$ & $\begin{array}{l}\text { Asn Bkb } \\
(+\mathrm{G})\end{array}$ & $\begin{array}{l}\text { Surface } \\
\text { type }\end{array}$ & $\begin{array}{l}\text { Local geometry of the protein } \\
\text { protein surface at the glyco- } \\
\text { sylation site }\end{array}$ \\
\hline 33.2 & $57.6 \pm 19.8$ & $34.4 \pm 27.0$ & $28.2 \pm 30.8$ & $\mathrm{xx}$
\end{tabular}


portance of hydrophobic protein/glycan interactions. In addition, the authors propose that, by occupying grooves or holes, these glycosylation sites become a direct marker of proper folding as enzymes of the quality control machinery, like UDP-glucose glycoprotein:glucosyltransferase (UGGT), would not process these sites during quality control which would in turn prevent protein degradation.

$\mathrm{N}$-Glycosylation is correlated with altered asparagine side chain torsion angle distribution and reduced flexibility [Figs. 14 and 15 (and Fig. 1 for angle definitions)]. Unmodified Asn residues show a preference for the $g^{-}$conformer compared to the $t$ conformer, largely irrespective of whether Asn is located inside the protein, at a solvent-accessible surface or in a glycosylation

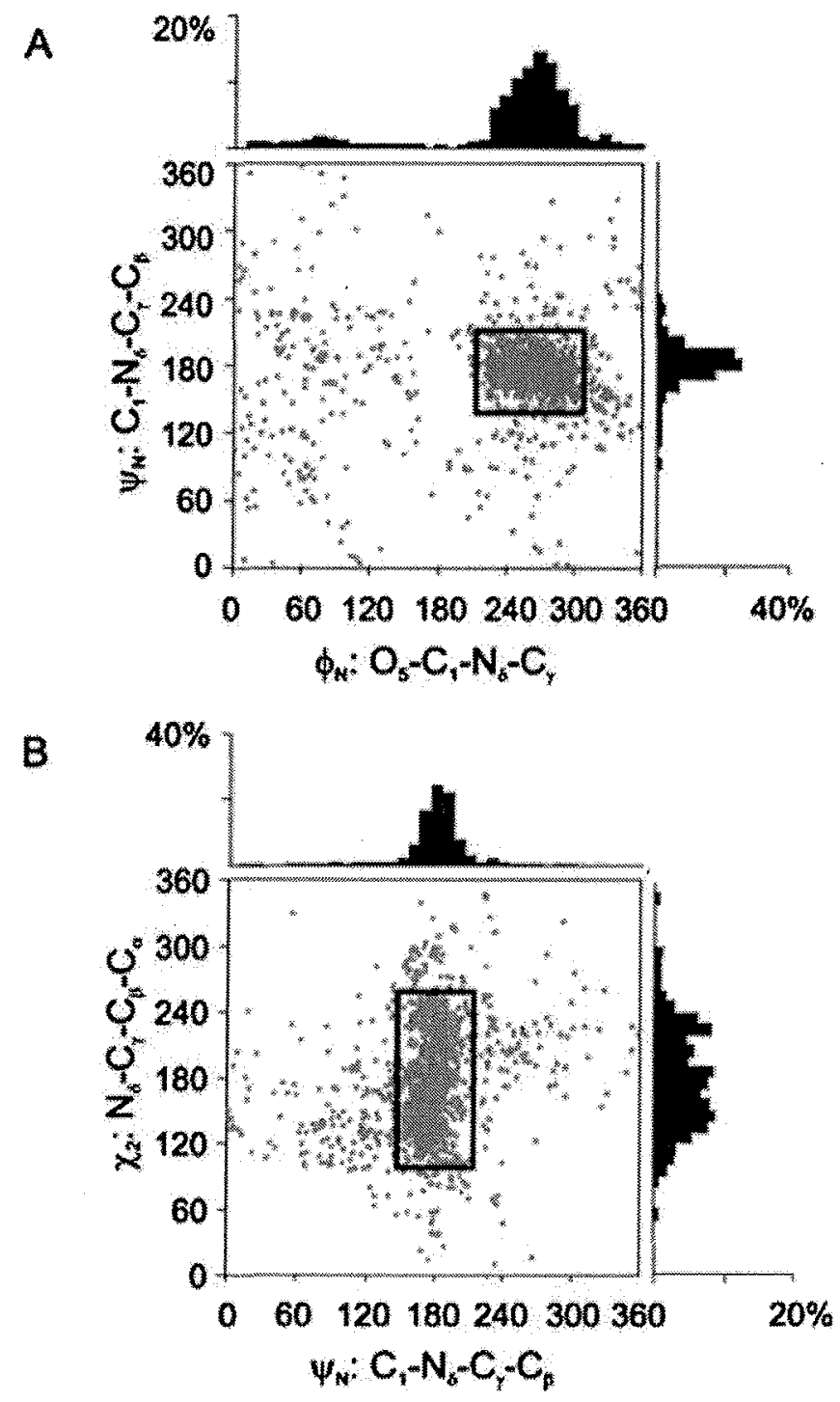

Fig. 14 Torsion angle and histogram plots for the Asn-GlcNAc linkage. Structures associated with a distinct conformer are shown by the boxes. A Plot of $\phi \mathrm{N}$ versus $\psi \mathrm{N}$. B Plot of $\psi \mathrm{N}$ versus $\chi 2$. (Reproduced with permission from [114]) 
sequon. In contrast, glycosylated Asn residues populate the $t$ conformer in preference to the $g^{-}$conformer which corresponds to an extended side chain conformation increasing the distance between the first GlcNAc and the peptide back bone. A further important outcome of the statistical analysis is that, in the glycosylated case, the $\chi 2$-angle displays a much narrower distribution compared to unmodified Asn residues while in both cases the $\chi 2$-dihedral centers at $180^{\circ}$ in agreement with previous work [20]. The reduced standard deviation of $\chi 2$ in the glycopeptide case is in agreement with a whole body

A

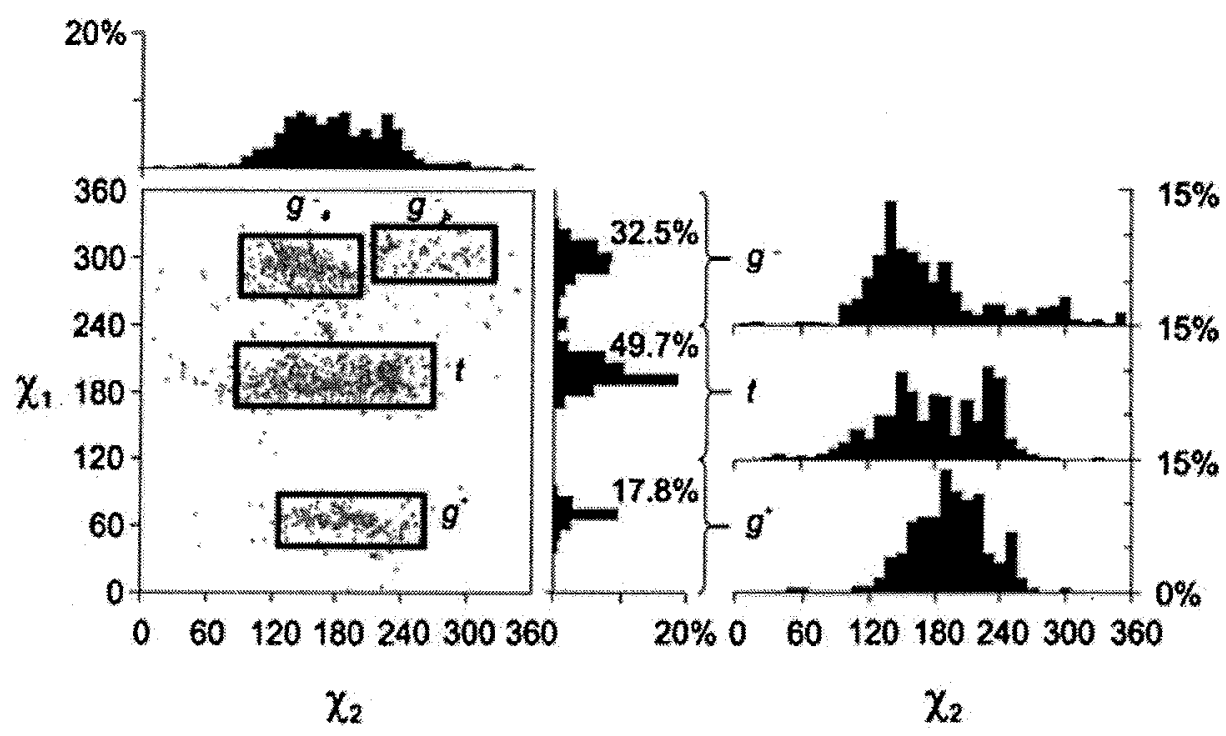

B

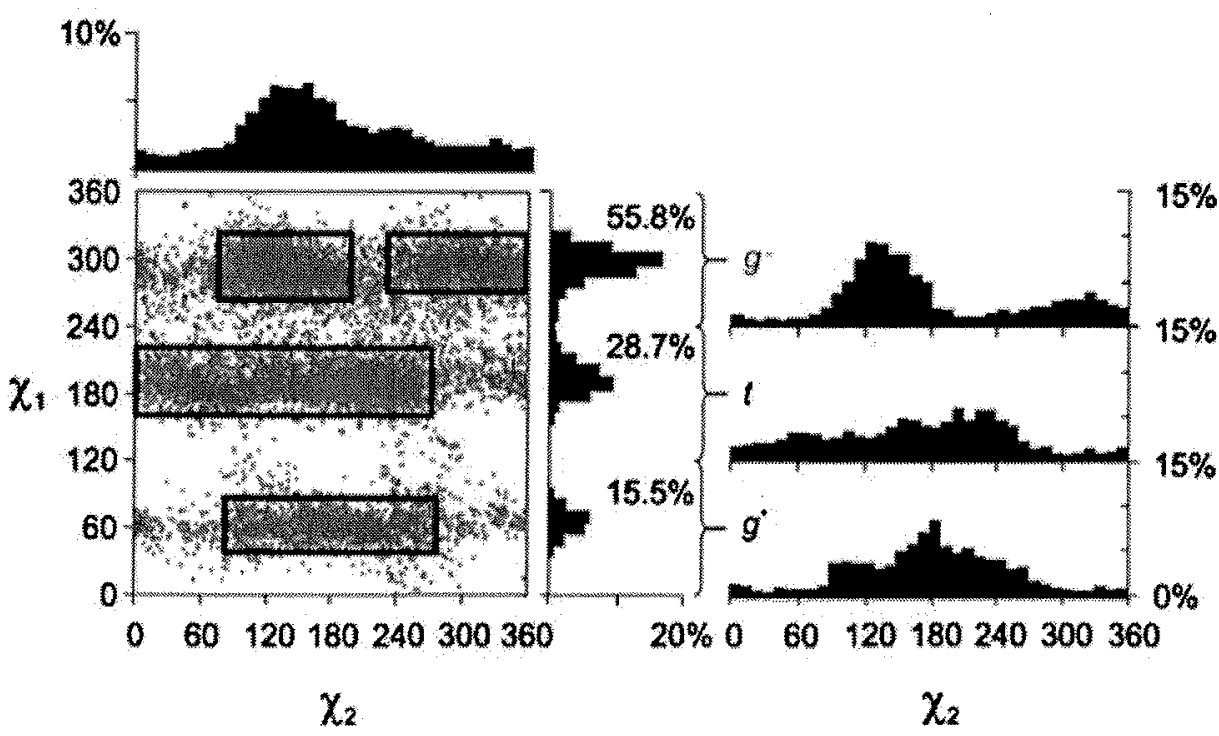

Fig. 15 Torsion angle and histogram plots of $\chi 1$ versus $\chi 2$ for Asn residue side chain subsets. The $\chi 2$ histogram plot is shown for each distinct $\chi 1$ conformer, as well as for the total population. A Asn residues in occupied glycosylation sequons. B Asn residues not in glycosylation sequons and with a solvent accessibility greater than zero. (Reproduced with permission from [114]) 
of literature saying that $N$-glycosylation leads to decreased flexibility of the peptide chain.

Ninety percent of $N$-glycosylation sites found in the PDB have the same conformation of the glycosidic linkage with a $\psi N$-angle of $180^{\circ}$ as expected for a trans amide bond and a $\phi N$-angle centered around $240^{\circ}$. This is in agreement with the previous statistical analysis of PDB structures by Imberty and Pérez and with structural information obtained by NMR spectroscopy [20,115-117]. Interestingly, the broader data basis surveyed in the latest statistical analysis by Petrescu et al. allowed the identification of a second conformational family populated by roughly $12 \%$ of structures. Here, $\phi N$ averages at $75^{\circ}$ significantly deviating from the value of $40^{\circ}$ predicted by force field calculations [20].

In a previous study, the peptide backbone conformation and the amino acid distribution at position +1 of the glycosylation sequon was analyzed by Veluraja and coworkers on a set of 696 Asn $-X-$ Ser/Thr motifs found in structures of the PDB [118]. Here, as well as by analyzing the amino acid sequences of the SWISS-PROT database it turned out that Gly is found with increased probability in the glycosylation sequon. In addition, the authors report elevated occurrence of Asn and Phe at this position although this could not be verified by the more recent study of Petrescu et al. [114].

It is noteworthy that the backbone angles of Gly residues found at glycosylation sites cluster around $\phi \mathrm{G}=+60^{\circ}$ to $+110^{\circ}$ and $\phi \mathrm{G}=-30^{\circ}$ to $+30^{\circ}$, a conformation that is disallowed for non-glycine residues (Fig. 16). This backbone conformation allows the formation of an $\mathrm{H}$-bond between the side chain of Asn and the hydroxy amino acid that has been proposed earlier to be essential for the function of the oligosaccharyltransferase $[119,120]$.

The whole set of confirmed $N$-glycosylating sequences could be classified into nine backbone conformations of the Asn-X-Ser/Thr motif with angular deviations smaller than $30^{\circ}$. In the majority of these conformations the authors were able to demonstrate the possibility of direct or water-mediated hydrogen bonds [118]. The significant number of structures analyzed by Christlet et al. that do not possess this kind of H-bonding and the fact that glycosylation occurs during synthesis of the polypeptide chain that is presumed to be unfolded at this stage, suggests on the other hand that conformations found in mature proteins need not reflect circumstances present at the time of glycosyltransfer [20].

\section{5 \\ Databases}

Databases that compile and order chemical, structural and biological information and make it searchable are largely responsible for the increasing pace in the life sciences and for major breakthroughs seen, for example in genetics and structural biology of proteins. 


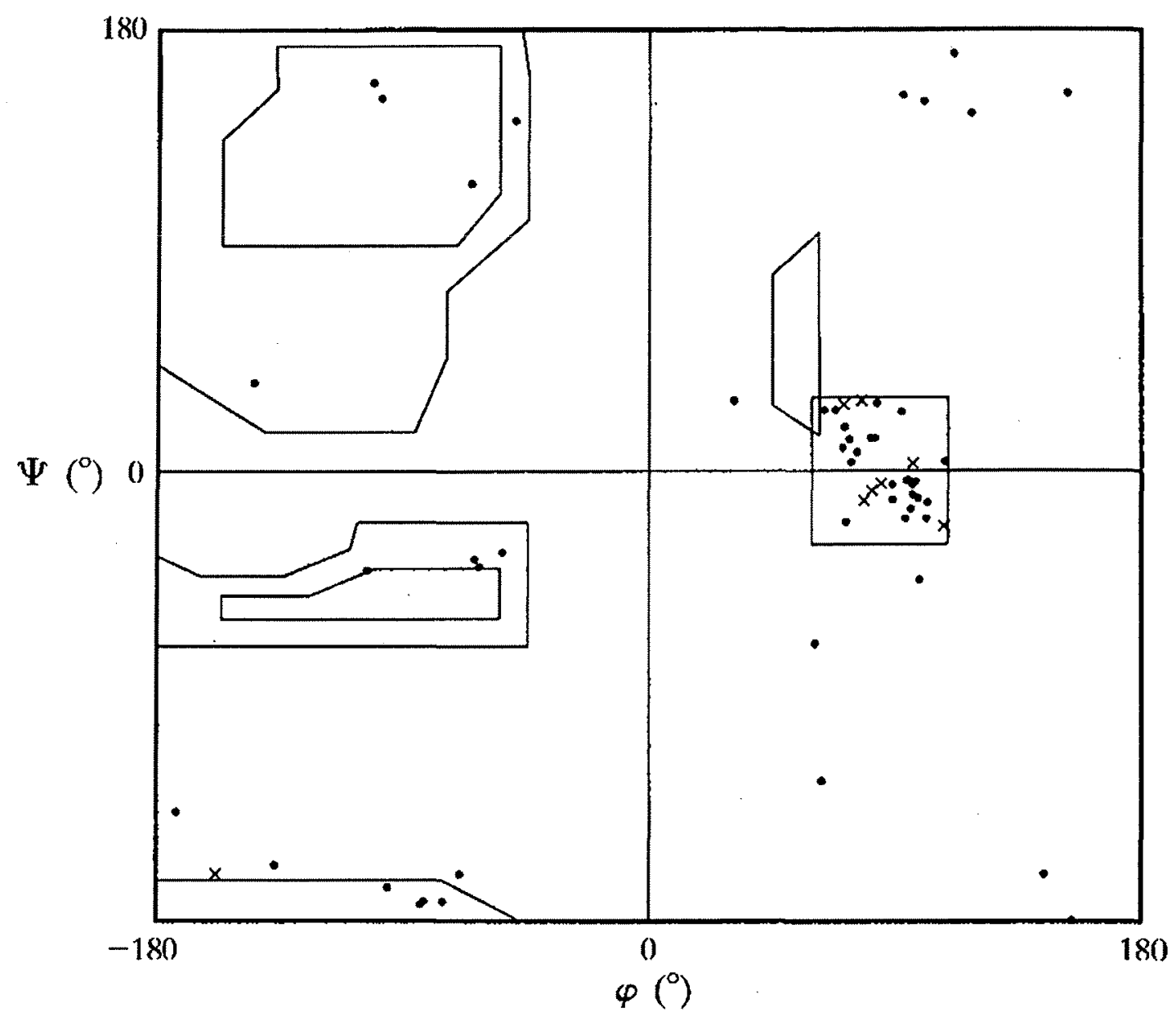

Fig. 16 Ramachandran plot showing the clustered region for Gly in the glycosylated consensus sequences Asn-Gly-Ser/Thr. The clustered region is marked as a rectangular box. Dots and crosses represent consensus sequences from a set of 488 non-homologous proteins and confirmed glycosylated sequences, respectively. (Reproduced with permission from [118])

\section{Protein Data Bank (PDB) (http://www.rcsb.org/)}

The most important source for 3D structural information on biomolecules is the PDB containing 36710 entries (May 2006) [1, 121]. Structures of proteins, glycoproteins as well as nucleic acids and biomolecular complexes determined by X-ray, NMR or theoretical methods are compiled together with information on sequence, experimental conditions, and methodical details. From 2006 on, the PDB has fully switched to a new web interface with improved search and browse functionality. However, it is still not straightforward to identify all PDB entries of glycoproteins that actually contain structural information on the carbohydrate part. In order to do so, Petrescu et al. applied their own search algorithm to a downloaded version of the PDB (cf. Sect. 4.4) [113, 114]. 
Biological Magnetic Resonance Data Bank (BMRB) (http://www.bmrb. wisc.edu/)

The pedant to the PDB in terms of NMR spectroscopic data is the BMRB maintained at the University of Wisconsin, Madison [58]. At the time of writing, it contained ca. 7000 entries on chemical shift assignment, and, in many cases, restraint lists and even NMR time domain data. However, chemical shift data on glycopeptides and glycoproteins are scarce. Most of the examples reviewed here are not, or only very incompletely, referenced in the BMRB.

\subsection{1}

\section{Glycoconjugate-Specific Databases}

The need for cross-linking available information on glycoconjugates has triggered the founding of several glyco-specific databases and internet resources. Currently, three major initiatives are, in part jointly, building-up comprehensive knowledge bases for glycobiology, namely Glycosciences.de, the Consortium for Functional Glycomics, and the Kyoto Encyclopedia of Genes and Genomes.

\section{Glycosciences.de (http://www.glycosciences.de/)}

A broad range of information and a versatile collection of tools is available at the Glycosciences.de web site located at the DKFZ, Heidelberg, Germany. The SWEET-DB [122] associates primary structures of carbohydrates with $3 D$ structures from the PDB, NMR data from Sugabase, and literature references from NCBI Pubmed and Carbbank. In addition, theoretically calculated mass spectra and 3D-coordinates can be retrieved for a given carbohydrate (sub)structure. Web-based tools allow for searching the PDB for carbohydrate structures, predicting protein $N$-glycosylation, building of $3 \mathrm{D}$ models and calculating of mass spectra of arbitrary glycan structures. Glycosciences.de has joined with the Consortium for Functional Glycomics and is part of the EuroCarbDB initiative which aims at creating a comprehensive database of glycoconjugate-specific information (http://www.eurocarbdb.org/).

\section{Consortium for Functional Glycomics (CFG) (http://www.functional glycomics.org/)}

The US pendant to Glycosciences.de is the CFG [123]. Its database integrates glycan structures from Carbbank, Glycominds Ltd., as well as structure synthesized or identified by members of the CFG. In addition, the CFG curates databases on glycosyl transferases, glycan binding proteins, and various microarray and profiling experiments. 
Kyoto Encyclopedia of Genes and Genomes (KEGG) Glycan Database (http://www.genome.jp/kegg/glycan/)

The KEGG Glycan database, part of the Kyoto Encyclopedia of Genes and Genomes, currently contains 11118 entries on glycans covering primary structure, pathways and related proteins [124].

Glyco3D (http://www.cermav.cnrs.fr/lectines/)

At the CERMAV division of the CNRS, 3D structural information on mono-, oligo-, and polysaccharides, lectins, glycosyltransferases, and glycosaminoglycan binding proteins has been organized in the form of a web site that provides links to the corresponding PDB entry.

O-Glycbase 6.0 (http://www.cbs.dtu.dk/databases/OGLYCBASE/)

This database, recently updated to version 6.0 , lists collected information on primary structure, site and type of glycosylation for $242 \mathrm{O}$ - and $\mathrm{C}$ glycoproteins with experimentally confirmed glycosylation [125]. In addition, content has been linked to various other databases like Medline, PDB, and GlycosuiteDB. Associated with this O-Glycbase is the netOglyc server that predicts $\mathrm{O}$-glycosylation sites in proteins based on an artificial neural network [126] (http://www.cbs.dtu.dk/services/NetOGlyc/).

GlycoSuite (http://www.glycosuite.com)

Release 8.0 of the commercial GlycosuiteDB lists 9436 curated entries which are searchable for information related to structure, disease, mass spectrometry, etc. [127].

\section{Sugabase (http://www.boc.chem.uu.nl/sugabase/sugabase.html)}

SUGABASE is a carbohydrate-NMR database that combines CarbBank Complex Carbohydrate Structure Data (CCSD) with proton and carbon chemical shift values. Funding has been discontinued and this database is no longer being updated. Its information content has been integrated into other databases, for example SWEET-DB.

Complex Carbohydrate Structure Data (CCSD) and CarbBank (http:// www.boc.chem.uu.nl/sugabase/carbbank.html)

The CCSD, formerly hosted at the Complex Carbohydrate Research Center, Georgia, USA, collected primary structures of carbohydrates and associated literature references. Funding has been discontinued [128]. The content of the CCSD has been integrated into other databases, for example SWEET-DB, CFG, and KEGG Glycan. 


\section{5}

\section{D Structures of Glycopeptides and Glycoproteins and Implications for Biological Function}

In the following we summarize recent results on glycoprotein structure that illustrate the diversity of glycan function and that highlight how fruitful structural research on glycoproteins and glycopeptides has become. We have compiled two sections, one on $\mathrm{N}$-glycosylated and one on $\mathrm{O}$-glycosylated peptides and proteins. Instead of presenting every structural work of the last five years, we will concentrate on a few examples that an extensive set of experimental data has been collected on, and we have to apologize to all researchers whose work we decided not to present here.

\section{1}

\section{Effect of $N$-Glycosylation on 3D Structure}

\subsection{1}

\section{HIV Envelope Glycoprotein GP120}

One of the great success stories of crystallography of glycoproteins centers around structure and interaction of the HIV envelope glycoprotein GP120. GP120 mediates adhesion of the viral particle to the host cell and, together with the transmembrane glycoprotein GP41, triggers viral entry. GP120, with a molecular mass of $120 \mathrm{kDa}$ half of which originates from carbohydrates, associates with GP41 to form a heterodimer. Three of these heterodimers assemble to the so-called viral spike which protrudes from the viral envelope, a membrane that originally stems from the virus-producing host cell. GP120 is the only viral protein accessible to the immune system. Tragically, the virus has developed a whole variety of mechanisms to escape host defense. First, GP120 is heavily $N$-glycosylated. Glycans, synthesized by the glycosylation machinery of the host cell are attached at 27 sequence positions. These oligosaccharides shield a significant portion of the virus from recognition by immune cells and antibodies. Second, GP120 contains five hypervariable peptide loops which are immunogenic, however, mutations in these areas quickly make antibodies useless, obviously without impairing viral infectivity. Third, viral entry is essentially organized as a two-step process, starting with a primary interaction of GP120 with the immune globulin superfamily (IgSF) protein CD4 of the host cell, which leads to a conformational change of GP120 and results in presentation of the co-receptor binding site. The subsequent interaction with a co-receptor belonging to the family of chemokine receptors finally triggers a reorganization of the viral spike, insertion of a fusion peptide of GP41 into the host cell membrane and membrane fusion. This two-step entry mechanism protects vital areas of GP120 inside the protein until the primary interaction with CD4 has taken place. 
The high content in carbohydrates and the presence of several flexible peptide loops constituted a significant hindrance for obtaining crystals. A major breakthrough was achieved by the groups of Hendrickson and Sodroski in 1998, when they succeeded in crystallizing a GP120-core in complex with two domains of CD4 and the $F_{a b}$ fragment of an anti-GP120 antibody $[129,130]$. This GP120-core construct had all of its carbohydrates cleaved off beyond the innermost GlcNAc residue and contained short Gly-Ala-Gly substitutions at the sequence positions of the V1/V2 and V3 hypervariable loops. Despite these radical modifications, GP120-core retains its affinity for CD4 and, upon interaction with $\mathrm{CD} 4$, presents an epitope which is recognized by the antibody $17 \mathrm{~b}$, the epitope of which overlaps with the chemokine receptor binding site.

This crystallographic study has put our knowledge about antigenicity, receptor requirements and sequence variability- and glycosylation-induced immune escape on a structural basis. GP120 has an inner and outer domain both of which are linked by a region called the bridging sheet, providing a basis for receptor-induced conformational changes. Contacts with the CD4 receptor are mainly made by main chain groups explaining why many mutations do not affect CD4 binding. The proposed co-receptor binding site is composed of conserved residues, yet, it is only exposed close to the host cell membrane after contact with CD4. A highly immunogenic surface, called a non-neutralizing face, is only accessible when monomeric GP120 is shed into solution, and consequently does not elicit antibodies with the capacity to bind to the fully assembled viral spike. Another surface, called the silent face, is not recognized by antibodies because of complete masking by complex carbohydrates.

On the basis of the described structure Kwong et al. followed-up by modeling the arrangement of GP120 in the oligomeric state of the viral spike [131]. Following criteria like carbohydrate exposure, occlusion of conserved residues and steric considerations with regard to CD4 and antibody binding, a model was developed that allows binding of multiple CD4 entities, contacting the oligomer from the periphery whereas the co-receptor binding site is exposed in the vicinity to the host cell membrane close to the threefold symmetry axis of the viral spike (Fig. 17). It appears that co-receptor binding is much more dependent on the charge of the third variable (V3) domain than on its precise structure providing yet another explanation for immune escape.

Recently, Huang et al. succeeded in crystallizing the GP120-core including the V3-loop which constitutes an immunodominant epitope and is of central importance for co-receptor binding and co-receptor usage, i.e. for using either CXCR4 or CCR5 as a secondary receptor [132]. With this structure, the whole co-receptor binding site of GP120 could be defined. From this, a consistent model of co-receptor binding could be proposed characterized by interactions of the positively charged base region of V 3 with the 

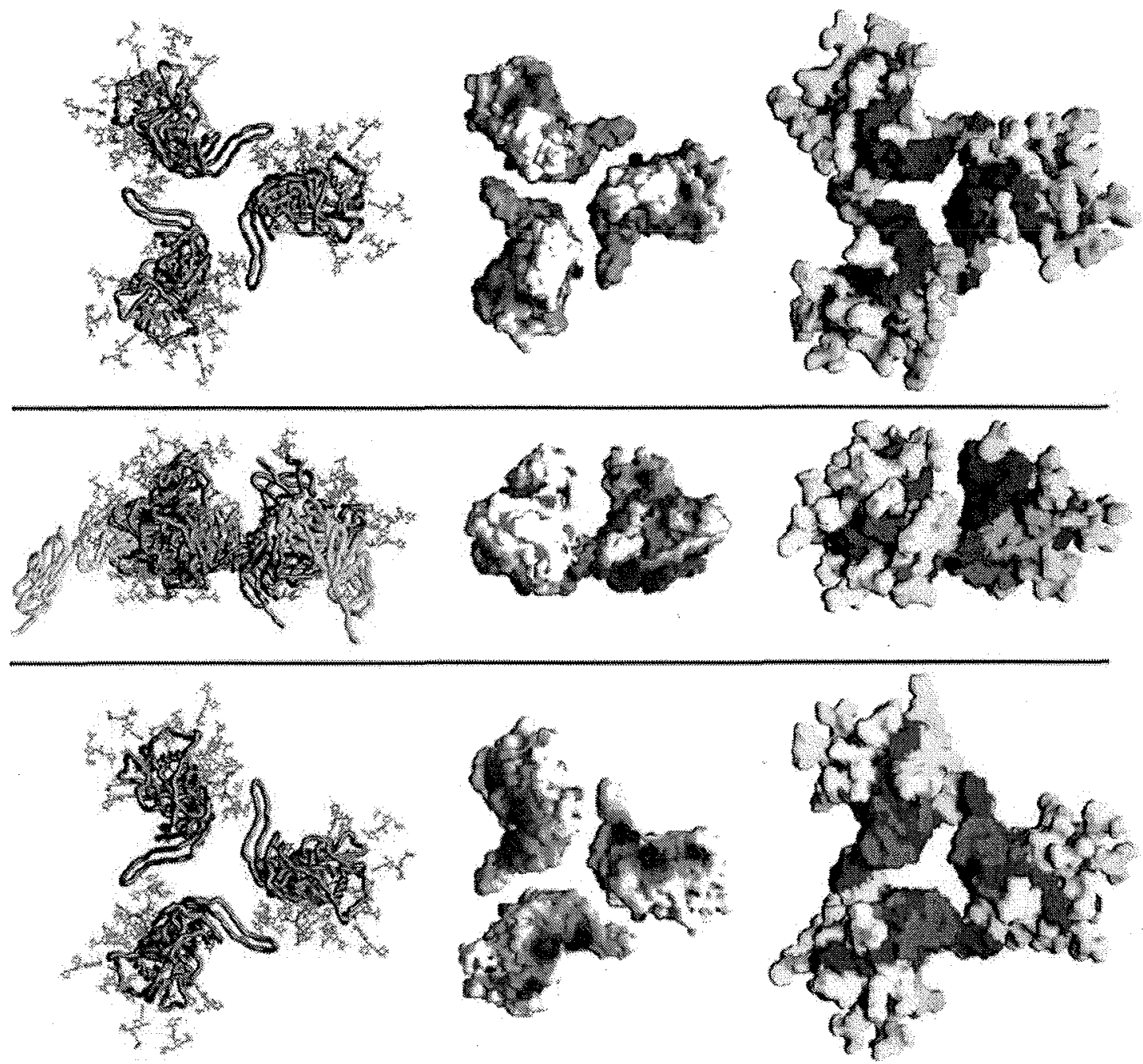

Fig. 17 Trimeric model of gp120. Three orientations of the model are shown. The images at the top depict the view from the orientation of the viral membrane. The middle images depict the view from the side, in between the viral and target cell membranes. The images at the bottom depict the view from the target cell membrane. The left-most three images are $\mathrm{C} \alpha$ worm representations of core gp120 (copper brown) and the two membrane-distal domains of CD4 (yellow). Also shown are the gp120 carbohydrate cores (blue), the (Man) $)_{3}$-(GlcNAc) 2 cores shared by both high-mannose and complex $N$-linked glycan moieties. The carbohydrate shown here represents approximately half the carbohydrate on gp120, with the rest extending further from the gp120 surface. The middle images show the electrostatic surface of gp120 for the core. The electrostatic potential is depicted at the solvent-accessible surface, which is colored according to the local electrostatic potential, ranging from dark blue (most positive) to red (negative). The right-most images show the gp120 core with carbohydrate, with the solvent-accessible surface colored cyan for carbohydrate, yellow for the surface of gp120 less than $3 \AA$ from CD4, green for the surface of gp120 less than $3 \AA$ from the $17 \mathrm{~b}$ antibody, and copper brown for the remaining surface of core gp120. The degree to which carbohydrate covers all of the solvent-accessible trimer surface is remarkable. Other than a small region at the viral proximal portion of the oligomer (where the missing $\mathrm{N}$ and $\mathrm{C}$ termini most likely reside), the only carbohydrate-free surfaces large enough to serve as an antibody epitope correspond to regions of receptor binding. (Reproduced with permission from [131]) 
sulfated $\mathrm{N}$-terminus of the co-receptor and by binding of the conserved tip of V3 to the second extracellular loop of the seven-helix transmembrane coreceptor. It remains to be seen whether this model of receptor interaction will be confirmed by a high-resolution structure of the whole assembly present just before viral entry.

Another "snapshot" of HIV entry has recently been contributed by Chen et al. who determined the crystal structure of an unliganded SIV GP120core, i.e. in the state prior to CD4 contact, something, that has been tried for more than 20 years $[93,94]$. Interestingly, in this case, the typical deglycosylation procedure prior to crystallization attempts prevented rather than facilitated crystal formation. Thus, the structure of the fully glycosylated GP120-core, expressed in insect cells, was determined. The oligosaccharide part shows an astonishing degree of order resulting in electron density to be found for all 13 oligosaccharides, identification of seven $\alpha 1,6$-linked fucose residues, and eight glycans with order at least out to the mannose branch (Fig. 18). These well-ordered sugars are most likely a consequence of sugarprotein contacts as well as tight hydrogen bonding within sugar clusters. The structure of the unliganded GP120-core illustrates once more how oligosaccharides shield the protein surface from recognition by the immune system. In addition, this pre-fusion state shows significantly different organization compared to the CD4-bound structure, providing detailed insight into conformational changes that accompany receptor binding. Structural elements necessary for co-receptor binding are spatially separated in the unliganded form and thus not detectable by the immune system. On the other hand, the dramatic structural changes upon CD4 contact require GP120 to have several cavities and pockets, and Chen et al. have identified one of those as the binding site for a known entry inhibitor (BMS-378806 [133]).

In conclusion, crystallographic research on HIV GP120 has provided invaluable insight into viral entry, immune escape and, not to the least, experimental aspects of crystallography of glycoproteins. We can hope that these results trigger the development of new vaccines and pharmaceuticals that will be urgently needed in the fight against HIV and AIDS.

\section{1 .2}

\section{Human T-Cell Specific Surface Glycoprotein CD2}

One of the relatively rare examples of glycoproteins that we have in-depth information on regarding structure, dynamics, interaction and biological function is the adhesion domain of the T-cell specific surface glycoprotein $\mathrm{CD} 2$ which is a key component of immune stimulation. It mediates adherence of T-cells to antigen-presenting cells by binding to the counter receptor protein CD58. Both proteins require $\mathrm{N}$-glycosylation for biological activity although it turns out that the mechanism of stabilization is completely different in each case. 


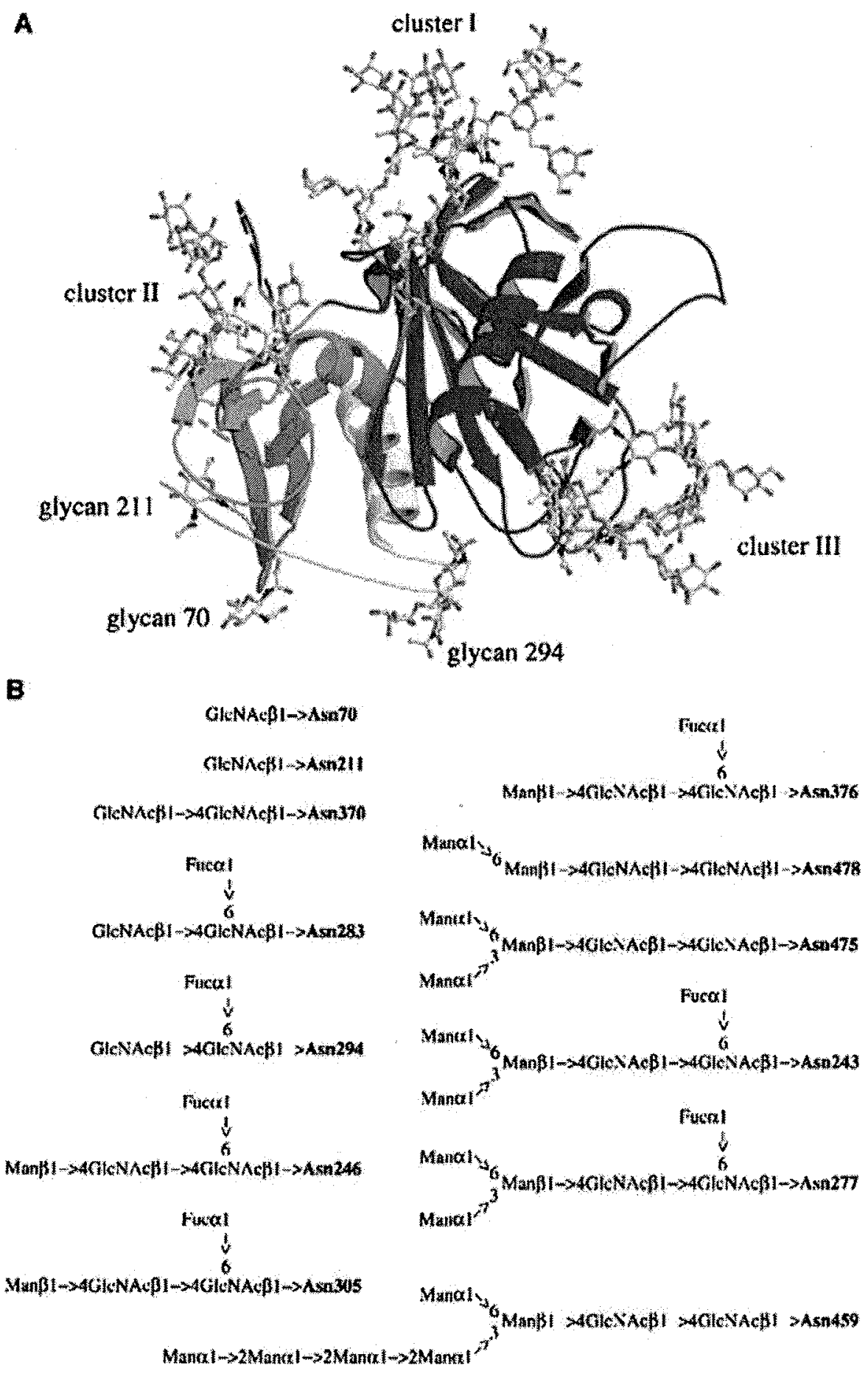

Fig. 18 Crystal structure of unliganded SIV GP120-core. The density for all $13 \mathrm{~N}$-linked oligosaccharides was found in the final electron density map. A A view of SIV gp120 core structure in a ribbon diagram showing that the long $N$-linked glycans (stick model) form apparent sugar clusters on the surface of the molecule. Cluster I includes glycan 277, 305, and 459; Cluster II, glycan 243 and 246; Cluster III, glycan 376, 475, and 478. B The structures are shown with ordered residues as well as linkages; Asn in bold shows the glycosylated asparagine. Glycan 459 was built as a high-mannose type, but the identity of the last three ordered residues of the longer branch, which make contacts with a symmetry-related molecule, is questionable at current resolution. (Reproduced with permission from [93]) 
Already in 1993, a solution structure of the glycosylated N-terminal domain of CD2, expressed in CHO cells was reported, based on NMR spectra acquired at natural isotopic abundance, and from a protein sample specifically labeled with ${ }^{15} \mathrm{~N}$-lysine. Because of severe overlap of the sugar resonances the precise conformation and orientation of the single (Man) $)_{5-8}(\mathrm{GlcNAC})_{2}$ glycan which is attached to Asn65 located at the tip of the DE loop could not be determined [134]. This was achieved two years later after successful expression of uniformly ${ }^{15} \mathrm{~N}$-labeled glycoprotein and with the aid of a highfield $(750 \mathrm{MHz})$ NMR spectrometer [28]. The N-terminal domain of CD2 adopts the characteristic overall fold of a V-set IgSF domain although lacking half of strand $\mathrm{A}$. The $\mathrm{N}$-glycan is oriented toward the $\beta$-sheet containing

A

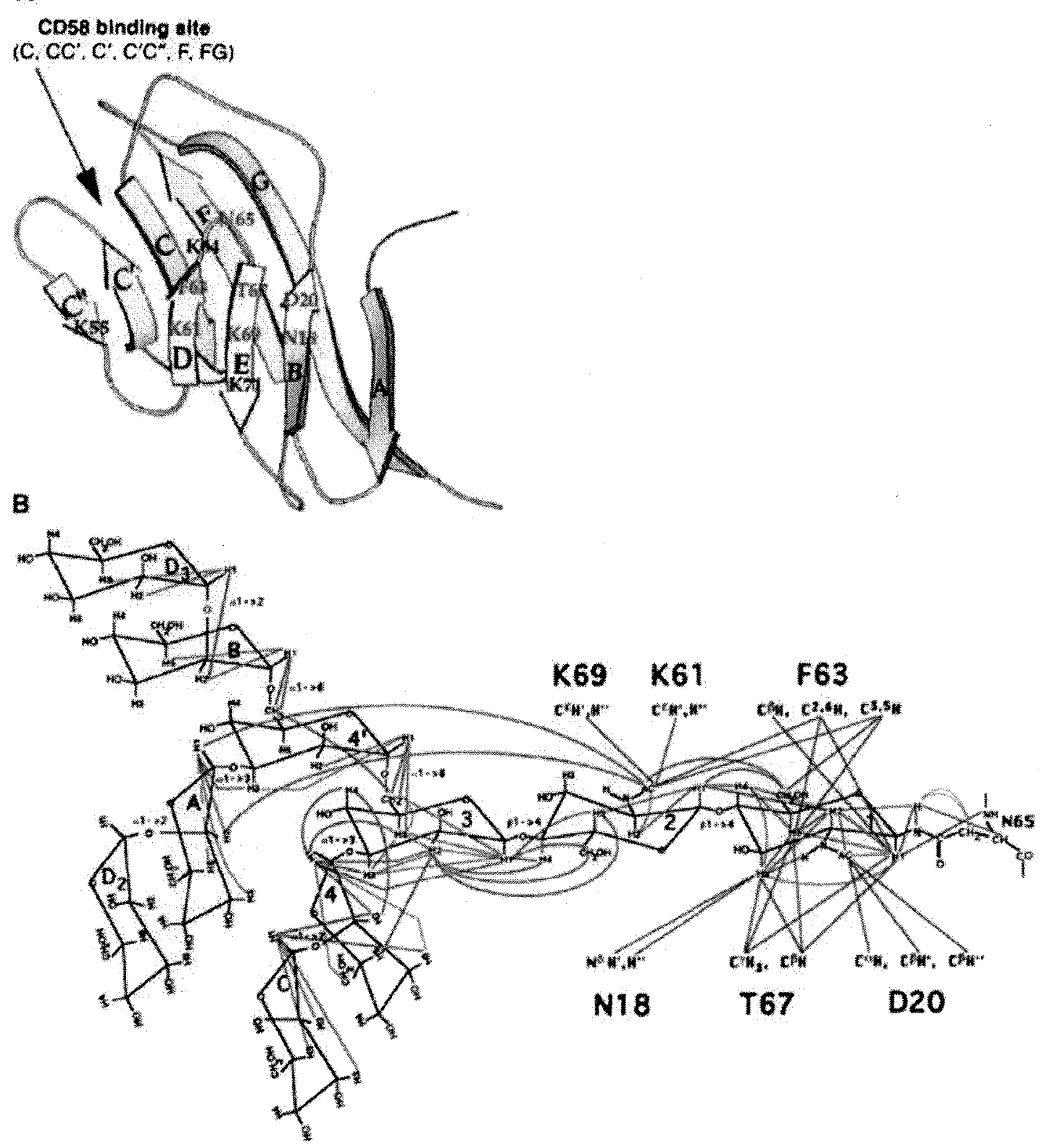


the strands $\mathrm{D}, \mathrm{E}$, and $\mathrm{B}$ and thus pointing away from the $\mathrm{CD} 58$ binding site (Figs. 19 and 20). There is no evidence for a direct interaction of CD2's glycan with CD58 or with residues of CD2 that have contact to the counter receptor. Rather, the carbohydrate stabilizes the conformation of the whole protein domain and prevents unfolding and aggregation. It is striking that already a single GlcNAc residue that remains attached to Asn65 after treatment with endoglycosidase $\mathrm{H}$ accounts for the major part of this effect [28].

The decisive difference between human $\mathrm{CD} 2$ and its homologs from other species that do not require glycosylation for activity is the presence of a lysine residue at position 61 whereas all other species have glutamic acid at this position. Lys61 leads to an unfavorable clustering of positive charges that obviously requires counterbalancing by hydrogen bonds, van der Waals interaction and entropic contribution of the $N$-glycan [28].

This and a follow-up study also provided a very detailed picture of the dynamics of $\mathrm{CD} 2$ and its high-mannose type oligosaccharide [135]. ${ }^{13} \mathrm{C}$ line width illustrate a significant reduction in the mobility of sugar residues close to the Asn65-GlcNAc linkage. In terms of flexibility GlcNAc-1 is as rigid as amino acid residues of the protein core. Sugar residues at the end of the $N$-glycan exhibit a mobility similar to that measured for amino acid side chain carbons and $\alpha$-carbons of terminal residues. The assessment of mobility is also reflected in the structural ensemble showing a well-ordered trisaccharide core (Man)-(GlcNAc) 2 contacting the DEB- $\beta$-sheet.

${ }^{15} \mathrm{~N}$-relaxation data confirm this picture showing the glycosylated face of $\mathrm{CD} 2$ to be as rigid as the protein core. The termini and several loops show, as expected, fast motions on the ps-ns time scale, but surprisingly, in

Fig. 19 A Ribbon diagram of a single representative solution structure of human CD2 (residues 1-105), which is composed of two $\beta$ sheets containing three (strands $\mathrm{D}, \mathrm{E}$, and B) and five (strands $C^{\prime \prime}, C^{\prime}, C, F$, and G) antiparallel $\beta$ strands. An additional $\beta$ strand, A, makes parallel NOE contacts to strand G. The overall fold is characteristic of a V-set lgSF domain, but lacks the first half of strand A. A single high-mannose $N$-glycan is attached to the protein at Asn65 at the tip of the DE loop and is oriented toward the $\beta$ sheet containing the strands $\mathrm{D}, \mathrm{E}$, and $\mathrm{B}$. Polypeptide residues that contact the $\mathrm{N}$-glycan are highlighted in red. The $\mathrm{CD} 58$ binding site, which includes residues in the $\mathrm{C}, \mathrm{C}^{\prime}$, and $\mathrm{F}$ strands as well as in the $\mathrm{CC}^{\prime \prime}, \mathrm{C}^{\prime} \mathrm{C}^{\prime \prime}$, and $\mathrm{FG}^{\prime}$ loops, is located on the opposite face of the glycoprotein. Lys55, Lys64, and Lys71, are highlighted in purple, and together with Lys69 form a clustering of positively charged residues around Lys61. The view is with the DEB face in front and the $\mathrm{C}^{\prime \prime} \mathrm{C}^{\prime} \mathrm{CFG}$ face in the back. B Summary of the NOE data obtained for the high-mannose $\mathrm{N}$-glycan of CD2, NOEs are indicated only if they were unambiguously assigned. More NOEs to carbohydrate protons are expected, but they were either not resolved in the NOESY spectra or could not be assigned because many of the $\mathrm{H}^{2}, \mathrm{H}^{3}, \mathrm{H}^{4}$, $\mathrm{H}^{5}$, and $\mathrm{H}^{6}$ sugar resonances exhibit similar chemical shifts. Carbohydrate intraresidue and inter-residue NOEs are shown by green and red lines, respectively, and carbohydrateprotein contacts are indicated by blue lines. Carbohydrate residues are labeled as in [139], and amino acid residues are abbreviated with the single-letter code and residue numbers. (Adapted and reproduced with permission from [28]) 

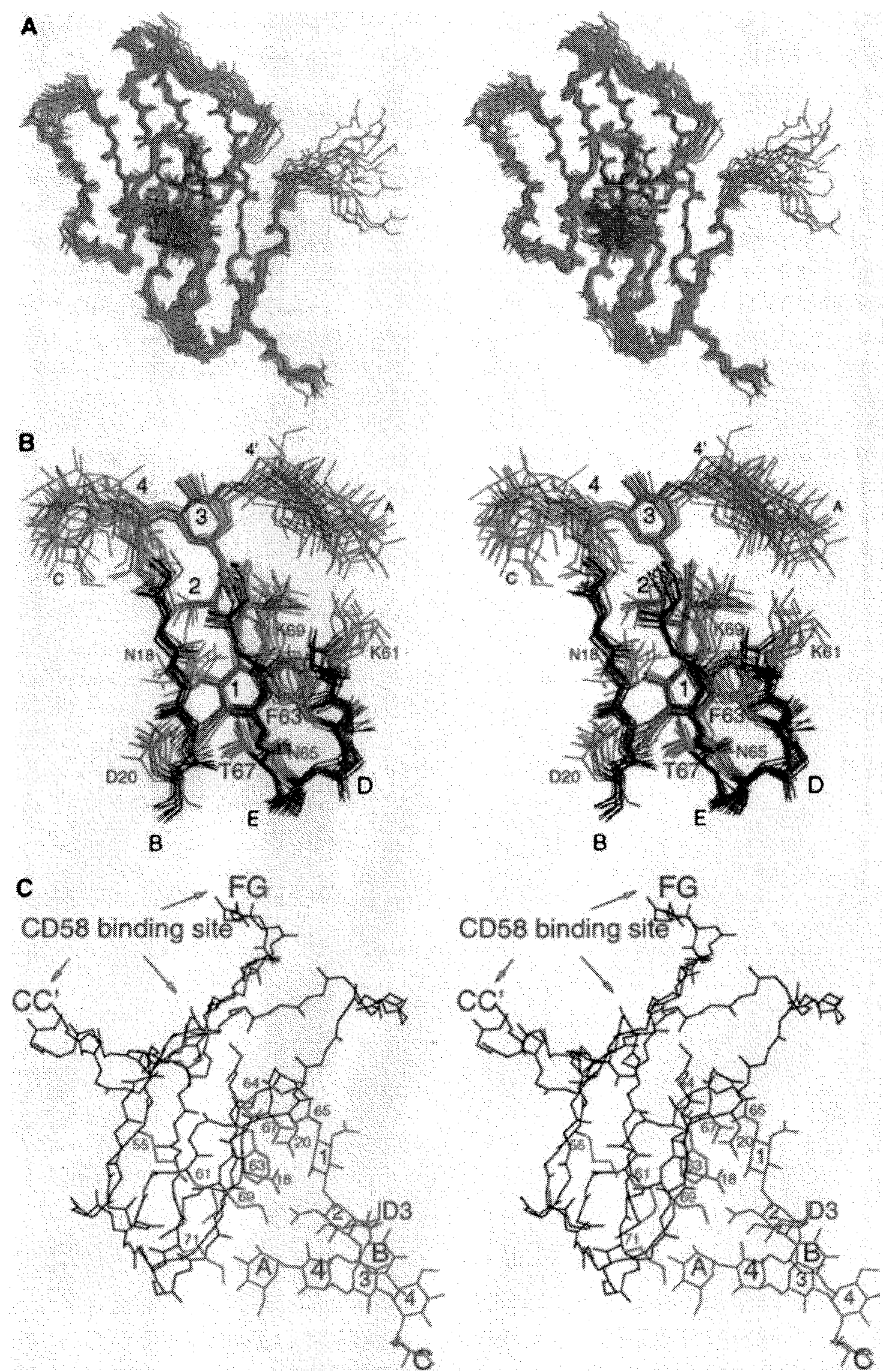
Fig. 20 A Stereo diagram of backbone atoms of the polypeptide (red) and heavy atoms of the trisaccharide core Man-3-( $\beta 1-4)$ GlcNAc-2-( $\beta 1-4)$ GlcNAc-1- $(\beta 1-N-A s n)$ (blue) for 16 NMR structures of human CD2 superimposed on the NMR mean coordinates. The orientation is the same as in Fig. 19A. B DEB sheet and part of the high-mannose $N$-glycan of 16 model structures based on the superposition of the backbone heavy atoms of all residues (16 to 20,60 to 71 ) in the DEB sheet and heavy atoms of the trisaccharide core Man-3-( $\beta 1-4)$ GlcNAc-2- $(\beta 1-4)$ GlcNAc-1- $(\beta 1-N-A s n)$. The backbone, the side chains for the contact residues, and the high-mannose $N$-glycan are shown in black, red, and blue, respectively. Glycoprotein structures were calculated for the (Man) $)_{7}$-(GlcNAc) 2 glycoform, but for clarity the more disordered arm Man-B-Man-D3 is not shown. The sugar residues are annotated as in Fig. 19B. C Representative glycosylated model structure of CD2 showing the polypeptide backbone in black, the side chains of the polypeptide residues that contact the glycan in red, the side chains of the polypeptide residues that together with Lys69 form a clustering of positively charged residues around Lys61 in purple, and the high-mannose $\mathrm{N}$-glycan (Man) $)_{7}(\mathrm{GlcNAc})_{2}$ in blue. This carbohydrate is located on the opposite site of the CD58 binding site, and a conformation in which its $\left[4^{\prime}-\mathrm{A}\right]$ arm is oriented toward the trisaccharide core Man-3- $(\beta 1-4)$ GlcNAc-2- $(\beta 1-4)$ GlcNAc-1- $(\beta 1-N-A s n)$ is significantly populated. (Reproduced with permission from [28])

the CD58 binding region these motions are largely absent and slow ms- $\mu \mathrm{s}$ fluctuations are found [135]. Later on, these relaxation data could be interpreted in terms of a model of concerted motion resembling conformational changes during counter receptor binding, albeit not taking slow motions into account [136].

As is the case for $\mathrm{CD} 2$, its receptor on antigen presenting cells, CD58, crucially requires glycosylation for bioactivity. Mature CD58 consists of $40-70 \%$ carbohydrate whereas the pure polypeptide part has a molecular weight of $11 \mathrm{KDa}$ only. For a long time structural studies were unsuccessful as no way of preparing CD58 suitable for crystallization or NMR could be found. In contrast to the situation with $\mathrm{CD} 2$, the glycans of $\mathrm{CD} 58$ seem to stabilize the protein structure not by interacting with charged surfaces but by shielding hydrophobic patches which, in the absence of carbohydrate, lead to aggregation and insolubility. A homology model of $\mathrm{CD} 58$, based on different 3D structures of $\mathrm{CD} 2$ allowed for identifying hydrophobic residues of CD58 that are not involved in CD2 binding but are located on different faces of the receptor, and are, in its native form, presumably shielded by carbohydrates. These surface-exposed residues were mutated into polar amino acids finally yielding a glycan free, yet fully functional adhesion domain suitable for NMR purposes [137]. These mutational and structural studies on each binding partner finally opened the route for engineering glycan-free protein domains that could be crystallized in complex with each other [138]. Overall, the shielding of clustered positive charges as found for the adhesion domain of $\mathrm{CD} 2$ seems to be a special case. Statistical analysis of available 3D structures indicates that carbohydrates predominantly cover hydrophobic regions [114]. 


\section{1 .3 \\ Human Chorionic Gonadotropin}

Human chorionic gonadotropin (hCG) is a glycoprotein hormone involved in the maintenance of the corpus luteum during early pregnancy. It consists of two subunits, $\alpha$ and $\beta$, with molecular weights of 17 and $22 \mathrm{kDa}$, respectively, carrying in total four $N$-glycans (Glycan structures are shown in Fig. 21). It is remarkable that hCG is still a subject of intense structural studies regarding that X-ray structures of the $\alpha \beta$-heterodimeric protein were solved more than 10 years ago $[140,141]$. This is mainly due to the observation that hCG preparations used for crystallization bind to the receptor but do not trigger signaling which is probably due to the presence of truncated $\mathrm{N}$-glycans, and possibly further alterations, as a result of treatment with HF.

While a solution structure of a functional heterodimer has not been reported, yet, a wealth of knowledge has been gained for the 92 residue $\alpha$-subunit in its native and various deglycosylated forms. $\alpha$ hCG carries $N$-glycans at two sites, Asn52 and Asn78, both of which are important for biological activity. The glycans at these sites display very different behavior in terms of flexibility and carbohydrate protein contacts, as became clear by work done in the groups of Vliegenthart, Kamerling and Homans.

Homans and coworkers pioneered NMR studies with ${ }^{13} \mathrm{C}$ - and ${ }^{15} \mathrm{~N}$-isotopically labeled $\alpha \mathrm{hCG}$ produced in CHO cells $[26,142,143]$. One key feature of this expression method is that hCG carrying complex oligosaccharides is obtained. In order to further approach the glycosylation state found in human hCG, sialyl moieties were enzymatically attached to the CHO-cell hCG. The study focused on conformational analysis of the oligosaccharides in the free $\alpha$ subunit and in complex with the $\beta$ hCG, and revealed that neither the glycan at Asn52 nor the one attached to Asn78 is in contact with the $\beta$ subunit of hCG. The authors report that both glycans when attached to the protein behave very similar to the glycans studied free in solution. For the oligosaccharide at Asn52, no NOE connectivities to the protein were detected. MD simulations further support that this oligosaccharide is highly flexible and not significantly constrained by the protein.

On the basis of chemical shift assignments achieved by deBeer et al. at natural abundance the solution structure of the isolated $\alpha$ subunit was recently determined by Erbel et al. [112, 144]. In this case hCG was purified from urine and its glycans were trimmed down to the GlcNAc residue directly attached to asparagine by treatment with endo- $\beta$ - $N$-acetylglucosaminidase-B. Free $\alpha \mathrm{hCG}$ is a glycoprotein with an unusual fold containing two twisted $\beta$-hairpins and a cysteine knot motif displaying structural disorder in a loop region from residue 33 to 57 and at the $N$ - and C-termini. Differences with respect to the crystal structure regarding the arrangement of the $\beta$-hairpins and the flexible loop region are caused by contacts with the $\beta$-subunit in the heterodimeric protein. 


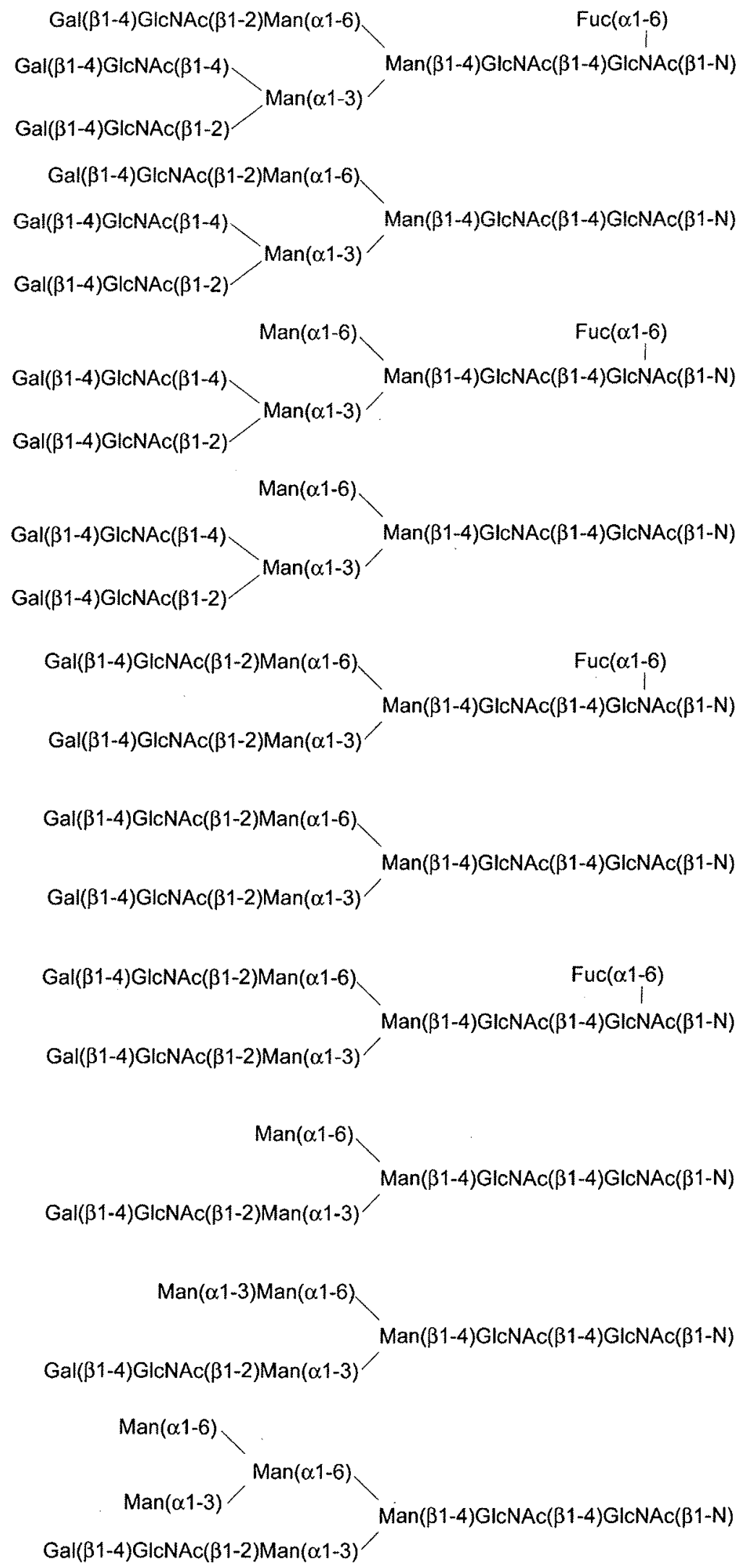

Fig. 21 Structures of desialylated $N$-linked sugar chains isolated from various hCG preparations (Adapted and reproduced with permission from [148]) 
Numerous NOE connectivities between GlcNAc-1 at Asn78 and hydrophobic amino acid side chains indicate that this residue is tightly packed onto the surface of the protein shielding this hydrophobic face from the solvent (Figs. 22 to 24). From that, the crucial role of this glycosylation site for protein stability becomes evident. In contrast, the glycan at Asn52 is located in a disordered region of free $\alpha \mathrm{hCG}$. These findings disprove the suggestion that, based on a single set of glycan signals measured by NMR at ${ }^{13} \mathrm{C}$ - and ${ }^{15} \mathrm{~N}$-labeled $\alpha$ hCG sample, both glycans should have a similar dynamic behavior, like a free glycan [143].

It has previously been reported that removal of carbohydrate residues other than GlcNAc-1 does not exert a major effect on the conformation of the protein part [144]. However, van Zuylen et al. demonstrated that glycosylation beyond GlcNAc-1 at Asn78 has a small but significant effect on the thermal stability of $\alpha \mathrm{hCG}$ [145]. A further investigation of $\alpha \mathrm{hCG} N$-glycosylated at Asn78, only, revealed additional NOE connectivities between GlcNAc-2 and the protein core. From the values of ${ }^{13} \mathrm{C}$-relaxation parameters $\mathrm{T}_{2}$ and $\mathrm{T}_{1 \rho}$ of the constituting monosaccharide residues, it was concluded that the inner three residues have a severely restricted mobility (Fig. 22). The Man-4 and Man- $4^{\prime}$ residues of the biantennary oligosaccharide exhibit a similar relaxation behavior, suggesting that the Man- $4^{\prime}$ branch occurs in a single conformation of the C5-C6 linkage of Man-3 instead of in rapidly interconverting conformations that are known to exist for this linkage for the free oligosaccharide [146].

A structure calculation of this $\alpha \mathrm{hCG}$ variant, carried out by Erbel et al., revealed restricted conformational freedom of the glycan at Asn78 as well as

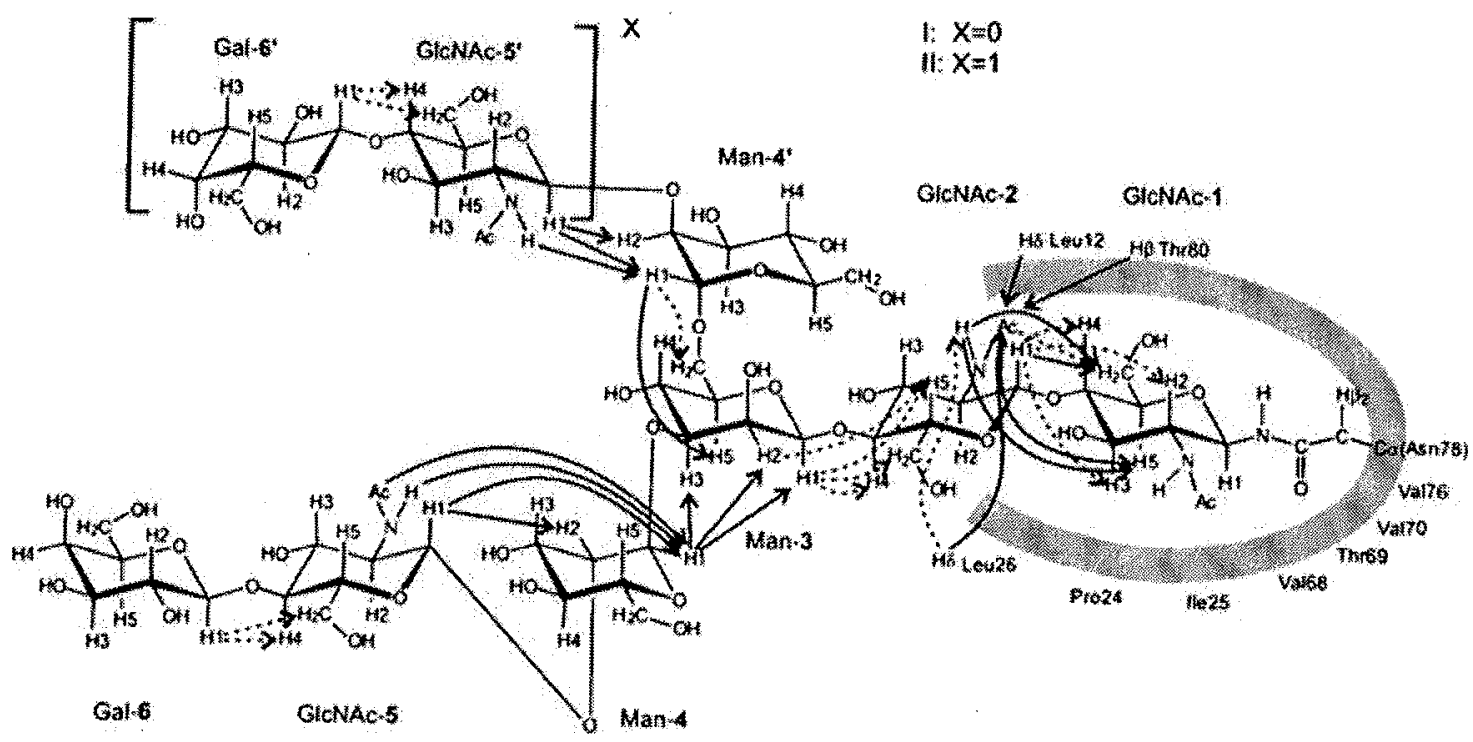

Fig. 22 NOE network of the glycan at Asn78 of $\alpha$ hCG. NOEs from GlcNAc-1 to the protein are identical with those published previously [144] and not indicated in this figure. Intraresidual NOEs and NOEs from GlcNAc- 2 to protein are indicated with arrows. In case of overlap, arrows are dashed. (Reproduced with permission from [146]) 


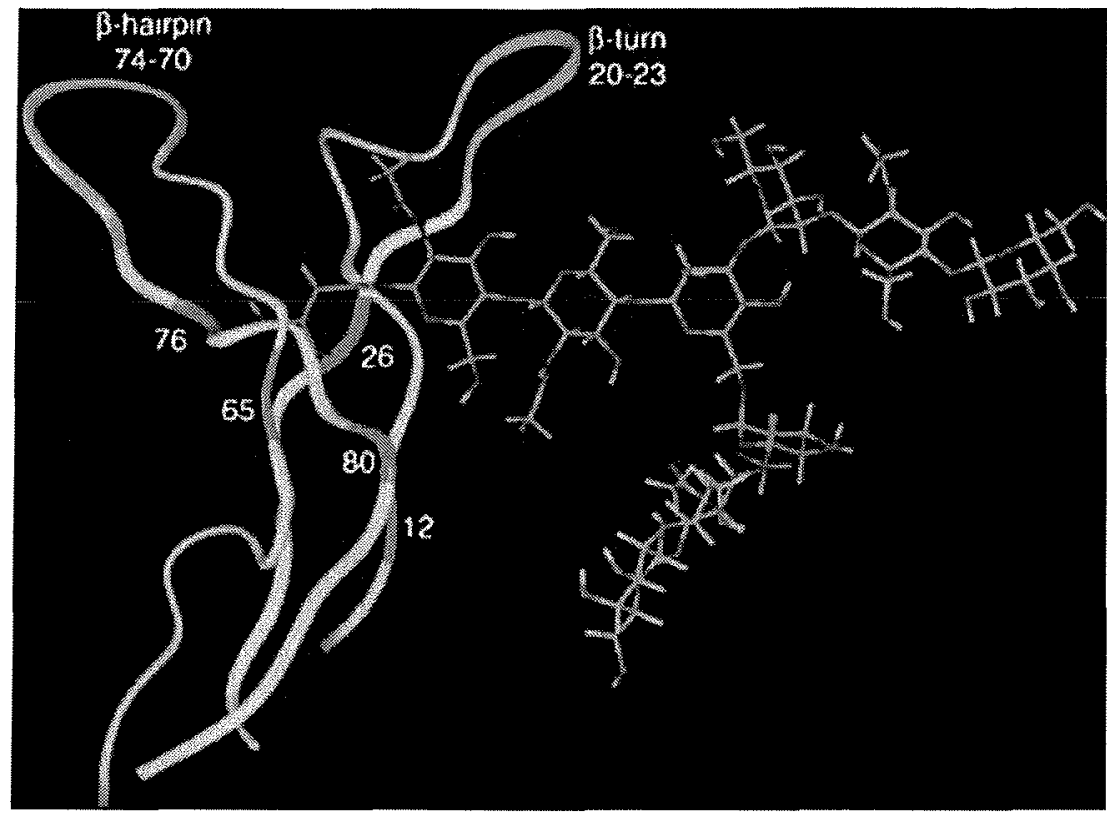

Fig. 23 Representation of the residues of $\alpha$ hCG influenced by the presence of the glycan at Asn78. The residues indicated in red show slightly different NOE intensities due to specific interactions with the glycan. The residues located in the heterogeneous $\beta$-turn and hairpin loop are drawn in orange. The residues that are unaffected by the presence of the glycan are represented in green. (Reproduced with permission from [112])

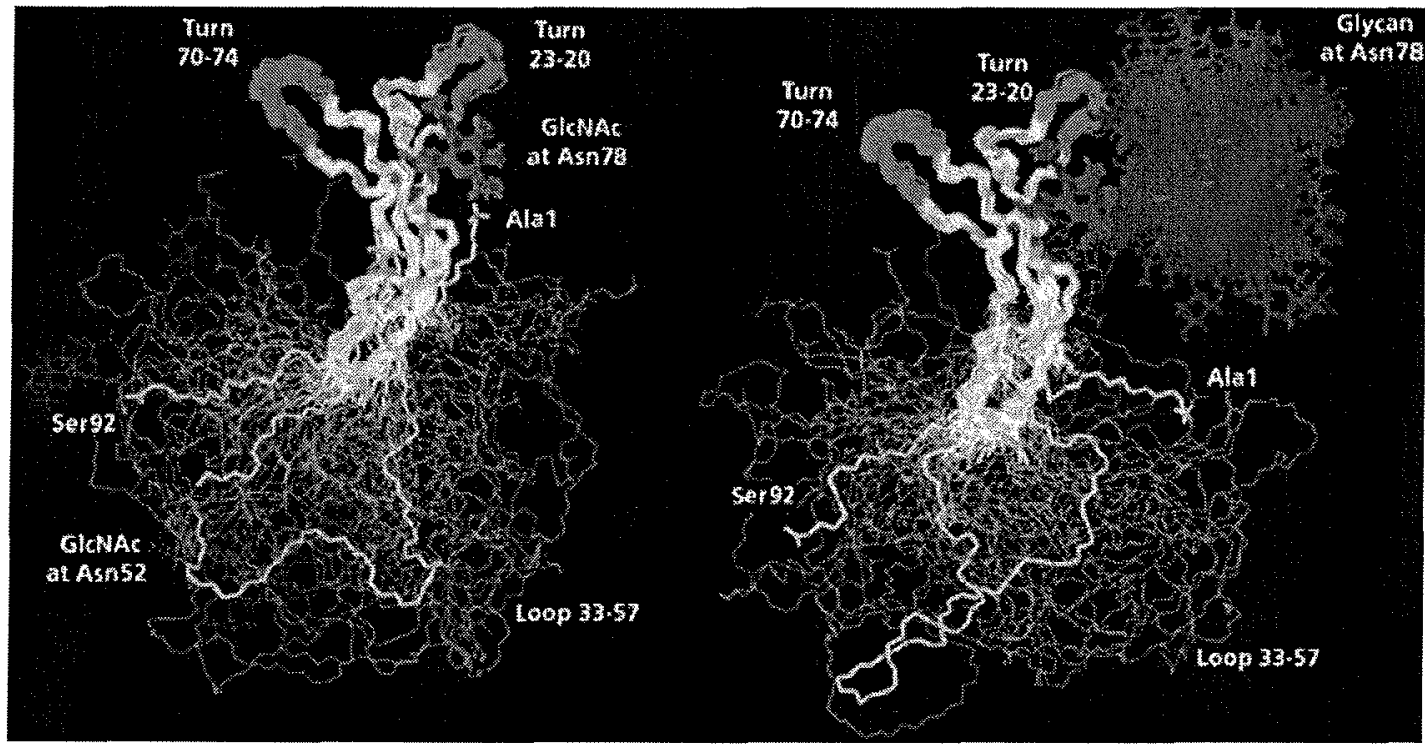

Fig. 24 Representation of the backbone conformation of the 26 conformers of $\alpha$ hCG[GlcNAc52,78] (left) and $\alpha$ hCG[glycan78] (right). The superposition was carried out including the backbone atoms of the residues 10-28, 59-70, and 75-84. The residues outside this region indicated in white represent the flexible and undefined part of the $\alpha$-subunit, except one conformer which is represented in a yellow ribbon. The $\beta$-sheet is drawn in yellow. The tight turn and the hairpin loop are colored in red. GlcNAc-1 is presented in purple and the residues beyond GlcNAc-1 in blue. (Reproduced with permission from [112]) 
increased order within the $\beta$-hairpin loops (Figs. 23 and 24) [112]. Interestingly, the glycan at Asn78 leads to a similar stabilization of protein structure as the one of the adhesion domain of human CD2 [28]. However, the underlying molecular mechanism by which this effect is achieved is completely different in both cases. In the case of $\alpha \mathrm{hCG}$ the glycan shields a hydrophobic surface of the protein from the solvent whereas in CD2 the glycan counterbalances five clustered positively charged lysines.

To further elucidate the role of the glycan at Asn52 of $\alpha \mathrm{hCG}$, Vliegenthart and coworkers compared native $\alpha \mathrm{hCG}$ with a variant that had its Asn52 glycan enzymatically removed without affecting the glycan at Asn78 or disturbing the protein folding. The $\beta$-subunit was recombined in solution with either the alpha-subunit or the alpha-subunit enzymatically deglycosylated at $\alpha$ Asn52. The effect of the glycan at Asn52 on refolding and recombination of the $\alpha / \beta$-hCG heterodimer was studied by SPR, CD and NMR spectroscopy and susceptibility toward proteolysis. The results give additional evidence that the glycan at Asn52 neither contributes significantly to the stability of the dimer nor is it responsible for large, overall, conformational differences with respect to the unglycosylated protein. However, minor changes regarding conformation and NOE pattern have been detected by CD and NMR spectroscopy, respectively. It is proposed that for bioactivity the bulky and extended glycan at $\alpha$ Asn- 52 is necessary for inducing and stabilizing a conformational change in hCG upon binding to the receptor, resulting in activation of the signal-transduction pathway [147]. Whereas the role of the glycan at Asn78 has become relatively clear, the mechanism by which glycosylation at Asn52 renders $\alpha$ hCG biologically active is still a matter of debate. There is evidence for a variety of models including interaction of the glycans with secondary receptors, prevention of downregulation of the hCG receptor or induction of subtle structural changes. To answer this question, a structure determination of a functional heterodimer including complex, sialylated oligosaccharides might be the key.

\subsection{4}

\section{Effect of $\mathbf{N}$-Glycosylation on the Structure of Peptides}

Imperiali and coworkers carried out extensive research on the influence of natural and non-natural glycosylation on the conformation of $\mathrm{N}$-linked glycopeptides. In the case of peptides derived from influenza virus hemagglutinin, $N$-glycosylation of the sequence Ac-Orn-Ile-Thr-Pro-Asn-Gly-Thr-TrpAla- $\mathrm{NH}_{2}$ with chitobiose (14) causes a conformational switching from an extended Asx-turn found in the peptide to a more closely packed type I $\beta$-turn of the glycopeptide. Astonishingly, this structural alteration is not accompanied by the formation of a strong NOE network between sugar and peptide but seems to be caused mainly by steric crowding or solvent-mediated effects [149]. The work on hemagglutinin glycopeptides was extended to the 
investigation of non-natural structures containing saccharide moieties other than chitobiose or a single GlcNAc residue. Peptides $\beta$ - $N$-glycosylated with cellobiose (Glc( $\beta 1-4)$ Glc (15)), Glc( $\beta 1-4)$ GlcNAc (16), and GlcNAc $(\beta 1-4)$ Glc (18) were synthesized and characterized by NMR (Figs. 25 and 26) [150]. A dramatic effect on conformation was only found when GlcNAc was directly attached to asparagine leading to a preference for a $\beta$-turn conformation. A weak effect was observed when the $N$-acetyl group was present on the sugar residue distal from asparagine. The cellobiose carrying glycopeptide 15 that lacks $\mathrm{N}$-acetyl groups was most flexible among the compounds studied and remains in an extended structure similar to the one found for the unglycosylated peptide. These findings were further strengthened by molecular

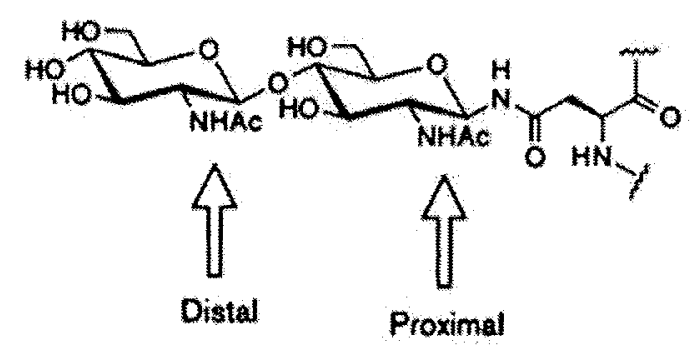

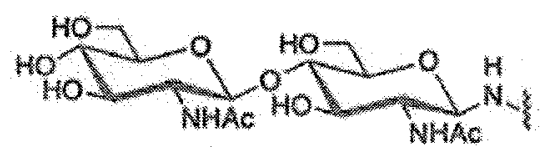

$0 \cdot$ GICNAC. $[B(1 \cdot 4)] \cdot B \cdot D \cdot G k N A C$ (Chitobiose) Glycopeptide 14

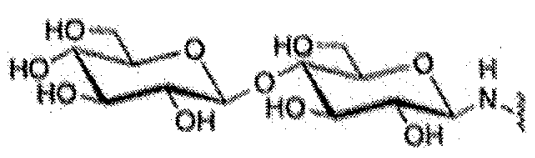

D-Gic-[ $[\beta(1-4)] \cdot \beta \cdot D-G i c$ (Cellobiose) Glycopeptide 15

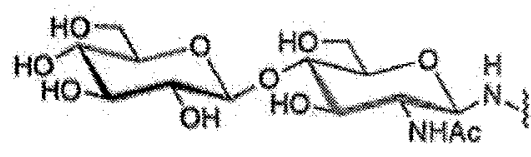

D. Gkot $[\beta(1-4)] \cdot \beta \cdot D \cdot G k N A C$ Glycopeptide 16

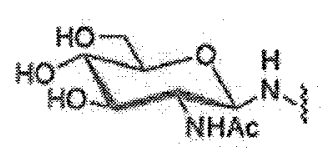

D. GICNAC Glycopeptide 17

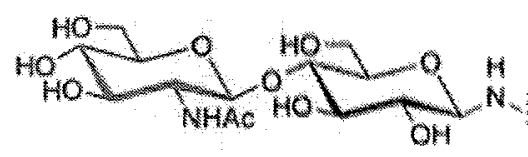

D. GlcNAc $[B(1-4)] \cdot B \cdot 0 \cdot$ Glc Glycopeptide 18<smiles>CC[C@H](C)C(NC(=O)[C@H](CCCN)NC(C)=O)C(=O)N[C@H](C(=O)N1CCC[C@H]1C(=O)N[C@@H](CC(=O)C(C)C)C(=O)NCC(=O)N[C@H](C(=O)N[C@H](Cc1c[nH]c2ccccc12)C(=O)N[C@@H](C)C(N)=O)[C@@H](C)O)C(C)O</smiles>

Fig. 25 Chemical structures of all glycopeptides examined by O'Conner et al. In each figure, $N$-acetylglucosamine is red, and glucose is blue. (Reproduced with permission from [150]) 


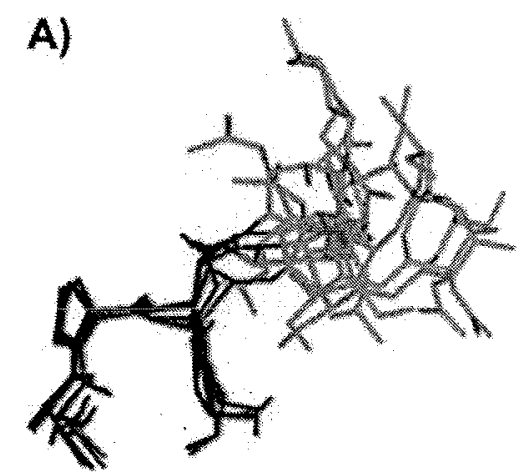

- GlONAC- $[\beta(1-4)]$ - O-GIONAC (Chitobiose) Glycopeptide 14
B)

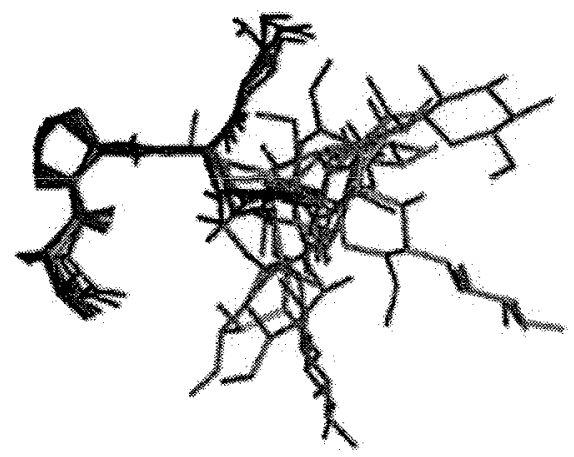

$D+G l c[p(1+4)]+\beta+0$ Glc

(Cellobiose)

Glycopeptide 15
C)

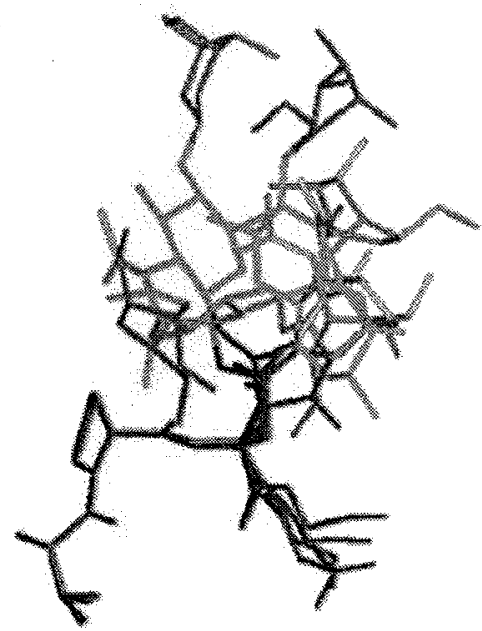

D.Glc- $[B(1-4)]$ B.O-GICNAC Glycopeptide 16
D)

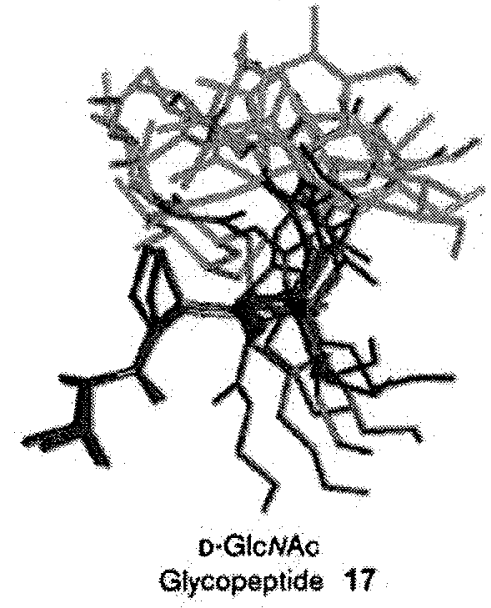

E)

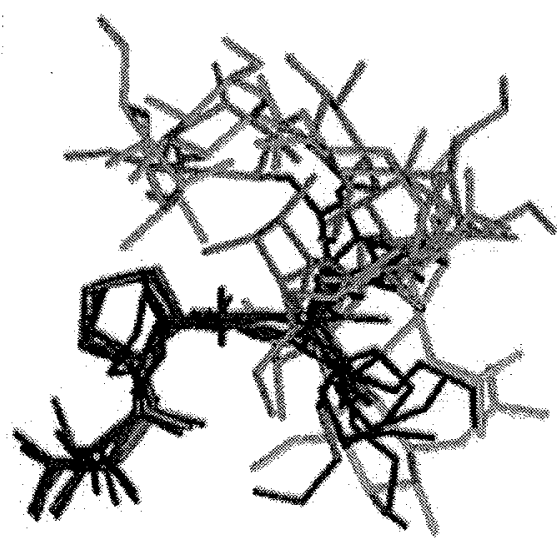

$0 \cdot G \mid c N A C \cdot[0(1-4)] \cdot \beta \cdot 0-G l c$

Glycopeptide 18 
Fig. 26 Minimized structures of the glycopeptides 14-18 shown in Fig. 25 resulting from a simulated annealing protocol that incorporated NOE-derived distance and ${ }^{3} \mathrm{~J}_{\mathrm{HNH} \alpha}-$ derived dihedral restraints. Root mean square deviation (rmsd) values were calculated from all atoms. In all cases, the large rmsd value for asparagine reflects the highly disordered carbohydrate that is covalently linked to this residue. Residues Thr3-Gly6 are shown. A Five of ten NMR-derived structures of glycopeptide 14 that converge to a type I $\beta$-turn. Thr3, 0.76 $\pm 0.07 \AA$; Pro4, $1 \pm 0.09 \AA$; Asn5, $6.5 \pm 2.6 \AA ;$ Gly6, $2.3 \pm 0.7 \AA$. B Seven of ten NMR-derived structures of glycopeptide 15, illustrating the more extended backbone. Thr3, 1.2 $\pm 0.4 \AA$; Pro4, 0.9 $\pm 0.2 \AA ;$ Asn5, $7 \pm 1.6 \AA ;$ Gly6, $1.8 \pm 0.5 \AA$. C Five of ten NMR-derived structures of glycopeptide 16 that converge to a type I $\beta$-turn. Thr3, $0.82 \pm 0.06 \AA ;$ Pro4, $0.88 \pm 0.3 \AA ;$ Asn5, 7.9 $\pm 3.1 \AA$; Gly6, $1.2 \pm 0.3 \AA$. D Seven of ten NMRderived structures of glycopeptide 17 that converge to a disordered $\beta$-turn. Thr3, $0.86 \pm$ $0.05 \AA ;$ Pro4, $0.76 \pm 0.3 \AA ;$ Asn5, $4.1 \pm 1.5 \AA ;$ Gly6, $2.4 \pm 0.2 \AA$. E Six of ten NMR-derived structures of glycopeptide 18 that converge to a disordered $\beta$-turn. Thr3, 2.9 $\pm 1.6 \AA$; Pro4, 1.2 $\pm 0.1 \AA$; Asn5, $12.5 \pm 3.7 \AA$; Gly6, 4.2 $\pm 0.7 \AA$. (Adapted and reproduced with permission from [150])

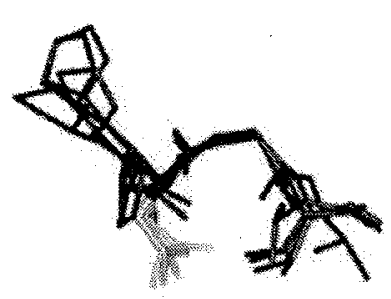

Asx-turn
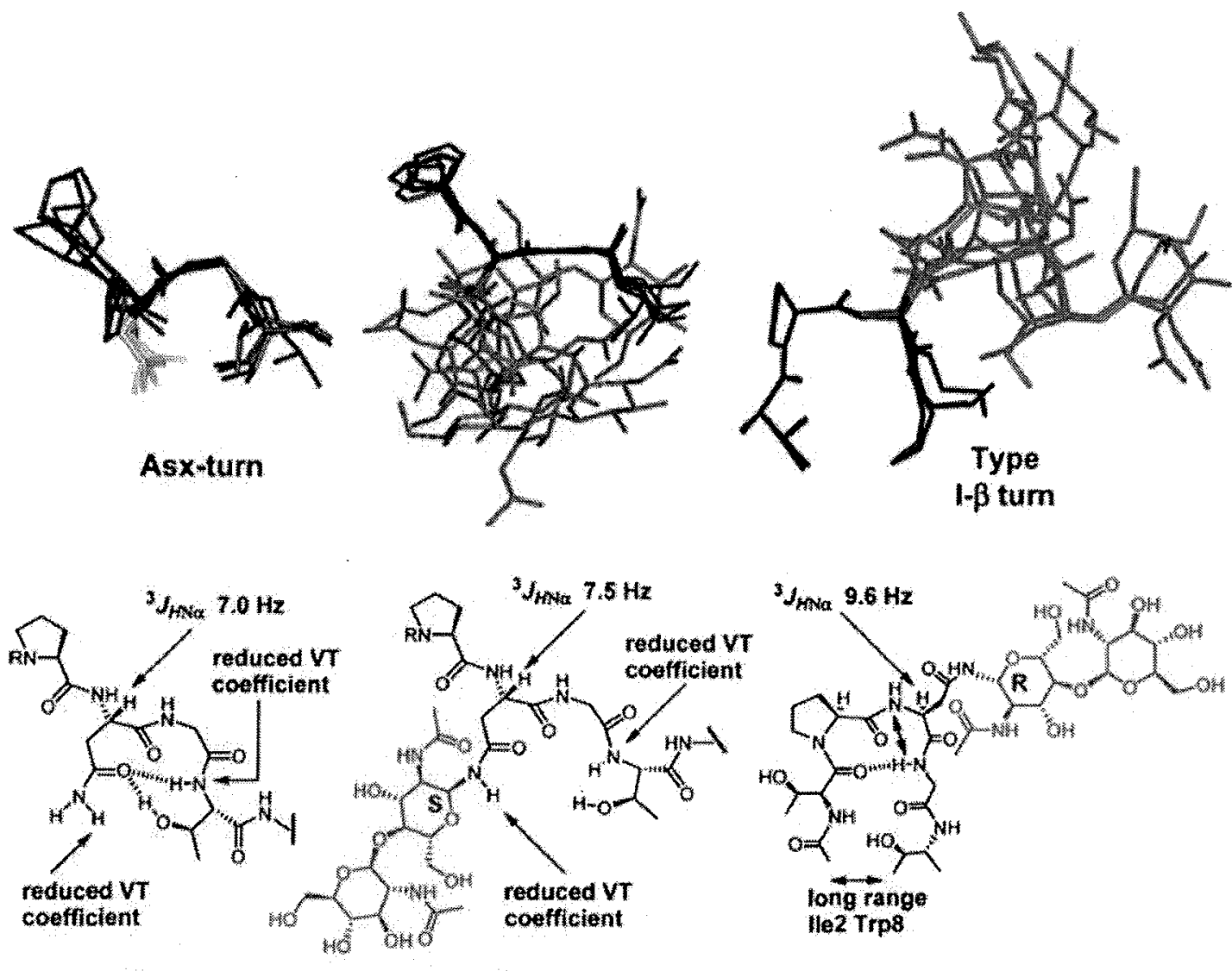

19

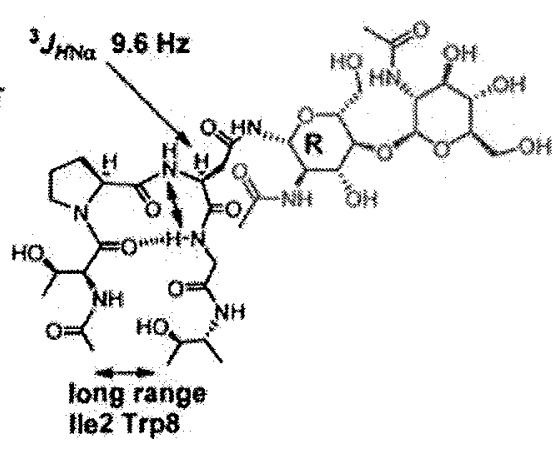

$19-\beta$

Fig. 27 Comparison of the solution-state structure between unglycosylated (19), $\alpha$ chitobiosylated (19- $\alpha$ ), and $\beta$-chitobiosylated (19- $\beta$ ) peptide Ac-Orn-Ile-Thr-Pro-AsnGly-Thr-Trp-Ala- $\mathrm{NH}_{2}$ derived from hemagglutinin. 19 and $19-\alpha$ are shown from Pro4 to Thr7. 19- $\beta$ is shown from Thr3 to Thr7. (Reproduced with permission from [151]) 
modeling studies indicating a rigidifying effect of $\mathrm{N}$-acetyl groups on the glycosidic linkage. The authors conclude that it is likely that the $\mathrm{N}$-acetyl groups of the carbohydrates have a critical role in promoting the more compact $\beta$-turn conformation through steric interactions with the peptide.

Recently, a conformational analysis of a glycopeptide with $\alpha-N$-linked chitobiose (19- $\alpha$ ) was reported. Thereby, the impact of this non-natural glycosidic linkage could be compared to that of the commonly present $\beta$-linkage. It was shown that only the $\beta$-linkage is capable of inducing a type I $\beta$-turn whereas the $\alpha$-glycosylated peptide adopted a conformation similar to the unmodified reference peptide displaying a more open Asx-turn-like structure in the vicinity of the glycosylation site (Fig. 27) [151]. In this regard it is noteworthy that statistical analysis of the stereochemistry of $\mathrm{N}$-glycosylation sites carried out by Imberty and Pérez and by Petrescu et al. revealed that only about a quarter of glycosylated asparagines are located at a $\beta$-turn $[20,114]$. This could mean, that the induction of $\beta$-turn structure by $N$-glycosylation is of transient character and of major importance only during the folding process.

\section{2 \\ Effect of O-Glycosylation on 3D Structure}

\subsection{1}

\section{Mucin-Type Glycoproteins}

Danishefsky and coworkers carried out extensive research on the influence of $O$-glycosylation on mucin-type peptides. Glycopeptides derived from the CD43 glycoprotein were prepared by total synthesis with a range of glycans attached to adjacent serine and/or threonine residues. Not only a $\alpha$-GalNAc monosaccharide ( $\alpha$-Tn-Antigen) but also di-( $\alpha$-TF and $\beta$-TF), tri- $(\alpha-\mathrm{STF})$ and hexasaccharides $\left(\alpha-\mathrm{Le}^{y}\right)$ were attached to peptide scaffolds (Fig. 28). The 3D structure of the triglycosylated peptide Ac-Ser(-O- $\alpha$-STF)Thr(-O- $\alpha$-STF)-Thr(-O- $\alpha$-STF)-Ala-Val (24) was investigated in detail by NMR (Fig. 29) [152,153]. The peptide part turns out to be very similar to that of a hexaglycosylated peptide fragment of glycophorin A investigated by Schuster et al. [154]. There, the clustered glycosylation of adjacent amino acid residues in the glycopeptide His-Thr(O- $\alpha$-D-GalNAc)-Ser(O$\alpha$-D-GalNAc)-Thr(O- $\alpha$-D-GalNAc)-Ser(O- $\alpha$-D-GalNAc)-Ser(O- $\alpha$-D-GalNAc)Ser(O- $\alpha$-D-GalNAC)-Val-Thr-Lys (26) leads to an extended, "wave-type" structure with the saccharides projecting away from the peptide into alternating directions (Fig. 30). In terms of position and conformation of the glycan residues, there are obvious differences between the glycopeptide derived from glycophorin $\mathrm{A}$ and the one related to the mucin CD43, illustrated, for example, by deviating $\chi 1$-angles. In the case of the glycophorin A-derived glycopeptide 26, strong NOEs between the GalNAc-NH and the 


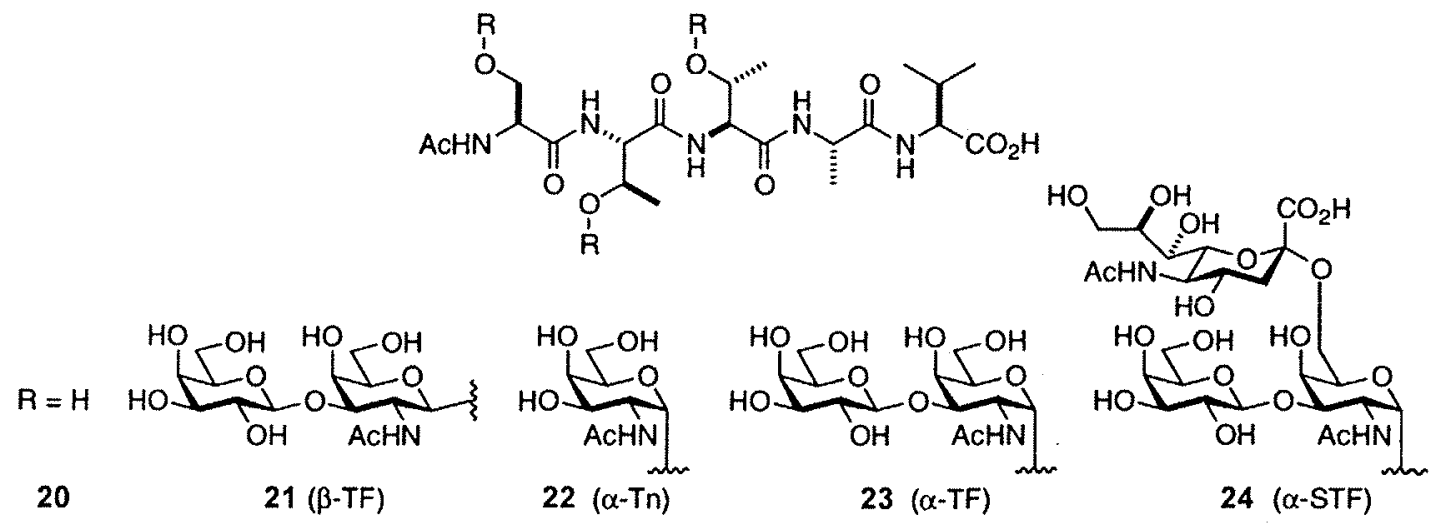

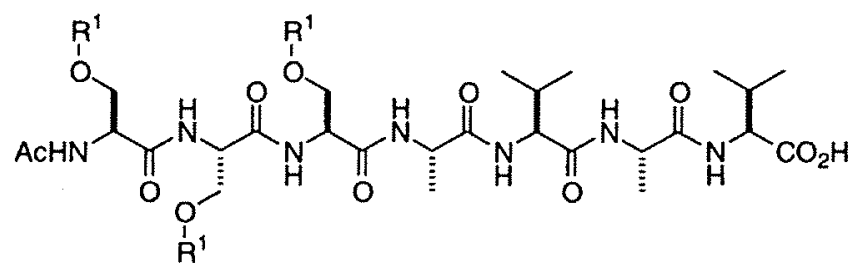

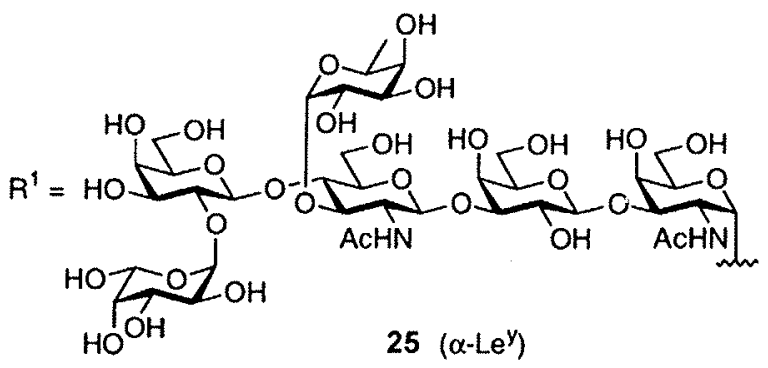

Fig. 28 Synthetic Muc-1 peptides with different O-Glycans attached to Ser and Thr residues. (Reproduced with permission from [152])

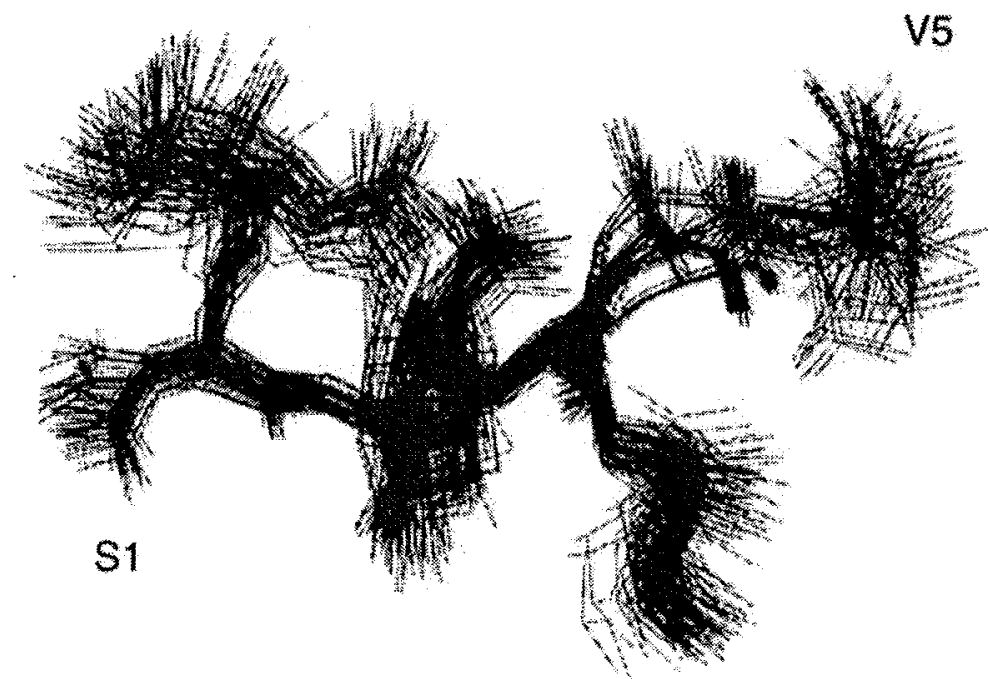

24

Fig. 29 Superposition of the peptide backbone and first sugar residue of the 59 best calculated structures of 24 from the restrained dynamics calculations (The chemical structure is shown in Fig. 28). (Reproduced with permission from [152]) 

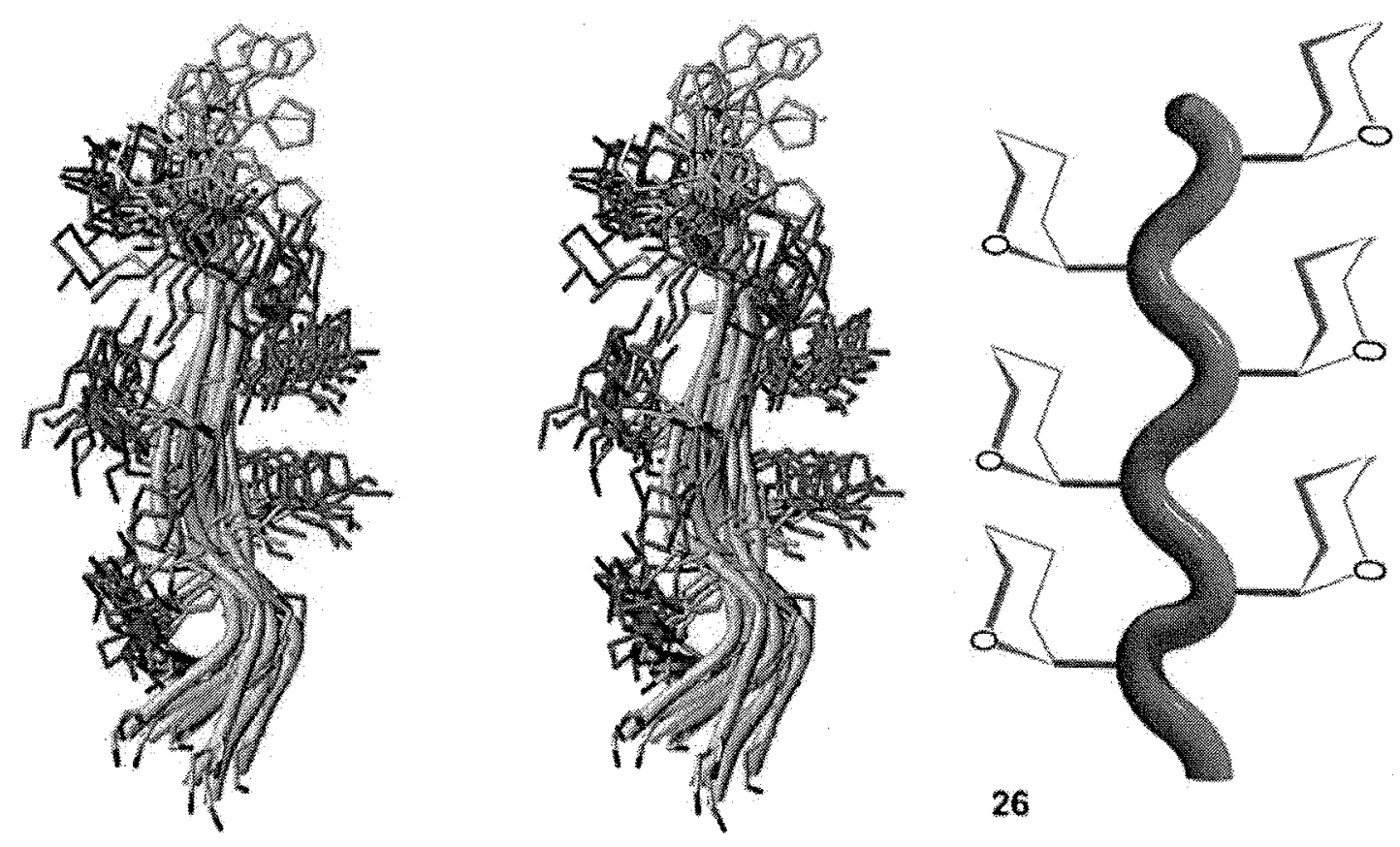

Fig. 30 Stereo plot of a superposition of 10 structures, obtained from a $1000 \mathrm{ps}$ constrained MD simulation of the glycopeptide His-Thr(O- $\alpha$-D-GalNAC)-Ser $(\mathrm{O}-\alpha-$ D-GalNAC)-Thr(O- $\alpha$-D-GalNAC)-Ser(O- $\alpha$-D-GalNAC)-Ser(O- $\alpha$-D-GalNAc)-Ser(O- $\alpha$-D-Gal NAc)-Val-Thr-Lys (26) derived from glycophorin A. Each structure is a snapshot every 100 ps. The sugar residues are colored red, the peptide cyan. The peptide backbone conformation is highlighted by a yellow tube. On the right a schematic drawing of the "wave-type" structure with the sugars projecting toward the N-terminus is shown. (Adapted and reproduced with permission from [154])

peptide $\mathrm{NH}$ of the same amino acid were observed, in combination with other constraints supporting an orientation of the sugar towards the $\mathrm{N}$ terminus. In contrast, in the $\mathrm{CD} 43$ glycopeptide 24, experimental data are indicative for hydrogen bonding of the sugar NH to both the glycosidic oxygen and to the carbonyl oxygen of its own amino acid. In addition, this conformation allows for hydrophobic interactions between $\mathrm{N}$-acetyl methyl groups and side chain methyl groups C-terminal from the site of glycosylation to stabilize the arrangement of the peptide backbone and of the sugars (Fig. 31). Structural rigidity is also supported by NMR-relaxation parameters.

The recent study on $\mathrm{CD} 43$ glycopeptides provides insight into the influence of inner and outer glycan residues and allows a comparison between native $\alpha$ - and the abnormal $\beta$-linkage. It was found that the innermost GalNAc residue, when attached $\alpha$-anomerically, is key to the structural organization of these glycopeptides. A distinct NOE fingerprint was found for all glycopeptides with the native $O-\alpha$-linkage, surprisingly independent from further glycosylation extending from the first GalNAc moiety. Strong induction of regular structure was observed for $O-\alpha$-linked glycosylation only. In contrast, 


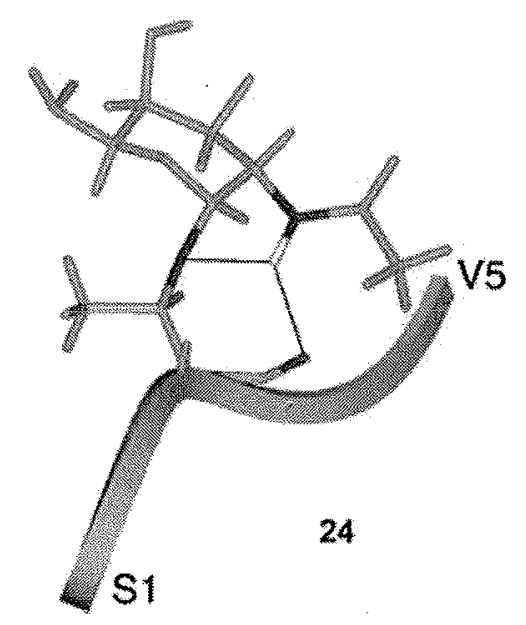

Fig. 31 Illustration of the hydrogen-bonding-type interactions of $\mathrm{N}$-acetyl amide proton of the T3 GalNAc, shown by black lines. These are typical for all the glycosylated residues of 24 (cf. also Figs. 28 and 29). The relevant oxygens are highlighted in red and the nitrogen in blue. The backbone trace of the rest of the peptide portion is shown as a ribbon. (Reproduced with permission from [152])

the non-native $O-\beta$-linkage (compound 21) did not seem to affect peptide conformation considerably leading to structures resembling the parent, unglycosylated peptides with a high degree of flexibility. This contrasts findings of Wong and coworkers who report significant conformational changes of a mucin peptide derived from MAdCAM-1 induced by glycosylation with $\beta$-O-SLe ${ }^{x}$ indicating a turn-like conformation in the vicinity of the glycosylated threonine $[155,156]$.

Levine and coworkers investigated the effect of $O$-glycosylation on the structure of human salivary mucin (MUC-7) glycopeptides. GalNAcmonosaccharide and Gal( $\beta 1-3)$ GalNAc-disaccharides were attached to adjacent serine or threonine residues of the two peptide sequences PAPPSSSAPPE and APPETTAAPPT derived from the tandem repeat region of MUC-7 [157]. The combined information from CD spectra, NMR chemical shifts, NOEs, and temperature dependence of amide proton chemical shifts, is indicative for an extended poly-L-proline type II or random conformation of the peptide backbone. Strong interaction with the peptide backbone is only reported for glycans attached to threonine. There, similar to the results of Coltart et al. [152], the NOE pattern supports the formation of an H-bond between the $\mathrm{N}$-acetyl NH and the C-terminal carbonyl group of the threonine residue that carries the glycan. In the case of glycosylated serine, a reduced number of sugar-peptide NOEs is observed and there is less influence on chemical shifts of $\alpha$-CH-protons of neighboring amino acids. Glycans attached to serine residues are thus likely to possess more rotational freedom and to have less influence on peptide conformation.

Kirnarsky et al. report on the conformation of the MUC-1 15-mer peptide PPAHGVTSAPDTRPA and the influence of glycosylation at Thr7 [158]. 
At lowered temperature $\left(5-10^{\circ} \mathrm{C}\right)$ and slightly acidic $\mathrm{pH}$ of 4.5 , a weak but distinct effect on conformational propensities could be detected by cluster analysis of backbone conformation. Under all conditions studied, a strong NOE between the GalNAc-NH and the NH of the glycosylated Thr could be detected. In addition, weak dipolar interaction was present between the GalNAc methyl group and the methyl group of Ala9 indicative for a similar conformation as reported for the $\mathrm{CD} 43$-related glycopeptide [152].

Very recently, Kunz and coworkers presented a conformational analysis of a MUC-1 glycopeptide (27) encompassing the whole tandem repeat of 20 amino acids with $(\alpha 2,6)$-sialyl-T-glycosylation at the same threonine residue as in the study of Kirnarsky et al. (Fig. 32) [158, 159]. In this case it was possible to carry out NMR experiments very close to physiological conditions at $\mathrm{pH} 6.5$ and ambient temperature. Cluster analysis of the conformational ensemble yielded a rod-like structure with the GalNAc methyl group oriented towards the C-terminus, similar to results by Coltart et al. (Fig. 33) [152]. Grinstead et al. report on the influence of glycosylation on a MUC-1 21-mer peptide single and double Tn-glycosylated at Thr3 and Ser4, respectively [160]. Both glycosylation sites display specific NOE connectivities with the $N$-acetyl group of GalNAc at Thr3 oriented towards the N-terminus and the one at Ser4 contacting C-terminal residues.

Kirnarsky et al. investigated the effect of MUC-1 glycosylation at different sites of the tandem repeat, namely at Thr5, Thr10, and Thr17 of the sequence AHGVTSAPDTRPAPGSTAPPA [161]. The NMR-based structure determinations indicate that glycosylation at different sites leads to distinct alterations of the backbone conformation around the glycosylation site. In the case of glycosylation at Thr5 of the VTSA motif, only minor changes of the peptide backbone were observed. In contrast, attaching $O-\alpha$-D-GalNAc to Thr 17 of the STAP motif promotes a significant change of the peptide backbone around Thr17. The authors propose that these conformational requirements could be the cause for the finding that GalNAc-transferases show distinct preferences for each glycosylation site [161]. A higher conformational flexi-

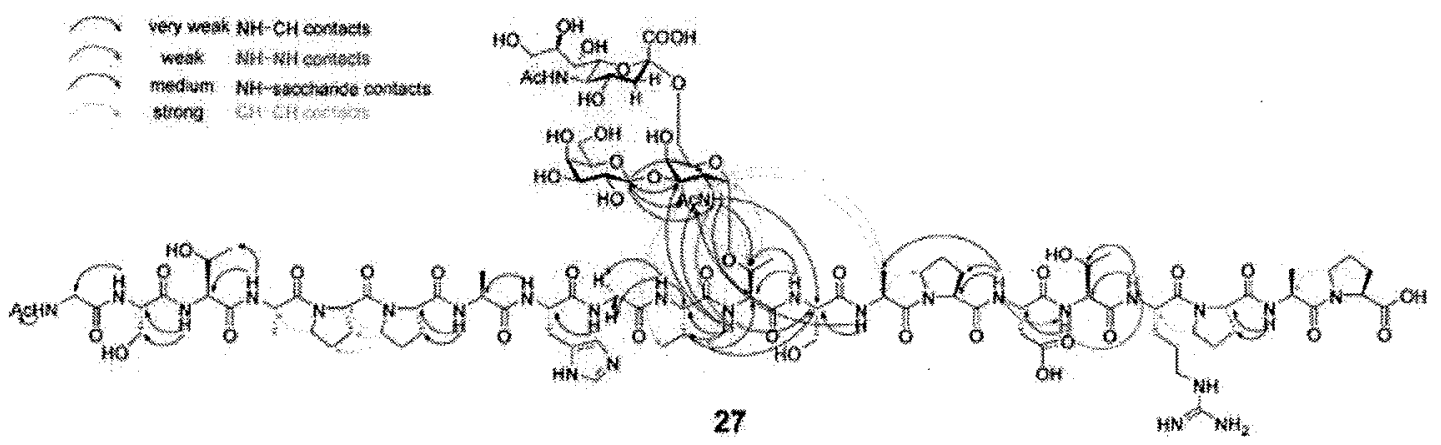

Fig. 32 ROE contacts, determining the structure of a Sialyl-Tn-glycosylated MUC-1 peptide 27 encompassing the whole tandem repeat sequence. (Reproduced with permission from [159]) 


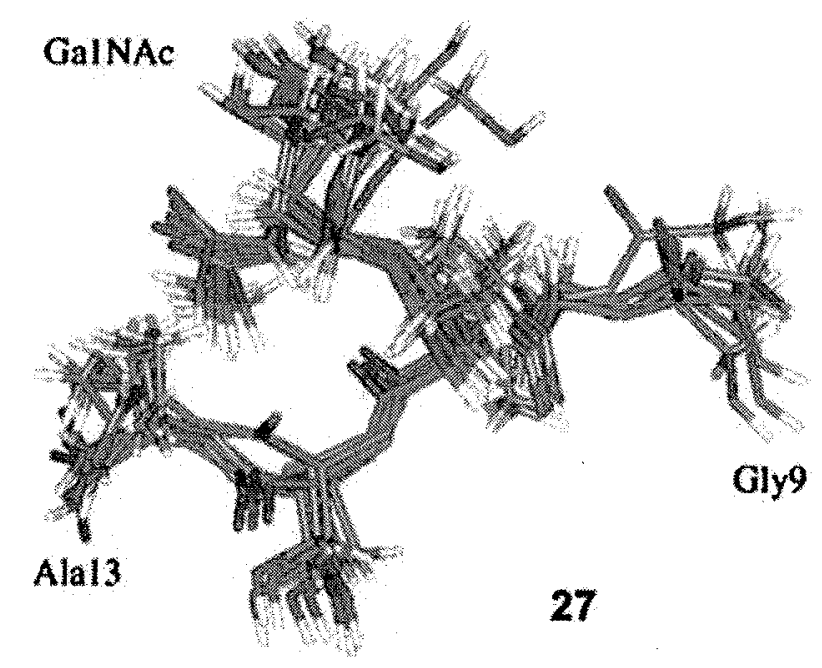

Fig. 33 The GVTSA sequence of glycopeptide 27 (chemical structure shown in Fig. 32) exhibits a rod-like secondary structure. Of the trisaccharide, only GalNAc is shown. (Reproduced with permission from [159])

bility of MUC-1 glycopeptides was reported by von Mensdorff-Pouilly et al. when MUC-1 sequence variants were investigated that have an ESR instead of a DTR motif. This could be a reason for differential antibody-mediated immune response observed in humans which is in turn related to the survival prognosis in breast cancer patients [162].

Interestingly, a type I $\beta$-turn-like structure was found for the immunodominant PDTRP region in the study of Dziadek et al. when Thr11 of the adjacent GVTSAP motif is glycosylated [159]. This epitope is often said to adopt a "knob-like" structure [163]. In contrast, the MUC-1 21-mer peptide studied by Kirnarsky et al. was found to have an S-shaped structure of the peptide backbone formed by consecutive inverse $\gamma$-turn, irrespective of glycosylation at Thr7 [158]. Also in the case of the diglycosylated MUC-1 21mer studied by Campbell and coworkers, a long range effect on the conformation of the immunodominant PDTRP epitope was not observed, however, their data supports a type I $\beta$-turn for both the peptide and the glycopeptide [160]. It is noteworthy that the breast cancer-specific antibody SM3 recognizes an extended structure in the case of an unglycosylated peptide as well as when binding to a glycopeptide bearing GalNAc at the central threonine of the PDTRP motif $[164,165]$.

In conclusion, it appears that the subtle interplay between peptide sequence, site of glycosylation, type of attached carbohydrate, and the clustering of $O$-glycans leads to induction of a variety of conformational motifs with a varying degree of stabilization. The unifying principle could be that all these conformations lead to a maximum exposure of presented carbohydrates facilitating interactions with receptors, especially in a multivalent fashion. 


\subsection{2}

\section{Antifreeze Glycoproteins}

Antifreeze glycoproteins (AFGPs) have attracted attention due to their peculiar biophysical behavior as well as because of a variety of potential medical and commercial applications $[166,167]$. AFGPs which can be isolated from fish blood plasma are complex mixtures comprising of repetitive Ala-Thr-Ala tripeptide units carrying $(\mathrm{Gal}(\beta 1-3) \operatorname{GalNAc}(\alpha 1-\mathrm{O})$ moieties at each threonine with some content in proline. Molecular weights range from 2.6 to $33 \mathrm{kDa}$. All AFGPs are said to inhibit freezing by binding to embryonic ice crystals, however, the precise mechanism of action is still unknown.

Recently, Tachibana et al. presented an extensive study on synthetic AFGPs composed of one to seven Ala-Thr-Ala repeating units [168]. Tripeptide oligomers with two or more units showed thermal hysteresis, a measure for the magnitude of the antifreeze effect, and were capable of changing the morphology of ice crystals into hexagonal bipyramids. Strong evidence indicates that the conformation of the peptide backbone plays a central role for the function of AFGPs as cryoprotectants. First, attaching GalNAc as a $\beta$-anomer leads to a complete loss of thermal hysteresis, and second, a glycopeptide made of Ala-Ser-Ala units exhibits no antifreeze activity. Both variations, and several others tested, either lead to loss of secondary structure or to a change from a polyproline type II helix in the active compounds to a largely $\alpha$-helical structure in the case of the Ala-Ser-Ala repeating unit as determined by $\mathrm{CD}$ spectroscopy.

Despite the absence of long- and medium-range NOE contacts, a surprisingly well-defined structure could be calculated for a triple repeat of the Ala- $(\mathrm{Gal}(\beta 1-3) \mathrm{GalNAc}(\alpha 1-\mathrm{O}) \mathrm{Thr}$-Ala unit (28) (Fig. 34). From a left-handed helix similar to the polyproline II helix all three disaccharides project to one side of the molecule forming a highly hydrophilic surface whereas the methyl groups of alanine and of the $\mathrm{N}$-acetyl groups cluster on another face of the molecule. The authors propose that the amphipathic structure of this AGFP is crucial to its antifreeze activity. Interestingly, also non-glycosylated antifreeze proteins were found to possess amphipathic structure [169].

Even though the study on synthetic AFGPs by Nishimura and coworkers presents a consistent picture the situation for naturally occurring AFGPs seems to be more complicated [167]. Structural studies on these molecules, isolated from fish, have a long history yielding conflicting interpretations [170-175].

In the latest NMR study on the tetra-[Gal( $\beta 1-3) \operatorname{GalNAc}(\alpha 1-0)]$-glycosylated 14-mer peptide AATAATPATAATPA (29), known as AFGP fraction 8 or AFGP-8, from arctic cod, Lane et al. find relatively well-determined ATPA segments resembling polyproline helix conformation according to NOEs and scalar couplings (Fig. 35 ). ${ }^{13} \mathrm{C}$ relaxation data indicate motional anisotropy, 
A
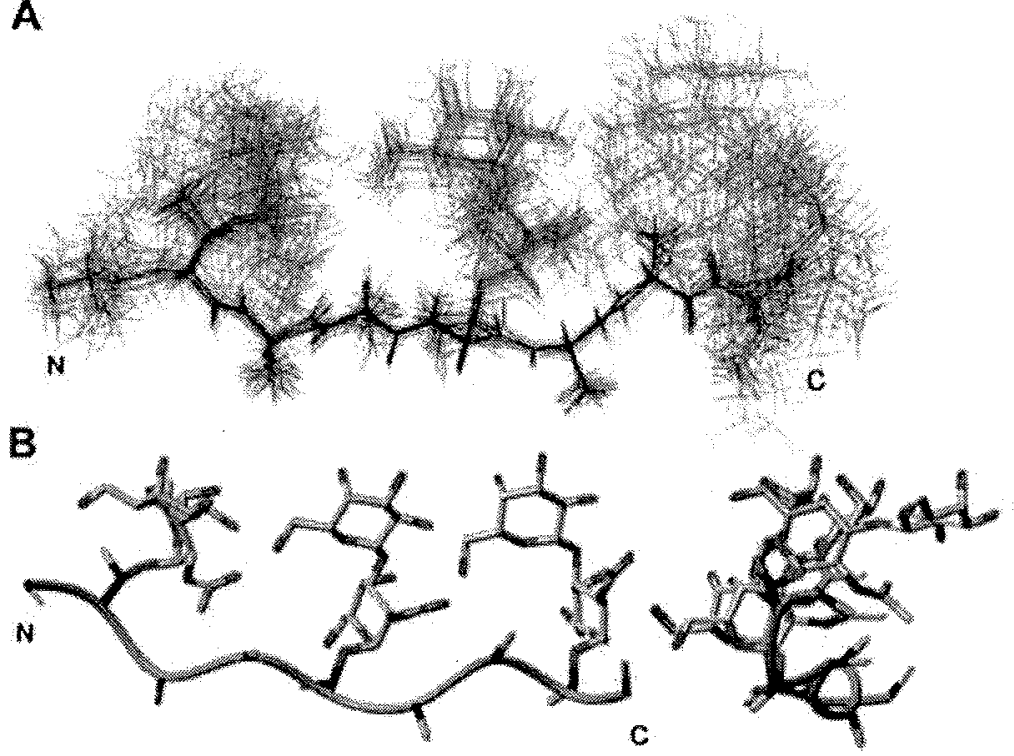

Fig. 34 A Superposition of the 25 lowest energy structures of the synthetic antifreeze glycopeptide [Ala-(Gal $\left.(\beta 1-3) \operatorname{GalNAc}(\alpha 1-\mathrm{O})) \mathrm{Thr}_{\mathrm{Ala}}\right]_{3}$ (28) calculated from NMR-based constraints. The peptide backbone is navy, and the carbohydrate moieties are royal blue. B Structure closest to the average of the 25 best calculated models for 28: yellow, methyl carbon; white, carbon in carbohydrate; gray, carbon in peptide side chains except for methyl carbon; blue, nitrogen; red, oxygen; the N- and C-terminal ends are identified. (Reproduced with permission from [168])

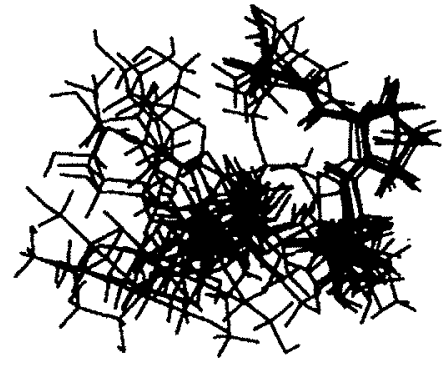

29 (A5-A8)

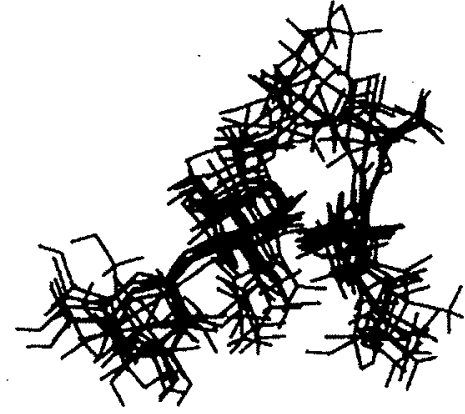

$29(\mathrm{~A} 8-\mathrm{A} 11)$

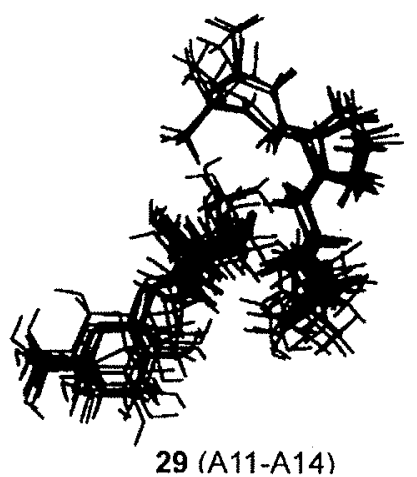

29 (A11-A14)

Fig. 35 Preferred conformations of the AFGP-8 peptide (29). Segments 2 (A5-A8), 3 (A8A11), and 4 (A11-A14) are shown left to right as superpositions of eight structures. (Reproduced with permission from [175])

however, long-range order in the form of a single preferred conformer could not be detected [175].

Nguyen et al. followed-up with $20 \mathrm{~ns}$ molecular dynamics simulations starting from 10 different conformers of the NMR ensemble obtained by Lane et al. [176]. From the simulation it was concluded that the AFGP8 backbone is structurally segmented into four semi-rigid segments while its disaccharides adopt well-defined conformations with respect to the peptide backbone. 
H-bonding between $\mathrm{N}$-acetyl $\mathrm{NH}$ groups and the peptide backbone stabilize the structure. The polyproline II helix is the overall conformation, yet AFGP 8 can reach many distinct and energetically equal structures. The authors propose that these interconverting conformations represent a thermal reservoir that inhibits ice crystal growth by local energy transfer.

\section{6 \\ Concluding Remarks}

By combining NMR spectroscopy, X-ray crystallography and molecular modeling, detailed insight into the influence of $\mathrm{O}$ - and $\mathrm{N}$-glycosylation on peptide and protein conformation and dynamics has been obtained. From this, the structural role of glycosylation for biological function could be identified in several cases. Synthetic glycopeptides have proven to be invaluable model systems for studying the impact of specific structural elements on conformation and molecular flexibility, and for identifying minimal glycopeptide epitopes suitable for medicinal applications. Future research will show whether our current knowledge already represents the general principles of glycoprotein structure and function. To answer this question, it will be of central importance to develop and optimize experimental and theoretical methods for handling molecules that are highly hydrated and possess, at least in part, a high degree of conformational flexibility. This will profit immensely from our capability to prepare more and more complex, yet defined glycoconjugates, either by chemical or by molecular biology techniques.

\section{References}

1. Berman HM, Westbrook J, Feng Z, Gilliland G, Bhat TN, Weissig H, Shindyalov IN, Bourne PE (2000) Nucleic Acids Res 28:235

2. Apweiler R, Hermjakob H, Sharon N (1999) Biochim Biophys Acta 1473:4

3. Dwek RA (1998) Dev Biol Stand 96:43

4. Borman $S$ (2005) Chem Eng News 83:41-50

5. Bush CA, Martin-Pastor M, Imberty A (1999) Annu Rev Biophys Biomol Struct 28:269

6. Wyss DF, Wagner G (1996) Curr Opin Biotechnol 7:409

7. Imperiali B, O'Connor SE (1999) Curr Opin Chem Biol 3:643

8. Haase C, Seitz O (2007) Top Curr Chem (in this volume)

9. Duus J, Gotfredsen CH, Bock K (2000) Chem Rev 100:4589

10. Woods RJ (1998) Glycoconj J 15:209

11. Imberty $A$, Pérez $S$ (2000) Chem Rev 100:4567

12. Wormald MR, Petrescu AJ, Pao YL, Glithero A, Elliott T, Dwek RA (2002) Chem Rev $102: 371$

13. Liu HL, Hsu JP (2005) Proteomics 5:2056

14. Heinemann U, Illing G, Oschkinat H (2001) Curr Opin Biotechnol 12:348 
15. Sattler M, Schleucher J, Griesinger C (1999) Prog NMR Spectrosc 34:93

16. Dauter Z (2006) Acta Crystallogr D Biol Crystallogr 62:1

17. Williams SP, Kuyper LF, Pearce KH (2005) Curr Opin Chem Biol 9:371

18. Grogan MJ, Pratt MR, Marcaurelle LA, Bertozzi CR (2002) Annu Rev Biochem 71:593

19. Fletcher CM, Harrison RA, Lachmann PJ, Neuhaus D (1994) Structure 2:185

20. Imberty A, Pérez S (1995) Protein Eng 8:699

21. Rudd PM, Morgan BP, Wormald MR, Harvey DJ, van den Berg CW, Davis SJ, Ferguson MA, Dwek RA (1997) J Biol Chem 272:7229

22. Yokoyama $S$ (2003) Curr Opin Chem Biol 7:39

23. Pickford AR, O'Leary JM (2004) Methods Mol Biol 278:17

24. Li P, Gao XG, Arellano RO, Renugopalakrishnan V (2001) Protein Expr Purif 22:369

25. Jarvis DL (2003) Virology 310:1

26. Lustbader JW, Birken S, Pollak S, Pound A, Chait BT, Mirza UA, Ramnarain S, Canfield RE, Brown JM (1996) J Biomol NMR 7:295

27. Hansen AP, Petros AM, Mazar AP, Pederson TM, Rueter A, Fesik SW (1992) Biochemistry $31: 12713$

28. Wyss DF, Choi JS, Li J, Knoppers MH, Willis KJ, Arulanandam AR, Smolyar A, Reinherz EL, Wagner G (1995) Science 269:1273

29. Wood MJ, Komives EA (1999) J Biomol NMR 13:149

30. Cubeddu L, Moss CX, Swarbrick JD, Gooley AA, Williams KL, Curmi PM, Slade MB, Mabbutt BC (2000) Protein Expr Purif 19:335

31. Wendeler M, Hoernschemeyer J, John M, Werth N, Schoeniger M, Lemm T, Hartmann R, Kessler H, Sandhoff K (2004) Protein Expr Purif 34:147

32. Laroche Y, Storme V, De Meutter J, Messens J, Lauwereys M (1994) Biotechnology (NY) $12: 1119$

33. McAlister MS, Davis B, Pfuhl M, Driscoll PC (1998) Protein Eng 11:847

34. Weikert S, Papac D, Briggs J, Cowfer D, Tom S, Gawlitzek M, Lofgren J, Mehta S, Chisholm V, Modi N, Eppler S, Carroll K, Chamow S, Peers D, Berman P, Krummen L (1999) Nat Biotechnol 17:1116

35. Xu R, Hanson SR, Zhang Z, Yang YY, Schultz PG, Wong CH (2004) J Am Chem Soc $126: 15654$

36. Zhang Z, Gildersleeve J, Yang YY, Xu R, Loo JA, Uryu S, Wong CH, Schultz PG (2004) Science 303:371

37. Meinjohanns E, Meldal M, Paulsen H, Dwek RA, Bock K (1998) J Chem Soc Perkin Trans 1:549

38. George SK, Schwientek T, Holm B, Reis CA, Clausen H, Kihlberg J (2001) J Am Chem Soc 123:11117

39. Thayer DA, Wong $\mathrm{CH}$ (2007) Top Curr Chem (in this volume)

40. Warren DJ, Geng X, Danishefsky SJ (2007) Top Curr Chem (in this volume)

41. Pratt MR, Bertozzi CR (2005) Chem Soc Rev 34:58

42. Holemann A, Seeberger PH (2004) Curr Opin Biotechnol 15:615

43. Herzner H, Reipen T, Schultz M, Kunz H (2000) Chem Rev 100:4495

44. Dawson PE, Muir TW, Clark-Lewis I, Kent SB (1994) Science 266:776

45. Evans TC Jr, Benner J, Xu MQ (1998) Protein Sci 7:2256

46. Macmillan D, Bertozzi CR (2004) Angew Chem Int Ed Engl 43:1355

47. Hojo H, Watabe J, Nakahara Y, Nakahara Y, Ito Y, Nabeshima K, Toole BP (2001) Tetrahedron Lett 42:3001

48. Hackenberger CP, Friel CT, Radford SE, Imperiali B (2005) J Am Chem Soc 127:12882

49. Smith KD, Davies MJ, Hounsell EF (1994) Methods Mol Biol 32:143

50. Dell A, Morris HR (2001) Science 291:2351 
51. Peter-Katalinic J (2005) Methods Enzymol 405:139

52. Rudd PM, Dwek RA (1997) Curr Opin Biotechnol 8:488

53. Gallego RG, Blanco JL, Thijssen-van Zuylen CW, Gotfredsen CH, Voshol H, Duus JO, Schachner M, Vliegenthart JF (2001) J Biol Chem 276:30834

54. Halkes KM, Gotfredsen CH, Grotli M, Miranda LP, Duus JO, Meldal M (2001) Chemistry $7: 3584$

55. Wüthrich K (1986) NMR of Proteins and Nucleic Acids. Wiley, New York

56. Kessler H, Seip S (1994) NMR of Peptides. In: Croasmun WR, Carlson RMK (eds) Two-Dimensional NMR Spectroscopy. VCH, New York, p 619

57. Leeflang BR, Faber EJ, Erbel P, Vliegenthart JF (2000) J Biotechnol 77:115

58. Seavey BR, Farr EA, Westler WM, Markley JL (1991) J Biomol NMR 1:217

59. Yamaguchi Y, Takizawa T, Kato K, Arata Y, Shimada I (2000) J Biomol NMR 18:357

60. Bock K, Thoegersen H (1982) Annu Rep NMR Spectrosc 13:1

61. Bock K, Pedersen C (1983) Adv Carbohydr Chem Biochem 41:27

62. Prytulla S, Lambert J, Lauterwein J, Klessinger M, Thiem J (1990) Magn Reson Chem 28:888

63. Prytulla S, Lauterwein J, Klessinger M, Thiem J (1991) Carbohydr Res 215:345

64. Haverkamp J, Spoormaker T, Dorland L, Vliegenthart JFG, Schauer R (1979) J Am Chem Soc 101:4851

65. Lommerse JP, van Rooijen JJ, Kroon-Batenburg LM, Kamerling JP, Vliegenthart JF (2002) Carbohydr Res 337:2279

66. Homans SW (1992) Glycobiology 2:153

67. Milton MJ, Harris R, Probert MA, Field RA, Homans SW (1998) Glycobiology 8:147

68. Harris R, Rutherford TJ, Milton MJ, Homans SW (1997) J Biomol NMR 9:547

69. Poppe L, van Halbeek H (1991) J Magn Reson 92:636-41

70. Poppe L, van Halbeek H (1991) J Magn Reson 93:214-17

71. Martin-Pastor M, Bush CA (1999) Biochemistry 38:8045

72. Bose B, Zhao S, Stenutz R, Cloran F, Bondo PB, Bondo G, Hertz B, Carmichael I, Serianni AS (1998) J Am Chem Soc 120:11158

73. Xu Q, Gitti R, Bush CA (1996) Glycobiology 6:281

74. Mulloy B, Frenkiel TA, Davies DB (1988) Carbohydr Res 184:39

75. Tvaroska I, Hricovini H, Perakova E (1989) Carbohydr Res 189:359

76. Tolman JR, Flanagan JM, Kennedy MA, Prestegard JH (1995) Proc Natl Acad Sci USA 92:9279

77. Tjandra N, Bax A (1997) Science 278:1111

78. Prestegard JH, Bougault CM, Kishore AI (2004) Chem Rev 104:3519

79. de Alba E, Tjandra N (2002) Prog Nucl Magn Reson 40:175

80. Griesinger C, Peti W, Meiler J, Bruschweiler R (2004) Methods Mol Biol 278:107

81. Deschamps M, Campbell ID, Boyd J (2005) J Magn Reson 172:118

82. Meiler J, Prompers JJ, Peti W, Griesinger C, Bruschweiler R (2001) J Am Chem Soc 123:6098

83. Peti W, Meiler J, Bruschweiler R, Griesinger C (2002) J Am Chem Soc 124:5822

84. Azurmendi HF, Bush CA (2002) Carbohydr Res 337:905

85. Almond A, Duus JO (2001) J Biomol NMR 20:351

86. Almond A, Petersen BO, Duus JO (2004) Biochemistry 43:5853

87. Reif B, Hennig M, Griesinger C (1997) Science 276:1230

88. Reif B, Diener A, Hennig M, Maurer M, Griesinger C (2000) J Magn Reson 143:45

89. Scheurer C, Skrynnikov NR, Lienin SF, Straus SK, Bruschweiler R, Ernst RR (1999) J Am Chem Soc 121:4242

90. Markwick PR, Sprangers R, Sattler M (2005) Angew Chem Int Ed Engl 44:3232 
91. Kover KE, Batta G, Kowalewski J, Ghalebani L, Kruk D (2004) J Magn Reson 167:273

92. Larsson EA, Urbina F, Yang Z, Weintraub A, Widmalm G (2004) Carbohydr Res 339:1491

93. Chen B, Vogan EM, Gong H, Skehel JJ, Wiley DC, Harrison SC (2005) Structure (Camb) 13:197

94. Chen B, Vogan EM, Gong H, Skehel JJ, Wiley DC, Harrison SC (2005) Nature 433:834

95. Case DA, Cheatham TE III, Darden T, Gohlke H, Luo R, Merz KM Jr, Onufriev A, Simmerling C, Wang B, Woods RJ (2005) J Comput Chem 26:1668

96. Homans SW (1990) Biochemistry 29:9110

97. Woods RJ, Dwek RA, Edge CJ, Fraser-Reid B (1995) J Phys Chem 99:3832

98. Glennon TM, Merz KMJ (1997) Theochem 395-396:157

99. Momany FA, Willett JL (2000) Carbohydr Res 326:194

100. Brooks BR, Bruccoleri RE, Olafson BD, States DJ, Swaminathan S, Karplus M (1983) J Comp Chem 4:187

101. Ha SN, Giammona A, Field M, Brady JW (1988) Carbohydr Res 180:207

102. Reiling S, Schlenkrich M, Brickmann J (1996) J Comp Chem 17:450

103. Christen $M$, Hunenberger PH, Bakowies D, Baron R, Burgi R, Geerke DP, Heinz TN, Kastenholz MA, Krautler V, Oostenbrink C, Peter C, Trzesniak D, van Gunsteren WF (2005) J Comput Chem 26:1719

104. Ott K-H, Meyer B (1996) J Comp Chem 17:1068

105. Jorgensen WL, Maxwell DS, Tirado-Rives J (1996) J Am Chem Soc 118:11225

106. Damm W, Frontera A, Tirado-Rives J, Jorgensen WL (1997) J Comp Chem 18:1955

107. Clark M, Cramer RDI, Van Opdenbosch N (1989) J Comp Chem 10:982

108. Imberty A, Hardman KD, Carver JP, Pérez S (1991) Glycobiology 1:631

109. Pérez S, Imberty A, Engelsen SB, Gruza J, Mazeau K, Jimenez-Barbero J, Poveda A, Espinosa J-F, Van Eyck BP, Johnson G, French AD, Kouwijzer MLCE, Grootenuis PDJ, Bernardi A, Raimondi L, Senderowitz H, Durier V, Vergoten G, Rasmussen K (1998) Carbohydr Res 314:141

110. van Gunsteren WF, Brunne RM, Gros P, van Schaik RC, Schiffer CA, Torda AE (1994) Methods Enzymol 239:619

111. Weis WI, Brunger AT, Skehel JJ, Wiley DC (1990) J Mol Biol 212:737

112. Erbel PJ, Karimi-Nejad Y, van Kuik JA, Boelens R, Kamerling JP, Vliegenthart JF (2000) Biochemistry 39:6012

113. Petrescu AJ, Petrescu SM, Dwek RA, Wormald MR (1999) Glycobiology 9:343

114. Petrescu AJ, Milac AL, Petrescu SM, Dwek RA, Wormald MR (2004) Glycobiology 14:103

115. Wormald MR, Wooten EW, Bazzo R, Edge CJ, Feinstein A, Rademacher TW, Dwek RA (1991) Eur J Biochem 198:131

116. Davis JT, Hirani S, Bartlett C, Reid BR (1994) J Biol Chem 269:3331

117. Kessler H, Matter H, Gemmecker G, Kling A, Kottenhahn M (1991) J Am Chem Soc 113:7550

118. Christlet TH, Biswas M, Veluraja K (1999) Acta Crystallogr D Biol Crystallogr 55(Pt8): 1414

119. Bause E, Legler G (1981) Biochem J 195:639

120. Marshall RD (1972) Annu Rev Biochem 41:673

121. Berman $H$, Henrick K, Nakamura H (2003) Nat Struct Biol 10:980

122. Loss A, Bunsmann $\mathrm{P}$, Bohne A, Loss A, Schwarzer E, Lang E, von der Lieth CW (2002) Nucleic Acids Res 30:405

123. Raman $R$, Venkataraman $M$, Ramakrishnan S, Lang W, Raguram S, Sasisekharan $R$ (2006) Glycobiology 16:82R 
124. Hashimoto K, Goto S, Kawano S, Aoki-Kinoshita KF, Ueda N, Hamajima $M$, Kawasaki T, Kanehisa M (2006) Glycobiology 16:63R

125. Gupta R, Birch H, Rapacki K, Brunak S, Hansen JE (1999) Nucleic Acids Res 27:370

126. Julenius K, Molgaard A, Gupta R, Brunak S (2005) Glycobiology 15:153

127. Cooper CA, Joshi HJ, Harrison MJ, Wilkins MR, Packer NH (2003) Nucleic Acids Res 31:511

128. Doubet S, Bock K, Smith D, Darvill A, Albersheim P (1989) Trends Biochem Sci $14: 475$

129. Kwong PD, Wyatt R, Robinson J, Sweet RW, Sodroski J, Hendrickson WA (1998) Nature 393:648

130. Wyatt R, Kwong PD, Desjardins E, Sweet RW, Robinson J, Hendrickson WA, Sodroski JG (1998) Nature 393:705

131. Kwong PD, Wyatt R, Sattentau QJ, Sodroski J, Hendrickson WA (2000) J Virol 74:1961

132. Huang CC, Tang M, Zhang MY, Majeed S, Montabana E, Stanfield RL, Dimitrov DS, Korber B, Sodroski J, Wilson IA, Wyatt R, Kwong PD (2005) Science 310:1025

133. Lin PF, Blair W, Wang T, Spicer T, Guo Q, Zhou N, Gong YF, Wang HG, Rose R, Yamanaka G, Robinson B, Li CB, Fridell R, Deminie C, Demers G, Yang Z, Zadjura L, Meanwell N, Colonno R (2003) Proc Natl Acad Sci USA 100:11013

134. Withka JM, Wyss DF, Wagner G, Arulanandam AR, Reinherz EL, Recny MA (1993) Structure 1:69

135. Wyss DF, Dayie KT, Wagner G (1997) Protein Sci 6:534

136. Kitao A, Wagner G (2000) Proc Natl Acad Sci USA 97:2064

137. Sun ZY, Dotsch V, Kim M, Li J, Reinherz EL, Wagner G (1999) EMBO J 18:2941

138. Wang JH, Smolyar A, Tan K, Liu JH, Kim M, Sun ZY, Wagner G, Reinherz EL (1999) Cell 97:791

139. Vliegenthart JFG, Dorland L, Van Halbeek H (1983) Adv Carbohydr Chem Biochem 41:209

140. Wu H, Lustbader JW, Liu Y, Canfield RE, Hendrickson WA (1994) Structure 2:545

141. Lapthorn AJ, Harris DC, Littlejohn A, Lustbader JW, Canfield RE, Machin KJ, Morgan FJ, Isaacs NW (1994) Nature 369:455

142. Lustbader JW, Pollak S, Lobel L, Trakht I, Homans S, Brown JM, Canfield RE (1996) Mol Cell Endocrinol 125:21

143. Weller CT, Lustbader J, Seshadri K, Brown JM, Chadwick CA, Kolthoff CE, Ramnarain S, Pollak S, Canfield R, Homans SW (1996) Biochemistry 35:8815

144. De Beer T, Van Zuylen CW, Leeflang BR, Hard K, Boelens R, Kaptein R, Kamerling JP, Vliegenthart JF (1996) Eur J Biochem 241:229

145. van Zuylen CW, Kamerling JP, Vliegenthart JF (1997) Biochem Biophys Res Commun 232:117

146. van Zuylen CW, de Beer T, Leeflang BR, Boelens R, Kaptein R, Kamerling JP, Vliegenthart JF (1998) Biochemistry 37:1933

147. Erbel PJ, Haseley SR, Kamerling JP, Vliegenthart JF (2002) Biochem J 364:485

148. Kobata A, Takeuchi M (1999) Biochim Biophys Acta 1455:315

149. O'Connor SE, Imperiali B (1997) J Am Chem Soc 119:2295

150. O'Conner SE, Imperiali B (1998) Chem Biol 5:427

151. Bosques CJ, Tschampel SM, Woods RJ, Imperiali B (2004) J Am Chem Soc 126: 8421

152. Coltart DM, Royyuru AK, Williams LJ, Glunz PW, Sames D, Kuduk SD, Schwarz JB, Chen XT, Danishefsky SJ, Live DH (2002) J Am Chem Soc 124:9833

153. Live DH, Williams LJ, Kuduk SD, Schwarz JB, Glunz PW, Chen XT, Sames D, Kumar RA, Danishefsky SJ (1999) Proc Natl Acad Sci USA 96:3489 
154. Schuster O, Klich G, Sinnwell V, Kranz H, Paulsen H, Meyer B (1999) J Biomol NMR $14: 33$

155. Seitz O, Wong CH (1997) J Am Chem Soc 119:8766

156. Wu W, Pasternack L, Huang D-H, Koeller KM, Lin C-C, Seitz O, Wong C-H (1999) J Am Chem Soc 121:2409

157. Naganagowda GA, Gururaja TL, Satyanarayana J, Levine MJ (1999) J Pept Res 54:290

158. Kirnarsky L, Prakash O, Vogen SM, Nomoto M, Hollingsworth MA, Sherman S (2000) Biochemistry 39:12076

159. Dziadek S, Griesinger C, Kunz H, Reinscheid UM (2006) Chem Eur J 12:4981

160. Grinstead JS, Koganty RR, Krantz MJ, Longenecker BM, Campbell AP (2002) Biochemistry 41:9946

161. Kinarsky L, Suryanarayanan G, Prakash O, Paulsen H, Clausen H, Hanisch FG, Hollingsworth MA, Sherman S (2003) Glycobiology 13:929

162. von Mensdorff-Pouilly S, Kinarsky L, Engelmann K, Baldus SE, Verheijen RH, Hollingsworth MA, Pisarev V, Sherman S, Hanisch FG (2005) Glycobiology 15:735

163. Fontenot JD, Mariappan SV, Catasti P, Domenech N, Finn OJ, Gupta G (1995) J Biomol Struct Dyn 13:245

164. Dokurno P, Bates PA, Band HA, Stewart LM, Lally JM, Burchell JM, TaylorPapadimitriou J, Snary D, Sternberg MJ, Freemont PS (1998) J Mol Biol 284:713

165. Möller H, Serttas N, Paulsen H, Burchell JM, Taylor-Papadimitriou J, Meyer B (2002) Eur J Biochem 269:1444

166. Bouvet V, Ben RN (2003) Cell Biochem Biophys 39:133

167. Harding MM, Anderberg PI, Haymet AD (2003) Eur J Biochem 270:1381

168. Tachibana Y, Fletcher GL, Fujitani N, Tsuda S, Monde K, Nishimura S (2004) Angew Chem Int Ed Engl 43:856

169. Sicheri F, Yang DS (1995) Nature 375:427

170. Bush CA, Feeney RE, Osuga DT, Ralapati S, Yeh Y (1981) Int J Pept Protein Res 17:125

171. Rao BN, Bush CA (1987) Biopolymers 26:1227

172. Filira F, Biondi L, Scolaro B, Foffani MT, Mammi S, Peggion E, Rocchi R (1990) Int J Biol Macromol 12:41

173. Dill K, Huang L, Bearden DW, Feeney RE (1992) J.Carbohydr Chem 11:499

174. Mimura Y, Yamamoto Y, Inoue Y, Chujo R (1992) Int J Biol Macromol 14:242

175. Lane AN, Hays LM, Feeney RE, Crowe LM, Crowe JH (1998) Protein Sci 7:1555

176. Nguyen DH, Colvin ME, Yeh Y, Feeney RE, Fink WH (2002) Biophys J 82:2892 